\title{
Effects of environmental stressors on the early development of intertidal and subtidal gastropod embryos
}

\author{
by \\ Jeannine Fischer
}

A thesis

Submitted to Victoria University of Wellington

In partial fulfilment of the

requirements for the degree of

Master of Science

In Marine Biology

Victoria University of Wellington

2012 


\section{ACKNOWLEDGEMENTS}

I would like to thank all the people who have helped me during my research. Firstly I would like to especially thank my supervisor Nicole Phillips for all her guidance, support, encouragement and advice for my research for the past few years. I feel very lucky to have you as my supervisor and have learnt a lot from you for which I am very grateful. I could not have asked for more.

Special thanks go to my husband James Grover for helping me with field and lab work, who gave me advice, peer-reviewed my thesis, endured hours of me running ideas past him, and who kept me sane and calm. Thank you for all your support, you are my rock. I am very thankful to my amazing family, Jennifer, Ingrid and Peter Fischer, Ilse Kiltz, Lieselotte Fischer, Katty, and Manfred. Ihr seid die besten. Thanks for all your different ways of support, for encouraging me to follow my passion and for being there for me in many different ways when I needed you during the past years. Also thanks to Karen Grover for your support and amazing brownies that kept me going.

I would also like to thank Ryan Hughes and Mairead Murphy for helping me measure thousands of larvae, Anne Dahse and Katie Clemens-Seely for your research assistance and comments. Thanks to everyone at VUCEL, especially Shane Geange for helping me collect my species and Fernanda Piraud for helping with the UV-B experiment setup. Thanks to Ken Ryan for letting me borrow his UV equipment, Cesar Cardenas for sacrificing his sponges as food, Nicky Fitzgibbon, Timothy Jones, Daniel McNaughtan, John van der Sman, Danelle Kara Lekan, Paul Mensink, the Phillips and Shima lab groups and everyone else from the Marine Discussion Group. I feel blessed to have spent my time and research with you.

Finally I thank Victoria University Coastal Ecology Laboratory (VUCEL) and the School of Biological Sciences (SBS) for providing facilities for this research.

This thesis is dedicated to my family. 


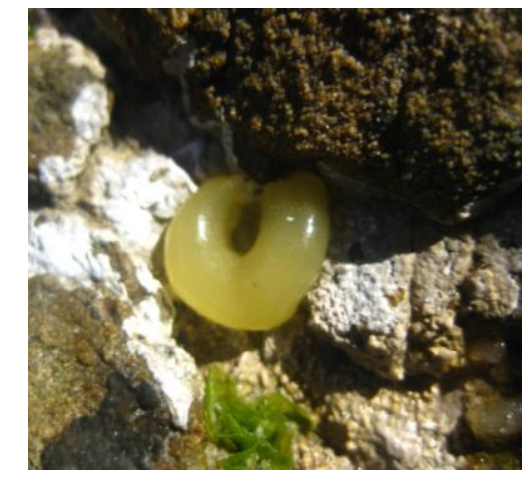

Fig. 1(a)

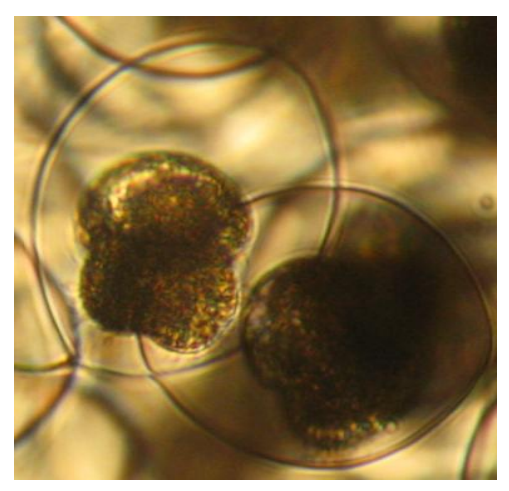

Fig. 1(b)

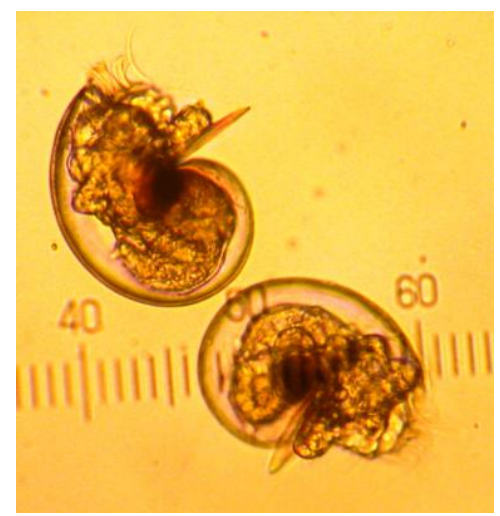

Fig. $1(\mathrm{c})$

Figure 1 (a) Freshly deposited Siphonaria australis egg mass in the rocky intertidal at Princess Bay, Wellington, New Zealand; (b) S. australis embryos during early development in the egg mass (at 100x magnification); (c) Newly hatched $S$. australis larvae under compound microscope (at 100x magnification). 


\begin{abstract}
Salinity, temperature and ultraviolet-B (UV-B) radiation are common environmental stressors in coastal habitats. These stressors are likely to increase in intensity due to the effects of climate change and can have important impacts on population and community dynamics for early development in gastropods that deposit egg masses on rocky shores. The aim of this study was to identify the effects of single and multiple stressors on the development of intertidal and shallow subtidal gastropods with encapsulated embryos.
\end{abstract}

In manipulative experiments I exposed egg masses of the gastropod species Siphonaria australis, Ercolania felina, Pleurobranchaea maculata, Aplysia juliana and Doris wellingtonensis to realistic levels of either salinity, temperature or UV-B radiation, or to a combination of stressors, for different lengths of time. Embryos were then subjected to the most stressful levels of each stressor at either early or late stages of development and at different days of embryonic development. Further, egg masses were exposed to sublethal salinity, temperature and UV-B radiation stress simultaneously, simulating tide pool conditions on a warm sunny summer day. Larvae hatching from stressed and unstressed egg masses were subsequently periodically subjected to increased temperature and UV-B radiation and examined over 10 days to detect possible carry-over effects of exposure to stress in the egg mass.

The results revealed that for individual stressors, low salinity (20\%), high temperature $\left(25^{\circ} \mathrm{C}\right)$ and high UV-B $\left(1.7 \mathrm{~W} \mathrm{~m}^{-2} \mathrm{~s}^{-1}\right.$, i.e. a level similar to a sunny NZ summer day) all caused the highest embryonic mortality. The response to stressors was species-specific but overall the intertidal species had lower embryonic mortality than the subtidal species. Generally, chronic exposure had higher impacts on the development of embryos than periodic exposure and early embryonic development stages were most vulnerable to stress. UV-B radiation had particularly damaging effects on embryonic and larval stages for the intertidal pulmonate limpet Siphonaria australis. Further, multiple stressors 
had synergistic effects and caused high embryonic mortality in the egg mass as well as impacting on the vulnerability of larvae to stressors. This study revealed that stress experienced during embryonic stages can result in sub-lethal damage that increases vulnerability to temperature and decreases vulnerability to UV-B radiation experienced in the larval stage.

In total, my results suggest that (1) the effects of different environmental stressors on early development of intertidal and subtidal gastropods are complex and depend on the intensity, duration and time of stress, and are generally species-specific; (2) multiple stressors can act synergistically to affect early development and (3) sublethal exposure to stress in the egg mass can have negative carry-over effects on later larval stages. 


\section{Table of Contents}

ACKNOWLEDGEMENTS............................................................................2

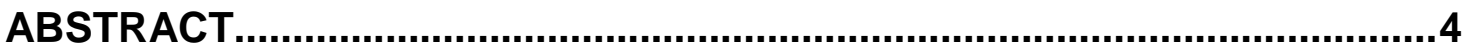

TABLE OF FIGURES........................................................................................ 10

LIST OF TABLES...................................................................................... 14

CHAPTER 1: General Introduction.............................................................15

CHAPTER 2: Effects of single environmental stressors on the early development of encapsulated intertidal and subtidal

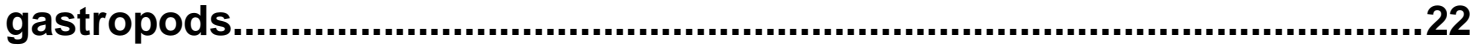

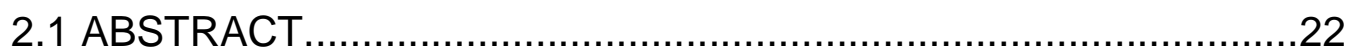

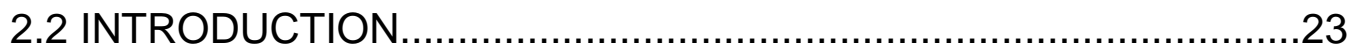

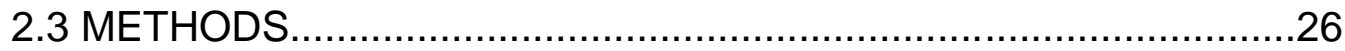

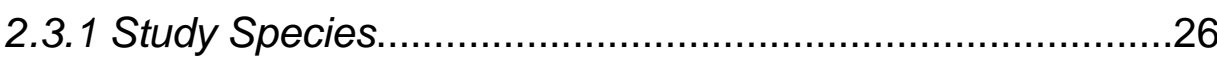

2.3.2 Locations..................................................................

2.3.3 Manipulative experiments...........................................32

2.3.3.1 Salinity. .................................................

2.3.3.2 Temperature................................................. 35

2.3.3.3 UV-B radiation...............................................36

2.3.4 Statistical Analysis...................................................38

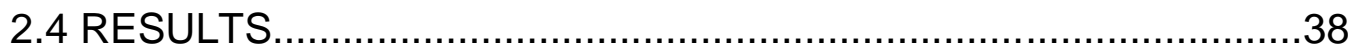

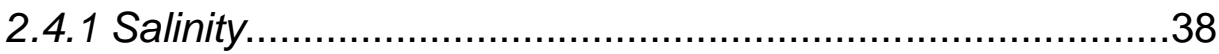

2.4.2 Temperature........................................................ 43

2.4.3 UV-B radiation......................................................... 48 


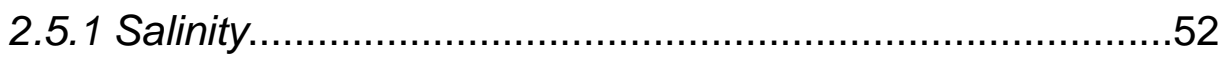

2.5.2 Temperature....................................................... 55

2.5.3 UV-B radiation.......................................................... 58

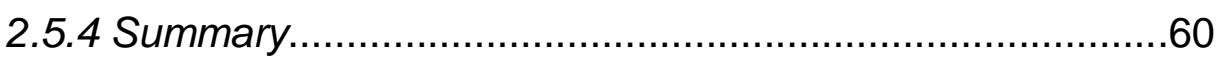

CHAPTER 3: Effects of timing of single and multiple stressors on the early development of encapsulated intertidal and subtidal gastropods .61

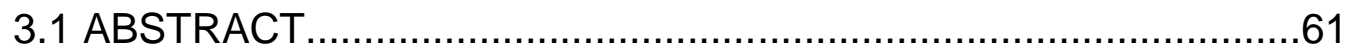

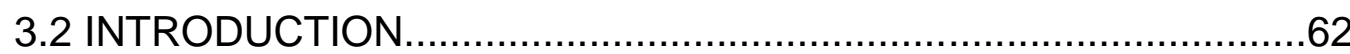

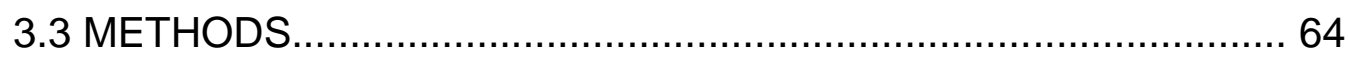

3.3.1 Timing and duration of single stressors.......................65

3.3.1.1 Early vs. late exposure to single stressors.............65

3.3.1.2 24-hour exposure to single stressors at different days after

deposition.

3.3.2 Effects of timing and duration to two stressors simultaneously

3.3.2.1 Chronic exposure to high temperature and variable salinity.....

3.3.2.2 Periodic exposure to high temperature and variable salinity

3.3.2.3 Early vs. late exposure to high temperature and low salinity 69 
3.3.2.4 24-hour exposure to high temperature and low salinity at different days after deposition. 69

3.3.3 Statistical Analysis................................................... 70

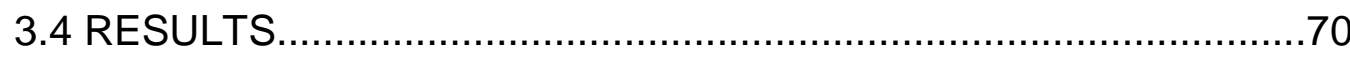

3.4.1 Timing and duration of single stressors.......................70

3.4.1.1 Early vs. late exposure to single stressors...........70

3.4.1.2 24-hour exposure to single stressors at different days after deposition.................................................. 74

3.4.2 Effects of timing and duration to two stressors simultaneously 78

3.4.2.1Chronic exposure to high temperature and variable salinity 78

3.4.2.2 Periodic exposure to high temperature and variable salinity .80

3.4.2.3 Early vs. late exposure to high temperature and low salinity .82

3.4.2.4 24-hour exposure to high temperature and low salinity at different days after deposition. .83

3.5 DISCUSSION 84

3.5.1 Single stressors .84

3.5.2 Multiple stressors. .87

3.5.3 Summary. 89 
CHAPTER 4: Effects of intertidal stressors on embryos of an intertidal gastropod and carry-over effects on larval life

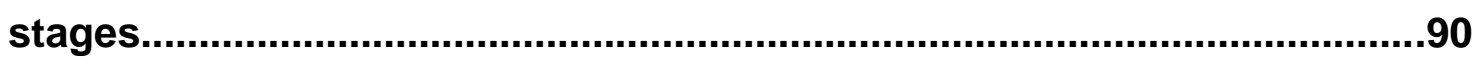

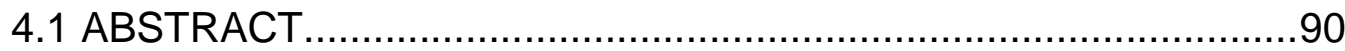

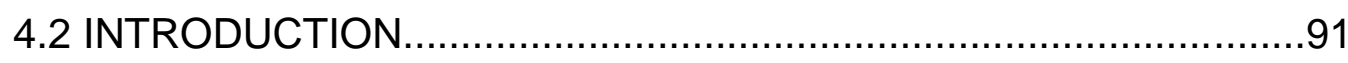

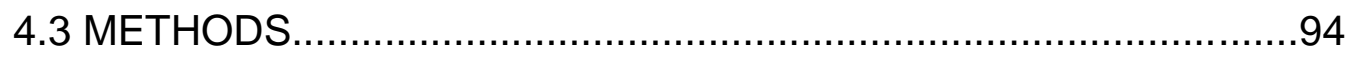

4.3.1 Simulated tide pool conditions...........................................94

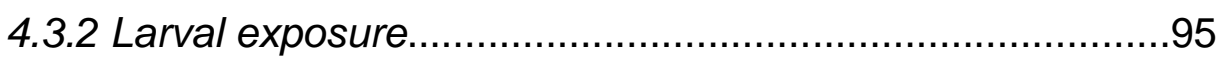

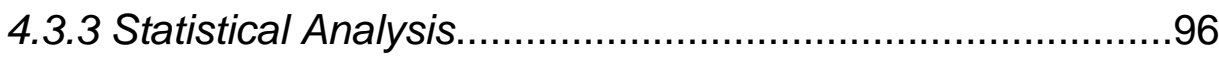

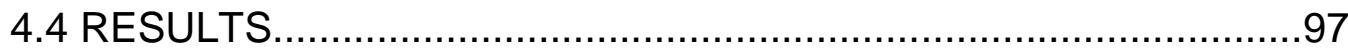

4.4.1 Simulated tide pool conditions..............................................

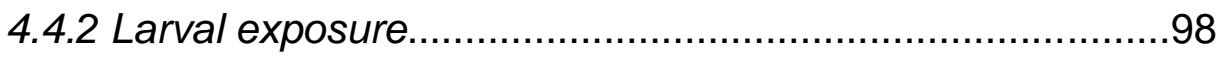

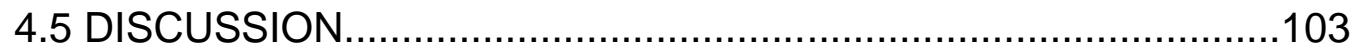

4.5.1 Summary .................................................................

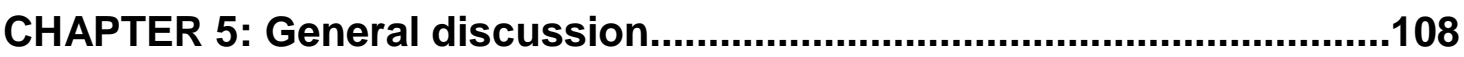

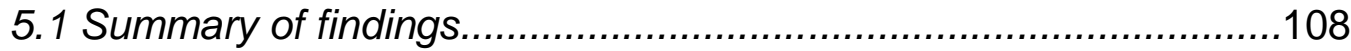

5.2 Future directions.....................................................................111

REFERENCES 


\section{Table of Figures}

Figure 1.(a) Freshly deposited Siphonaria australis egg mass in the rocky intertidal at Princess Bay, Wellington, New Zealand; (b) S. australis embryos during early development in the egg mass (at 100x magnification); (c) Newly hatched $S$. australis larvae under compound microscope (100x magnification)

Figure 2.1 Adult Siphonaria australis and a freshly deposited egg mass, VUCEL, November 2009

Figure 2.2 Adult Ercolania felina and a freshly deposited egg mass in Chaetomorpha 28

Figure 2.3 Adult Pleurobranchaea maculata (left) and adult depositing an egg mass in a glass tank (ventral view)

Figure 2.4 Adult Aplysia juliana in the shallow subtidal and various egg masses laid in the tanks.

Figure 2.5 Doris wellingtonensis adult and spiral egg masses

Figure 2.6 Location of collection sites in Wellington for adult Siphonaria australis (Princess Bay), Ercolania felina (Tarakena Bay), Pleurobranchaea maculata (Kau Bay) and Aplysia juliana and Doris wellingtonensis (Breaker Bay)

Figure 2.7 Examples of viable (left) and inviable (right) embryos of Pleurobranchaea maculata after 5 consecutive days (press) in the control (35\%o, left) and low salinity ( $20 \%$, right) treatment.

Figure 2.8 Shell length of a newly hatched Siphonaria australis larva being measured under the microscope. 
Figure 2.9 Mean percentage of embryonic mortality in egg masses for two intertidal and two subtidal species with mixed development subjected to different levels of chronic salinity for a period of 5 days $( \pm S E)$

Figure 2.10 Mean Pleurobranchaea maculata larval size $(\mathrm{mm})$ at hatching after being subjected to different levels of salinity for a period of 5 days $( \pm S E)$ 41

Figure 2.11 Mean percentage of mortality of embryos in egg masses for 3 different species subjected to different levels of periodic variation in salinity for 4 hours/day for 5 days $( \pm S E)$

Figure 2.12 Mean percentage of embryonic mortality in egg masses for one intertidal and one subtidal species with mixed development subjected to different levels of chronic temperatures for a period of 5 days $( \pm S E)$.

Figure 2.13 Mean Siphonaria australis larval size $(\mathrm{mm})$ at hatching after being subjected to different levels of chronic temperatures for a period of 5 days $( \pm S E)$

Figure 2.14 Mean percentage of embryonic mortality in egg masses for one intertidal and two subtidal species with mixed development subjected to different levels of periodic high temperature for 4 hrs/day over 5 days $( \pm \mathrm{SE})$

Figure 2.15 Mean Aplysia juliana larval size $(\mathrm{mm})$ at hatching after being subjected to different levels of periodic temperature for a period of 5 days $( \pm S E)$

Figure 2.16 Mean percentage of embryonic mortality in Siphonaria australis egg masses subjected to different levels of chronic UV-B radiation for 12 hrs/day, over a period of 5 days ( \pm SE) 
Figure 2.17 Mean percentage of embryonic mortality in Siphonaria australis egg masses subjected to different levels of periodic (4 hrs/day) UV-B radiation for a period of 5 days $( \pm S E)$.

Figure 3.1 Mean percentage of embryonic mortality in egg masses of 1 intertidal and 2 subtidal species subjected to 3 -day exposure to low salinity at different times of development $( \pm S E)$.

Figure 3.2 Mean percentage of embryonic mortality in Siphonaria australis egg masses subjected to 3-day exposure to high temperature at different times of development

Figure 3.3 Mean percentage of embryonic mortality in Siphonaria australis egg masses subjected to 3-day exposure to high UV-B radiation at different times of development $( \pm \mathrm{SE})$.

Figure 3.4 Mean percentage of embryonic mortality in egg masses of 1 intertidal and 1 subtidal species subjected to 1 -day exposure to low salinity at different days of embryonic development $( \pm S E)$

Figure 3.5 Mean percentage of embryonic mortality in egg masses of 1 intertidal and 1 subtidal species subjected to 1-day exposure to high temperature at different days of embryonic development $( \pm S E)$. .76

Figure 3.6 Mean percentage of embryonic mortality in Siphonaria australis egg masses subjected to 1-day exposure to high UV-B radiation at different days of embryonic development $( \pm \mathrm{SE})$ .77

Figure 3.7 Mean percentage of embryonic mortality in Siphonaria australis egg masses subjected to different combinations of chronic temperature and salinity over a period of 5 days $( \pm$ SE). 
Figure 3.8 Mean percentage of embryonic mortality in egg masses of intertidal and 1 subtidal species subjected to different combinations of periodic temperature and salinity for 4 hours/ day over a periodc of 5 days $( \pm S E)$

Figure 3.9 Mean percentage of embryonic mortality in Siphonaria australis egg masses subjected to 3-day exposure to high temperature and low salinity at different times of development $( \pm S E)$ .83

Figure 3.10 Mean percentage of embryonic mortality in Siphonaria australis egg masses subjected to 1-day exposure to high temperature and low salinity at different days of embryonic development $( \pm S E)$

Figure 4.1 Cilia length $(\mathrm{mm})$ of a newly hatched Siphonaria australis larva being measured under the microscope (400x magnification) .96

Figure 4.2 Mean percentage of embryonic mortality in Siphonaria australis egg masses subjected to stressed (simulated tide pool) conditions and unstressed (control) conditions for 4 hours/ day over 5 consecutive days ( \pm SE).

Figure 4.3 Mean percentage of live Siphonaria australis larvae from stressed or unstressed egg masses subjected to three temperature and UV-B treatments after different days of exposure $( \pm S E)$. 99

Figure 4.4 Mean Siphonaria australis larval size $(\mathrm{mm})$ from stressed or unstressed egg masses subjected to three temperature and UV-B light treatments after different days of exposure $( \pm S E)$

Figure 4.5 Mean length of cilia $(\mathrm{mm})$ of Siphonaria australis larvae from stressed or unstressed egg masses subjected to three temperature and UV-B treatments after different days of exposure $( \pm S E)$. 102 


\section{List of Tables}

Table 2.1 Hatching success (in \%) and days till hatching ( \pm SD) of each species in response to chronic salinity treatments .40

Table 2.2 Hatching success (in \%) and days till hatching ( \pm SD) of each species in response to periodic salinity treatments.

Table 2.3 Hatching success (in \%) and days till hatching ( \pm SD) of each species in response to chronic temperature treatments.

Table 2.4 Hatching success (in \%) and days till hatching ( \pm SD) of each species in response to periodic temperature treatments.

Table 2.5 Hatching success (in \%) and days till hatching ( \pm SD) of Siphonaria australis in response to chronic UV-B radiation treatments

Table 2.6 Hatching success (in \%) and days till hatching ( \pm SD) of Siphonaria australis in response to periodic UV-B radiation treatments

Table 3.1 Species used in the single and multiple stressor experiments and the dates during which these experiments were conducted .65

Table 3.2 Hatching success (in \%) of each species in response to 3-days of low salinity at two different developmental stages.

Table 3.3 Hatching success (in \%) of each species in response to $24 \mathrm{hrs}$ at high temperature.

Table 3.4 Hatching success (in \%) of Siphonaria australis in response to high UV-B radiation treatments. 
Table 3.5 Hatching success (in \%) of Siphonaria australis in response to chronic temperature and salinity treatments..................................................

Table 3.6 Hatching success (in \%) of Siphonaria australis in response to periodic temperature and salinity treatments. 82 


\section{CHAPTER 1}

\section{General Introduction}

Marine invertebrates have various life history strategies with different types of reproduction and development (Thorson, 1950). These strategies have been recognized to have important implications on later life stages and population dynamics (Thorson, 1950; Strathmann, 1985; Marshall \& Keough, 2006). While many marine invertebrates are free spawning with embryos developing in the plankton, various species, especially marine gastropods, have mixed developmental strategies. These species deposit embryos in either gelatinous or encapsulated egg masses on the benthos, on rocks, in crevices, in tide pools or on algae (Thorson, 1950; Pechenik, 1979; Chambers \& McQuaid, 1994b; Przeslawski et al. 2004). After embryonic development in the egg masses or capsules, larvae hatch as free-swimming feeding or non-feeding veliger larvae which then develop in the water column for anywhere from several weeks to months before settling and metamorphosing into juveniles on benthic habitat (Caswell, 1981; Pechenik, 1979, 1999). These life history strategies have been proposed to be advantageous for many species in certain environments such as exposed rocky shores where species have to withstand harsh conditions (Pechenik, 1979; Paine \& Levin, 1981;Collin, 2003).

The most critical times of development for invertebrates are the early life stages (Thorson, 1950). Embryonic and larval mortality and rates of abnormal development have been shown to increase in stressful conditions. While many marine invertebrates avoid intertidal stress by free-spawning gametes into the open water column, a large number of marine gastropods deposit benthic egg masses in which embryos are enclosed in the intertidal and shallow subtidal zones. Embryos within these egg masses cannot avoid environmental stressors during low tide and are therefore suggested to be very vulnerable (Kennedy et al.1974; Spight, 1975; Levin, 1984; Strathmann, 1985; Etter, 1989; 
Pechenik, 1999; Podolsky, 2003; Sponaugle \& Grorud-Colvert, 2006; Rius et al. 2009;).

There has been some evidence suggesting that egg masses may provide protection for embryos against an array of damaging environmental stressors including salinity changes (Pechenik, 1982; Woods \& DeSilets, 1997; Pechenik et al. 2003), ultraviolet radiation (UVR) (Carefoot et al. 1998; Adams \& Shick, 2001; Przeslawski et al. 2005), thermal stress (Podolsky \& Hofmann, 1998), predation (Rawlings, 1990), bacterial infection (Benkendorff et al. 2001; Haug et al., 2002) and desiccation (Strathmann \& Hess, 1999; Pechenik et al. 2003).

In species with mixed life cycles, the planktonic phase is often considerably longer than the egg mass phase. Larval duration can range from a few hours in the plankton (e.g. ascidian tadpoles) to months (e.g. echinoderm plutei and bipinnaria). During their time in the plankton larvae may face food shortages, predation and dispersal to the open ocean where they experience great mortality (Rumrill, 1990; Metaxas \& Young, 1998; Allen, 2008). The development and survival of larvae is affected by a variety of biological and physiological factors including salinity, temperature, food availability and quality, transport and predation (Moloney et al. 1994). The mixed development thus appears to be subjected to a large range of potential threats during both embryonic and larval life stages (Caswell, 1981).

Rocky shores are one of the most extreme habitats; wave action, tidal flux, food availability, levels of oxygen availability, temperature and salinity levels fluctuate widely and can cause high stress for intertidal invertebrates and their embryos (Dahlhoff et al. 2002). The intertidal zone is a very heterogeneous environment with biotic and abiotic factors shaping the distribution of species and influencing the community structure. 
Species distribution in the intertidal zone is mainly dictated by the low tide and influenced by the ability to tolerate stressors such as aerial exposure, desiccation, extreme temperatures, UV radiation and salinity changes (Menge et al. 2002; Benedettic-Cecchi, 2006; Finke et al. 2007; Shafer et al. 2008). All these stressors can fluctuate widely through time and space and act synergistically on species, especially in summer on hot sunny days, which can lead to limited growth, reduced reproduction rates and increased mortality rates (Sanford, 2002).

Wellington is one of the wettest places in New Zealand (NIWA, 2009). Even during the spring and summer months, the time when egg masses are being deposited in the intertidal and shallow subtidal by various gastropods, the mean monthly rainfall can be very high. Heavy rainfall influences the salinity in tide pools and can quickly lower salinity levels as well as extend the freshwater layer in the shallow subtidal area. Salinity plays an important role in the intertidal and shallow subtidal zone, it can rapidly increase by evaporation of water in tide pools on hot sunny days or decrease if a tide pool gets flooded by rain or freshwater run-off (Metaxas \& Scheibling, 1993; Woods \& DeSilets, 1997). Rapid changes in salinity can cause osmotic stress in intertidal organisms (Trowbridge, 1994), often causing higher respiration rates, and it has been shown that low salinity levels put higher strains on osmoconforming organisms than high salinity levels and adversely affect respiration (Talbot \& Lawrence, 2002).

Gastropods living in the high intertidal are frequently exposed to high and low salinity changes during tide cycles and high-shore gastropod adults and larvae have been shown to tolerate a range of salinities (Richmond \& Woodin, 1996; McMahon, 2003). Embryonic mortality within gastropod egg masses however has been shown to increase with wide salinity fluctuations (Struhsaker \& Costlow, 1969; Woods \& DeSilets, 1997). 
Salinity and temperature are environmental factors that simultaneously change in the field together (Thiyagarajan et al. 2003); as temperature increases, water evaporates and salinity increases. Temperature has long been recognized to be an important factor for the development rate of marine invertebrates (Pechenik \& Lima, 1984). Within species-specific tolerable ranges, development time generally decreases as temperature increases (Spight, 1975; Rumrill, 1990). As temperature exceeds tolerable levels, metabolic rates of organisms can increase and cause thermal stress. Lower temperatures generally reduce metabolic activities or slow down development altogether (Morgan \& Cowlesb, 1997; Anil et al. 2001). Although development may be halted, embryos often remain viable and continue normal development once the temperature increases to its normal range if they were only exposed to low temperatures for a short period of time (reviewed in Przeslawski, 2004).

Temperature is an important factor in intertidal and shallow subtidal areas, and can be especially stressful in tide pool environments (Trowbridge, 1994). Temperature in shallow, small rock pools can rise quickly during low tide, especially on hot sunny days, and invertebrates situated in the pools are trapped as there is no connection to the open water until the tide comes in (Pyefinch, 1943). The shallow subtidal area can warm up on hot days and it has been suggested that temperature and UVR can act synergistically (Przeslawski et al. 2005; Przeslawski \& Davis, 2007). Early life stages of marine molluscs are vulnerable to temperature changes and both embryonic and larval stages had increased mortality in several studies (Costlow et al. 1960; Kennedy et al. 1974; Lee et al. 2003; Brennand et al. 2010).

Ultraviolet radiation (UVR) comprises UV-A (320-400 nm) and UV-B (280-320 nm). The damaging effects of UVR to organisms have been recognized since the late 1800s (Downes \& Blunt, 1877). Due to stratospheric ozone depletion and interaction with climate change, the amount of harmful ultraviolet radiation (UVR) that reaches the biosphere has increased in the past decades (Schindler et al. 1996; Madronich et al. 1998; Kaurola et al. 2000; Häder et al. 2011). UVR can cause DNA, cellular, membrane and structural 
damage that can lead to biological impairment (McDonald \& Chapman, 2002; Situm et al. 2008), and it can cause death and effects on growth, development, behaviour and physiology. These effects may vary between life stages, ecological context and species (Romansic et al. 2009).

The shorter wavelength UV-B causes more damage to organisms than the longer wavelength UV-A, inducing DNA damage in various organisms including bacteria, primary producers, humans, and animals (Karentz \& Lutze, 1990; Sinha et al., 1996; Blaustein et al. 1997; Bischof et al. 1998; Häder et al. 2007; Häder, 2011). The harmful UV-B wavelengths are not only increasing at the Earth's surface but are also penetrating deeper into the water column. Stratospheric ozone depletion and the associated increase in harmful UV-B radiation reaching the sea surface have resulted in an increased interest in how UV-B affects marine organisms (Hockberger, 2002; Lamare \& Hoffmann, 2004).

Exposure to UVR, and UV-B in particular, and its effects has become a growing concern in the marine environment (Lesser \& Barry, 2003). UVB radiation is an increasing threat to aquatic organisms and levels vary widely at small spatial and temporal scales but it is particularly high at mid and high latitudes (Olson et al. 2006; Bancroft et al. 2008).

Increases in mean temperatures, UVR and changes in rainfall indices and salinity have all been attributed to global climate change (Seckmeyer \& McKenzie, 1992; IPCC, 2007; Croteau et al. 2008; Brierley \& Kingsford, 2009; Deschaseaux et al. 2010). These changes have already led to shifts in species distribution and abundance and changes in marine communities in recent years (Blaustein et al. 1994; Häder et al. 1998; Godley et al., 2001; IPCC, 2007; Nahon et al. 2010). Species inhabiting intertidal areas already experience large fluctuations in salinity, temperature and UVR (Dayton, 1971; Sousa, 1979; Gosselin \& Chia, 1995; Przeslawski et al. 2005; Beuchel et al. 2006;). These species may already be living at their tolerance limits and further increases in 
environmental stressors may push these species "over the edge" (Barry et al. 2008; Deschaseaux et al. 2010).

Abiotic stressors are highly variable in duration and intensity. The interaction between tidal cycles, seasonality, cloud cover and differences in microhabitats are all factors influencing the magnitude of environmental stress. During low tide, and especially during spring tides, conditions can become extreme in the intertidal and often change the shallow subtidal conditions. Further, species which inhabit and deposit egg masses in the shallow subtidal are likely to be exposed to less dramatic changes and extremes in physical conditions compared to intertidal species (Witman \& Grange, 1998; Allen \& Pechenik, 2010; Diederich et al. 2011). Previous research has revealed high embryonic mortality in intertidal encapsulated egg masses of gastropods (Russell, 2008; Russell \& Phillips, 2009a).

\section{Aims and Hypotheses}

The overall aim of this thesis is to examine the effects of salinity, temperature and UV-B radiation as both individual stressors and synergistic stressors on the early development of intertidal and subtidal gastropod species with mixed development and to increase the understanding of how sub-lethal stresses experienced in intertidal benthic egg masses may affect the larval stages. This aim is explored in three chapters. The first chapter compares the effects of long-term and short-term exposure of the single stressors salinity, temperature and UV-B radiation on embryonic development of intertidal (Siphonaria australis, Ercolania felina) and subtidal (Pleurobranchaea maculata, Aplysia juliana, Doris wellingtonensis) gastropods, using manipulative experiments. The second chapter examines the timing and duration of exposure to single stressors and the effects of two synergistic stressors on intertidal (S. australis) and subtidal ( $P$. maculata, A. juliana) gastropods. Finally, the third chapter explores synergistic effects of tide pool conditions (i.e. high temperature, high salinity and UV-B radiation) on the embryonic development of an intertidal gastropod ( $S$. australis). Further, it 
investigates the effects of high temperature and UV-B radiation on larvae hatched from both stressed and unstressed conditions during the embryonic development to determine possible carry-over effects between early life stages. This study aims to explore which environmental stressor (or combination of stressors) is mainly responsible for high mortality in intertidal and subtidal egg masses and at which early life stage species are particularly vulnerable to the identified stressors.

I hypothesise that egg masses from intertidal species will be more tolerant to environmental stressors than egg masses from subtidal species. Further, for $S$. australis, I expect UV-B radiation to be the most detrimental factor causing embryonic mortality, and that exposure to multiple environmental stressors simultaneously will result in higher embryonic mortality than exposure to single stressors. Additionally, larvae hatching from egg masses exposed to stressful conditions will cope with stress in their larval stages better than larvae hatching from egg masses which did not experience stress during embryonic development. 


\section{CHAPTER 2}

\section{Effects of single environmental stressors on the early development of encapsulated intertidal and subtidal marine gastropods}

\subsection{ABSTRACT}

Salinity, temperature and ultraviolet-B (UV-B) radiation are common environmental stressors for intertidal and shallow subtidal organisms. I examined the effects of these stressors for different lengths of exposure time on embryos of five gastropod species that all have benthic egg masses in either of these coastal habitats.

Chronic low salinity $(20 \%)$ caused high embryonic mortality for three out of four species examined (S. australis, P. maculata, and A. juliana). Chronic high salinity $(45 \%)$ resulted in much lower embryonic mortality in egg masses for all species compared to low salinity. Responses to the length of exposure to stressful levels of salinity were species-specific. Embryonic mortality in $S$. australis was higher in chronic low salinity compared to periodic low salinity. Embryonic mortality was overall low for $E$. felina across all salinity levels. $P$. maculata had overall higher mortality than the other species and larval size at hatching was affected by both lower and higher salinity. A. juliana embryos however had similar mortality in both chronic and periodic treatments. Hatching success was high for the intertidal species in all salinity treatments and low for the subtidal species in low salinity.

Chronic high temperature $\left(25^{\circ} \mathrm{C}\right)$ caused significantly higher embryonic mortality in both $S$. australis and $P$. maculata whereas the periodic high temperature caused significantly higher embryonic mortality in $P$. maculata and $D$. wellingtonensis egg masses but did not affect $S$. australis. Mean embryonic mortality was highest at $25^{\circ} \mathrm{C}$ for all species and decreased with lower 
temperature. Further, mortality of $S$. australis was much lower in the elevated temperature treatments compared to the other two species. Hatching success was highest at the control temperature and decreased as temperature increased for all species. However, hatching success at elevated temperatures was much higher for the intertidal $S$. australis than for the subtidal $P$. maculata, $A$. juliana and $D$. wellingtonensis. Larval size at hatching was larger for $A$. juliana with periodic exposure to $25^{\circ} \mathrm{C}$; size at hatching was slightly larger at the control temperature in the chronic exposure treatment for $S$. australis.

For S. australis, the chronic exposure to UV-B radiation at 2 levels similar to sunny days in Wellington resulted in high embryonic mortality and lower hatching success compared to the shade treatment. Short-term exposure to high UV-B had no significant effect on embryonic mortality, and hatching success was $100 \%$ in all treatments. Neither chronic nor periodic exposure to UV-B affected larval size at hatching.

Overall, these results suggest that although tolerances to different stressors is species-specific and mediated by the duration of exposure, embryos of marine gastropods that deposit egg masses in the intertidal zone seem to cope better with physical stress, especially with shorter term pulse exposure, compared to subtidal species. Further, exposure to salinity, temperature and UV-B stress generally resulted in strong mortality responses, but did not affect larval size at hatching.

\subsection{INTRODUCTION}

Marine organisms in coastal marine habitats are often exposed to stressful environmental conditions (e.g. extremes and variation in salinity, humidity, temperature, UVR), that can change rapidly due to weather and tidal conditions. Many species of marine gastropods deposit egg masses in these coastal environments, thus subjecting developing embryos to a range of these stressors, especially in spring and summer months (the main reproductive 
season of most molluscs and the time at which egg masses are being laid) when stressors can be very high.

For example, salinity can rapidly increase in tidal pools by evaporation or if there are long time periods in high tide pools without flushing events; alternatively it can also quickly decrease if a tidal pool gets flooded by rain and/ or terrestrial freshwater runoff during low tide (Trowbridge, 1994). Shallow subtidal habitats can also experience dramatic salinity change when high rainfall and freshwater runoff can create a low-salinity layer up to several meters deep (Witman \& Grange, 1998). For early life stages, osmotic stress may affect development, i.e. slow the developmental rate, cause abnormalities or result in high mortality, and at least in echinoderms, low salinity levels may have stronger negative effects than high salinity (Talbot \& Lawrence, 2002).

Temperature can also increase rapidly, particularly on summer days when low tides coincide with high midday temperatures (Trowbridge, 1994; Podolsky, 2000). Temperature has been shown to play an important part in early life stages, including embryonic development in invertebrate egg masses (Przeslawski, 2004; Mita et al. 2007). Gastropod embryos have been suggested to be more able to tolerate low temperatures than high temperature extremes (Przeslawski, 2004) and may be extremely vulnerable to high temperature during their embryonic life stage (Thorson, 1950).

UV-B causes more damage to organisms than UV-A. It has been shown to induce DNA and protein damage in a large range of organisms including bacteria, primary producers, humans, and animals (Karentz \& Lutze, 1990; Sinha, et al. 1996; Blaustein, et al.1997; Bischof, et al. 1998; Häder, et al. 2007; Häder, 2011). Although marine environments vary widely in how much UVR they attenuate, UV-B can penetrate more than $20 \mathrm{~m}$ in clear ocean waters (Karentz \& Lutze, 1990; Booth et al. 1997; Huang et al. 2006; Liu et al. 2008). Due to the ozone hole over Antarctica and the Southern Hemisphere's close proximity to the Sun, UVR is extremely high in summer in New Zealand where 
the amount of UVR can exceed the amount in the Northern Hemisphere in summer by 40\% (Seckmeyer \& McKenzie, 1992; McKenzie et al. 1997; Madronich et al. 1998; McKenzie et al. 2006). Early life stages of aquatic animals are at high risk from UV damage (reviewed by Häder et al. 2007). Previous studies have shown that UVR can cause retarded development, malformations and death in mollusc embryos (Biermann et al. 1992; Rawlings, 1996; Carefoot et al. 1998; Russell \& Phillips, 2009a, 2009b).

Because early life stages are often particularly vulnerable to stress, and mortality at this stage can have strong implications for population dynamics (Gaudy et al. 1982; Roughgarden et al. 1988; Miliou \& MoraitouApostolopoulou, 1991; Trowbridge, 1994; Grubert \& Ritar, 2004b), it is important to understand how abiotic conditions affect embryos in benthic egg masses. Further, species which inhabit and deposit egg masses in the shallow subtidal are likely to be exposed to less dramatic changes and extremes in physical conditions compared to intertidal species (Witman \& Grange, 1998; Allen \& Pechenik, 2010; Diederich, et al. 2011;). Therefore one aim of this chapter was to compare responses between species in these two habitats.

Because environmental stresses can originate from various sources and span different time frames, another aim was to examine responses to two temporal exposures: chronic stress (press) and short-term (pulse) stress (Bender et al. 1984; Trowbridge, 1994; Richmond \& Woodin, 1996). Press stress could occur from severe weather over a long period of time or during low neap tides when water in shallow tidal pools does not get flushed daily. Pulse stress may occur via short, extreme weather events that occur during low tide cycles.

Previous research suggests that press exposures have stronger effects than pulse exposures (Keough \& Quinn, 1998; Veale et al. 2000b; Marshall \& Bailey, 2004; Peterson-Smith \& Shea, 2010). The resilience to or recovery from a pulse disturbance is usually higher than a press disturbance (Lake, 2000). 
In this chapter, the effects of salinity, temperature and UV-B radiation stress during both press and pulse exposures were examined on the development of two intertidal and three subtidal species of marine gastropods. I hypothesised that (1) salinity is more stressful at low levels (a pilot study beforehand had determined the tolerance to high salinities), (2) high temperature increases mortality, (3) high UV radiation is detrimental to embryonic development, (4) long term (press) exposure to each environmental stressor is more stressful than short term (pulse) exposure, and (5) that the responses are species-specific, intertidal species should cope better with a range of stressor levels than subtidal species.

\subsection{METHODS}

\subsubsection{Study Species}

All the focal species are hermaphroditic marine gastropods with a mixed life history which can be found in the intertidal or subtidal. After internal fertilization occurs, these species produce and deposit numerous benthic gelatinous egg masses that vary in shape, size and colour between species, on rocks, in crevices, on algae, on substrate, or in rock pools during the austral spring and summer. The embryos spend several days developing in the benthic egg mass, hatching as planktotrophic veliger larvae which spend several weeks in the water column before settling and metamorphosing into juveniles.

Intertidal: Siphonaria australis is a small pulmonate limpet inhabiting semi-exposed and exposed intertidal rocky shores in the low, mid and upper zone, and are commonly found in crevices (Chambers \& McQuaid, 1994a). They are distributed throughout New Zealand, Auckland Islands, Snares Islands and the Subantarctic (Morley, 2004; Schiel, 2006). S. australis deposits small, gelatinous egg masses throughout the intertidal between September and March (Russell \& Phillips, 2009a, Fischer,personal observation, Fig 2.1). The embryos spend 5-8 days developing in the benthic egg mass, before they hatch as planktotrophic veliger larvae (Creese, 1980). 


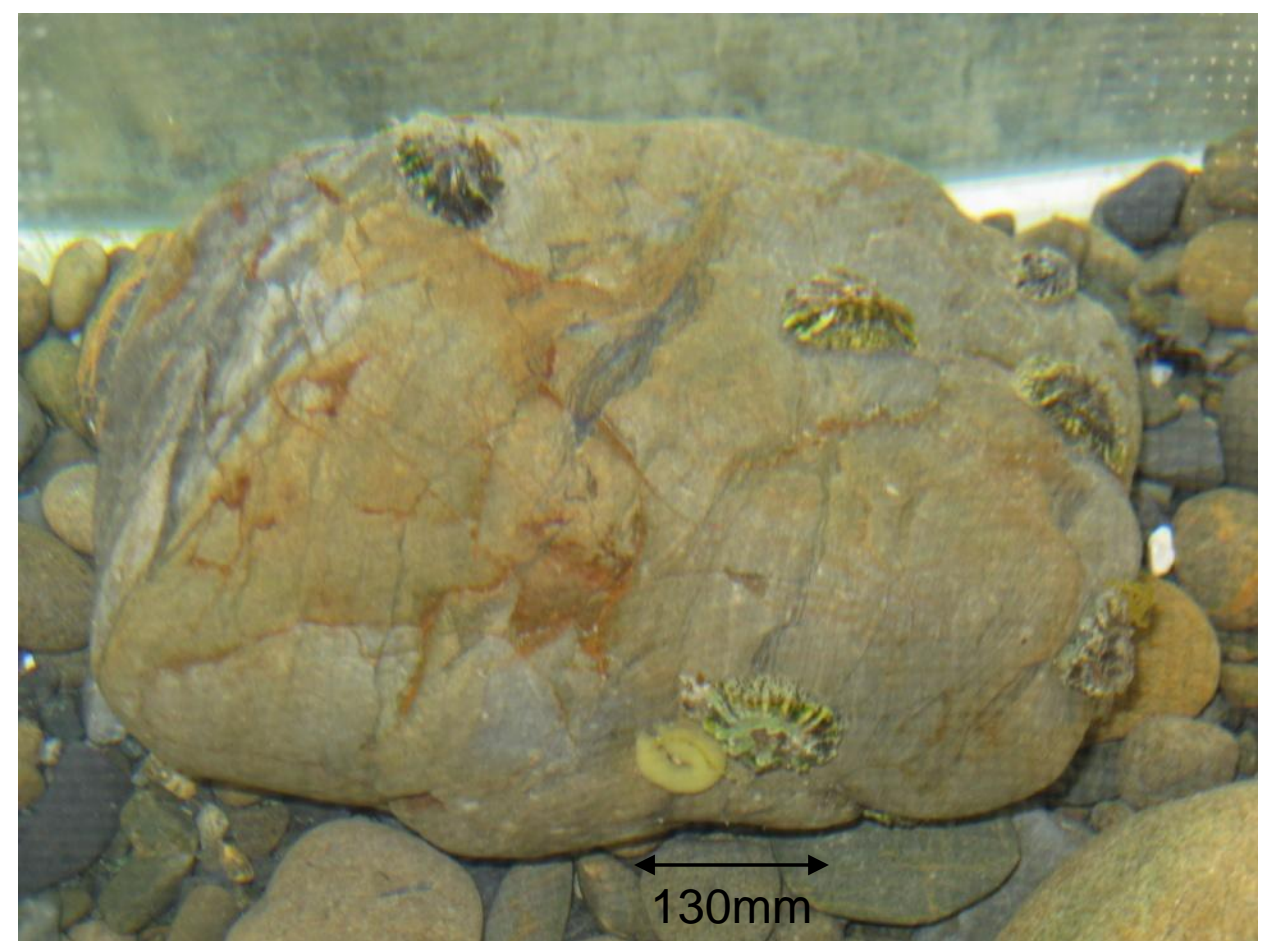

Figure 2.1 Adult Siphonaria australis and a freshly deposited egg mass, VUCEL, November 2009.

Ercolania felina is a small sacoglossan sea slug that inhabits high, often ephemeral, intertidal pools. It feeds on, and is associated with, the green alga Chaetomorpha. E. felina mates in tide pools around September and lays benthic egg masses, attached to the algae (Fig 2.2) from which planktotrophic veligers hatch after 6 to 8 days. Tidal flushing is necessary for these veligers (as well as adults) to emigrate (Trowbridge, 1994). 


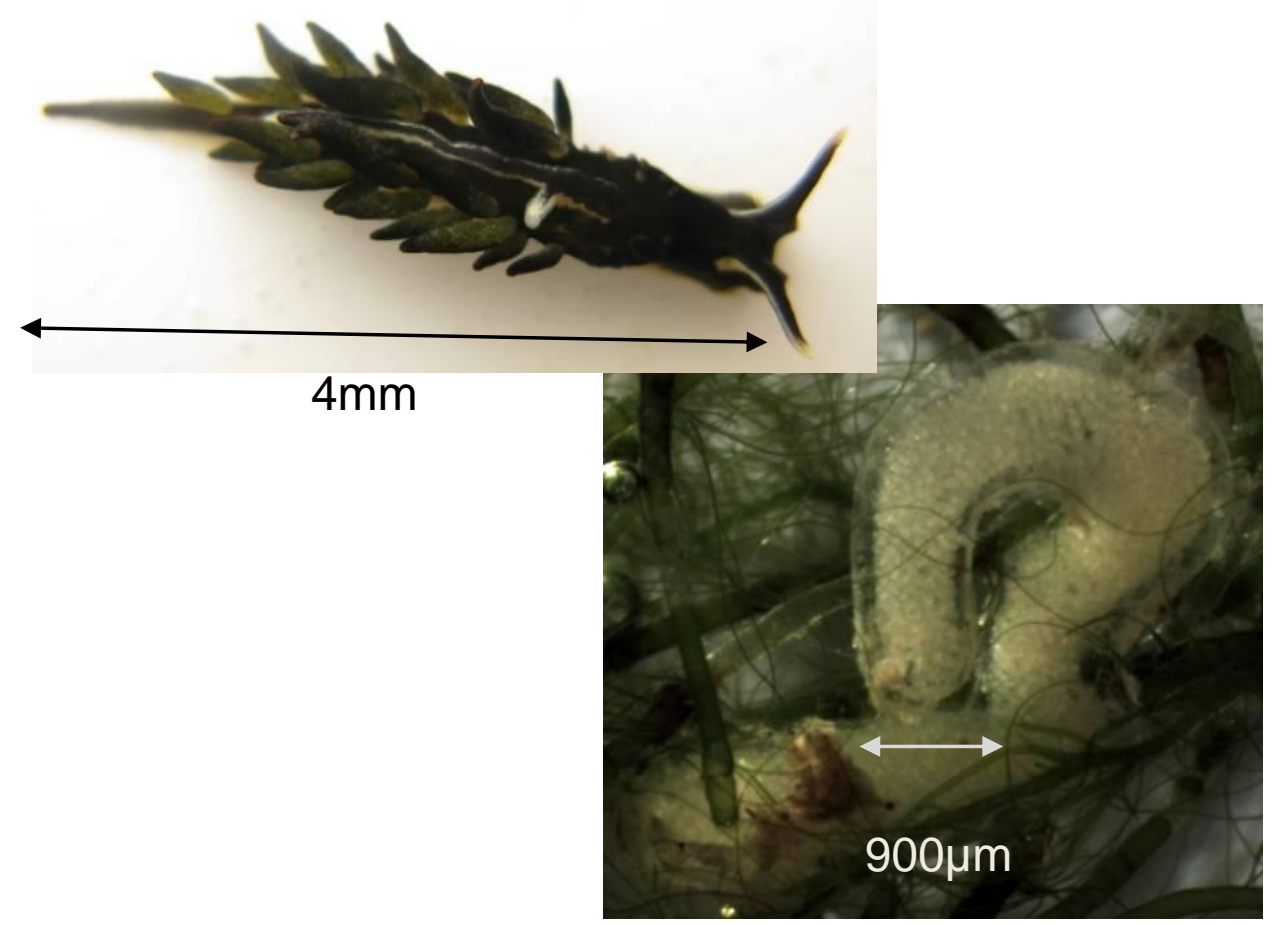

Figure 2.2 Adult Ercolania felina and a freshly deposited egg mass in Chaetomorpha. Photos: Shane Geange

Subtidal: Pleurobranchaea maculata (Quoy \& Gaimard, 1832), the grey side-gilled sea slug, is distributed throughout New Zealand and can be found in various habitats and on all substrates from the shallow subtidal to depths of $250 \mathrm{~m}$ off open coasts (Morley, 2004). P. maculata produce gelatinous coils of egg masses with small eggs that hatch in 8 days (Gibson, 2003, Fig 2.3). Information on spawning time is scarce but it bread all year round in tanks when provided with food (Fischer, personal observation). 


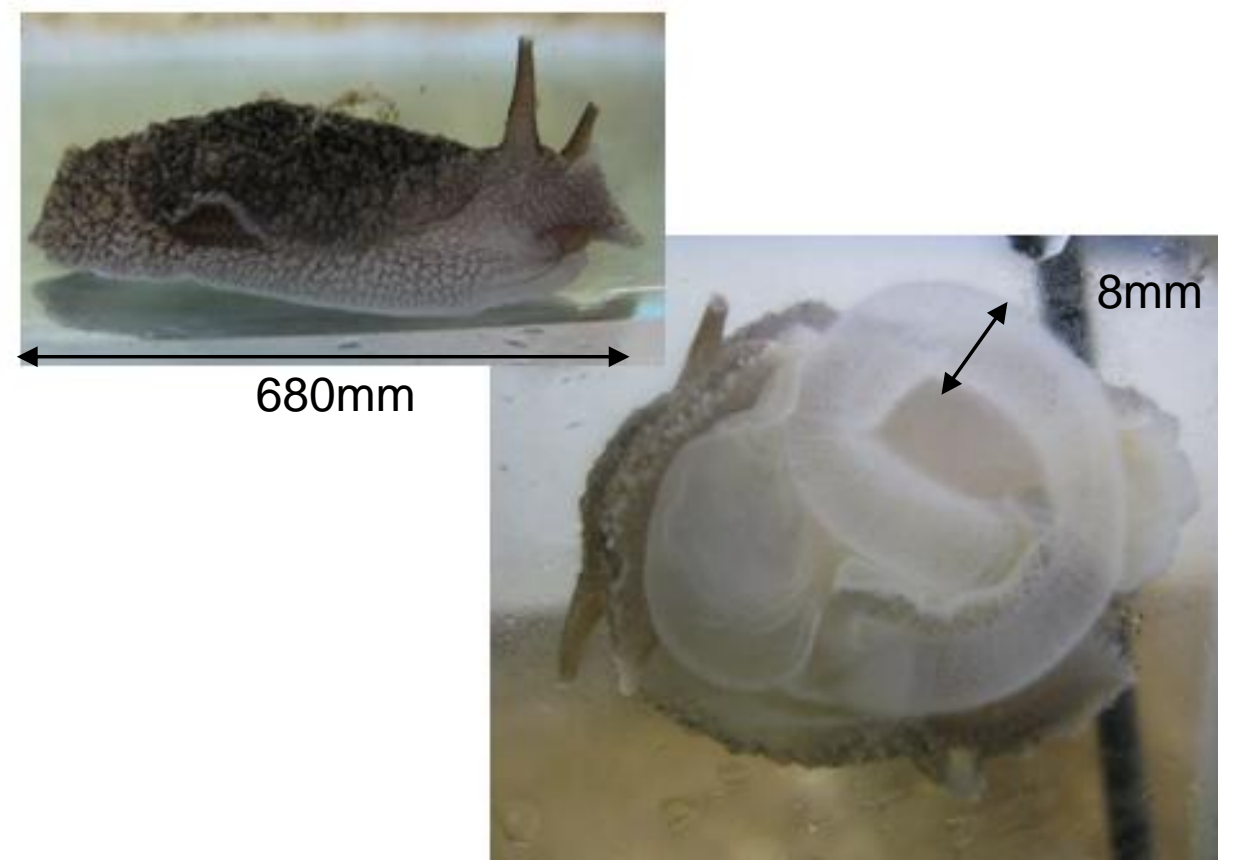

Figure 2.3 Adult Pleurobranchaea maculata (left) and adult depositing an egg mass in a glass tank (ventral view).

Aplysia juliana (Quoy \& Gaimard, 1832) is a large sea hare (up to 300 $\mathrm{mm}$ in length) found in all temperate and tropical water regions around the globe and throughout New Zealand's North, South and Stewart Islands (Fig 2.4). It is generally found on rocky reefs amid kelp in calm subtidal waters and sheltered shallows from the low intertidal to 3 m depth (Eales, 1960; Hutton, 1874). A. juliana produces large yellow to dark orange spaghetti-like egg ribbons between April and May. Veligers hatch after 9 days after oviposition at $15^{\circ} \mathrm{C}$ (own personal observation) and reportedly after $7-8$ days at $23.5-30^{\circ} \mathrm{C}$ (Kempf, 1981). A. juliana reared in the laboratory can produce as many as 2.72 $X 10^{8}$ eggs during its lifetime (Switzer-Dunlap \& Hadfield, 1977). Densities in field populations may be as high as 3.5 animals $\mathrm{m}^{-2}$ and spawn production may reach $6.56 \times 10^{6}$ eggs $\left(\mathrm{m}^{-2} \mathrm{wk}^{-1}\right)$ (Sarver, 1978). The large numbers of larvae emerging from these egg masses increase the chance that some veligers avoid predation or mortality from other environmental factors during extended periods adrift in the plankton (Kempf, 1981). 


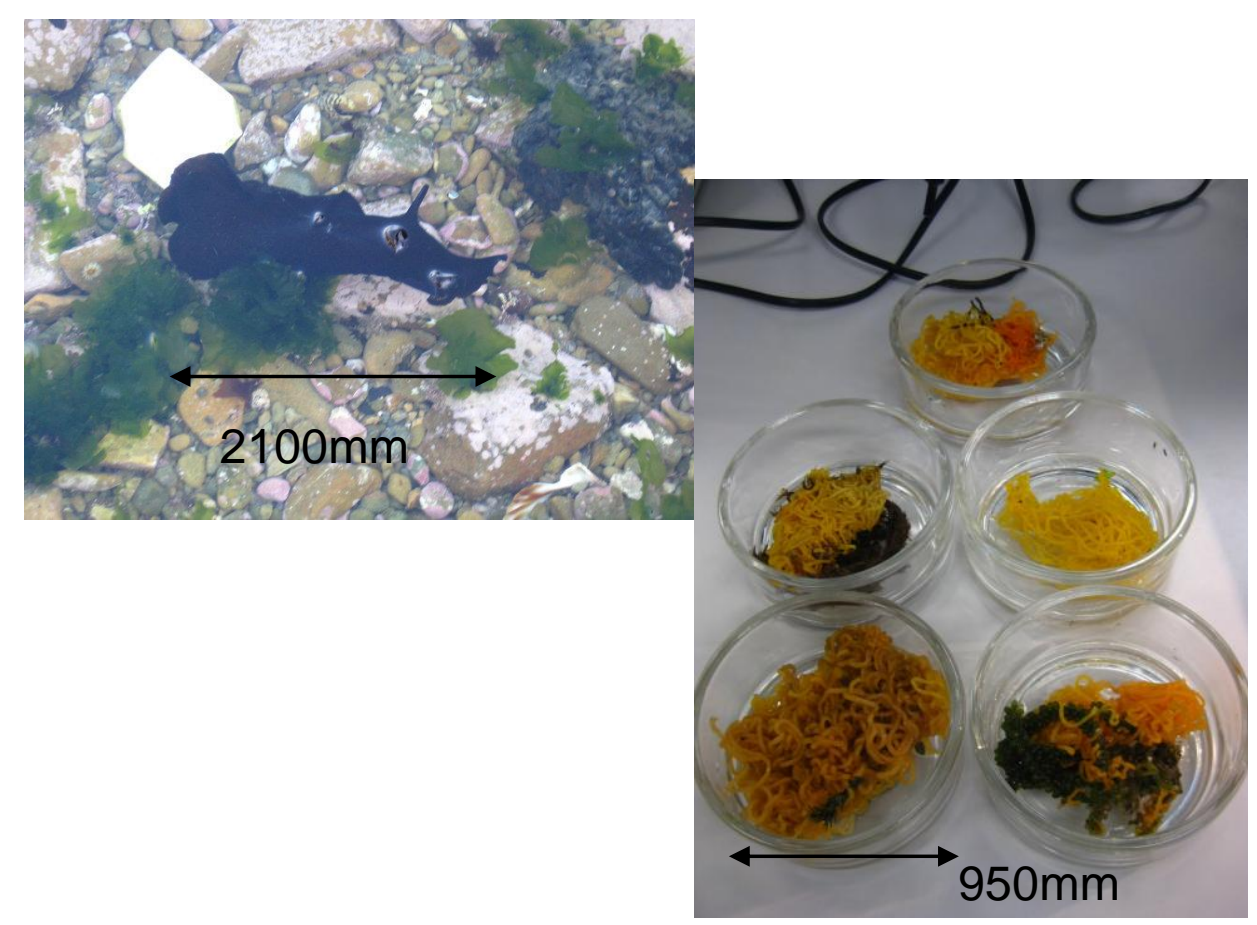

Figure 2.4 Adult Aplysia juliana in the shallow subtidal and various egg masses collected from the tank.

Doris wellingtonensis, the Wellington nudibranch, is the largest nudibranch in New Zealand, growing up to between 100-200 mm in length. The body is fleshy and of ochre-orange to yellow colour and covered in fleshy bumps (Fig 2.5). D. wellingtonensis lives under boulders on rocky shores from the intertidal to $20 \mathrm{~m}$ depth throughout the North, South and Stewart Islands as well as southern Australia. It can often be found on encrusting yellow sponges upon which it feeds. Reproduction is seasonal and occurs during spring and summer (approximately October to January); the egg masses of $D$. wellingtonensis are large orange to yellow and spiral (Morley, 2004; Cook, 2010). 

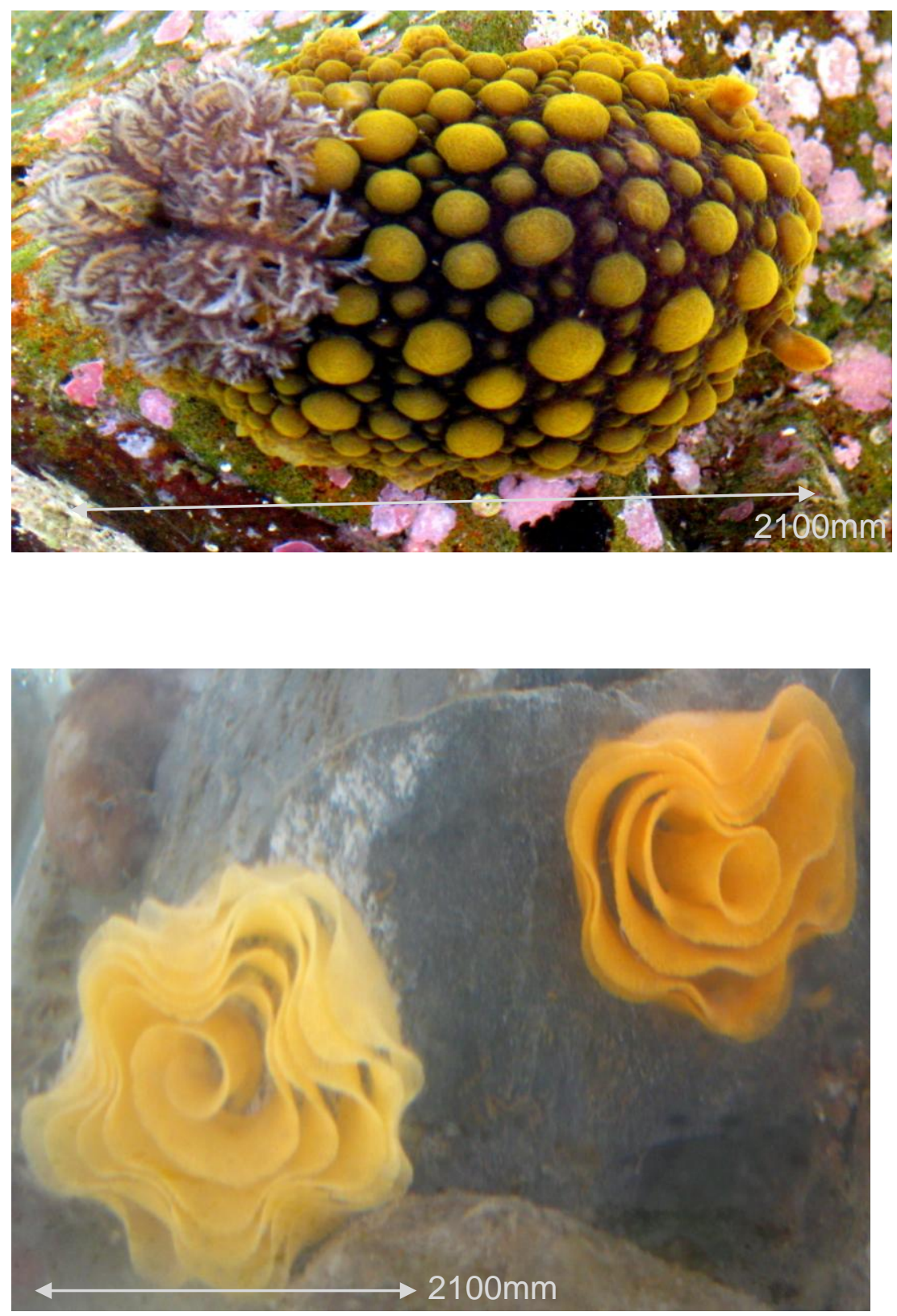

Figure 2.5 Doris wellingtonensis adult and spiral egg masses laid in the tank.

\subsubsection{Locations}

Adults of five species were collected (between six [D. wellingtonensis] and 35 [S. australis] individuals per species, depending on availability) from around Wellington, New Zealand: Siphonaria australis from intertidal rocky platforms at Princess Bay (4120'42.42"S, 17447'12.56"E), Ercolania felina from intertidal pools at Tarakena Bay (4120'36.54”S, $\left.174^{\circ} 49^{\prime} 03.55^{\prime \prime E}\right)$, 
Pleurobranchaea maculata from Kau Bay at approximately $5 \mathrm{~m}$ depth (41 ${ }^{\circ} 20^{\prime} 13.10^{\prime \prime}$ S, $\left.174^{\circ} 49^{\prime} 30.30^{\prime \prime} \mathrm{E}\right)$, and $A$. juliana and D. wellingtonensis from shallow subtidal rocky habitat at Breaker Bay at 2 to $6 \mathrm{~m}$ depth, respectively (411'11.15”S, 17449'47.00”E, Fig 2.6).

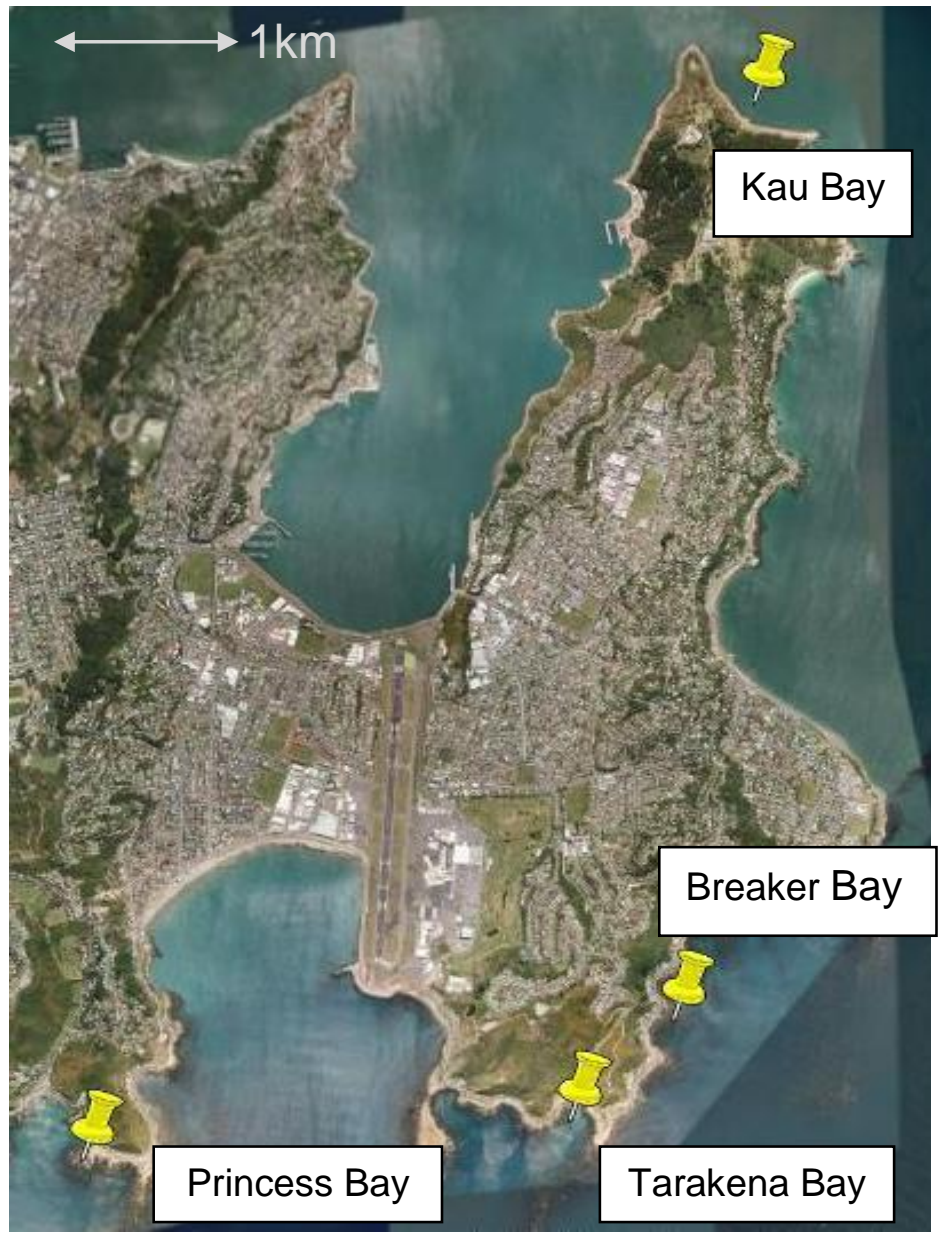

Figure 2.6 Location of collection sites in Wellington for adult Siphonaria australis (Princess Bay), Ercolania felina (Tarakena Bay), Pleurobranchaea maculata (Kau Bay) and Aplysia juliana and Doris wellingtonensis (Breaker Bay).

Each of the five species was maintained in separate tanks with flowing seawater at the Victoria University Coastal Ecology Lab (VUCEL) to breed and deposit egg masses. S. australis was fed by letting it constantly graze on rocks that had been collected from the low intertidal. E. felina and $A$. juliana were provided with Chaetomorpha sp. and Ulva sp., respectively. P. maculata was 
"handfed" at least twice a week with frozen fish and squid and $D$. wellingtonensis was provided with various sponges to feed on.

The availability of egg masses of some species was limited and dependent on seasonal variability in the timing of spawning. It was therefore not possible to include all species in all the experiments. Only Siphonaria australis egg masses were regularly available, and thus used in every experiment; egg masses of other species were used when they were available.

\subsubsection{Manipulative Experiments}

\subsubsection{Salinity}

In February 2010 salinity was measured in intertidal pools and in the open water at low tide on the rocky shore in Island Bay to obtain realistic upper limits for experiments. Salinity in intertidal pools ranged from 35-44\%o ( $n=30$ pools); the open water ( $3 \mathrm{~m}$ deep, out from the rocky shore) was $35 \%$ on one occasion, $40 \%$ on another.

\section{Experiment One- Press}

This experiment was designed to examine the effects of chronic levels of different salinities on mortality, hatching success and larval size at hatching. Species used in this experiment were $S$. australis and $E$. felina from the intertidal, and $P$. maculata and $A$. juliana from the subtidal. For each species, six freshly deposited egg masses ( $\leq 24$ hours post spawning) were collected from the tanks in the lab. Each egg mass was cut into five sections of approximately equal size and each section from each egg mass was placed into a glass dish $(236 \mathrm{ml})$ and exposed to one of the following salinity treatments for five consecutive days: $20 \%$, 25\%, 30\%, 35\%o (control), and $40 \%$. Five days was chosen as the length of the exposure in press treatments because after that hatching becomes imminent for all species. Salinity treatments were established by adding appropriate amounts of salt (Instant 
Ocean (B) to distilled water. Salinity in each dish was confirmed with a refractometer. Water in the dishes was replaced and mixed up fresh daily.

This experiment was conducted between the $4^{\text {th }}$ and $9^{\text {th }}$ of November 2011 for $S$. australis, the $23^{\text {rd }}$ and $28^{\text {th }}$ of September for E. felina, the $8^{\text {th }}$ and $22^{\text {nd }} 2010$ of May for $P$. maculata and the $4^{\text {th }}$ and $13^{\text {th }}$ of May 2010 for $A$. juliana. These dates were due to availability and seasonality of egg masses.

After 5 days, each egg mass section from each treatment was examined under 100x magnification and 100 embryos were scored as either viable (alive and appearing to be developmentally normal) or inviable (dead or severely abnormal in appearance) to measure mortality (Fig 2.7).
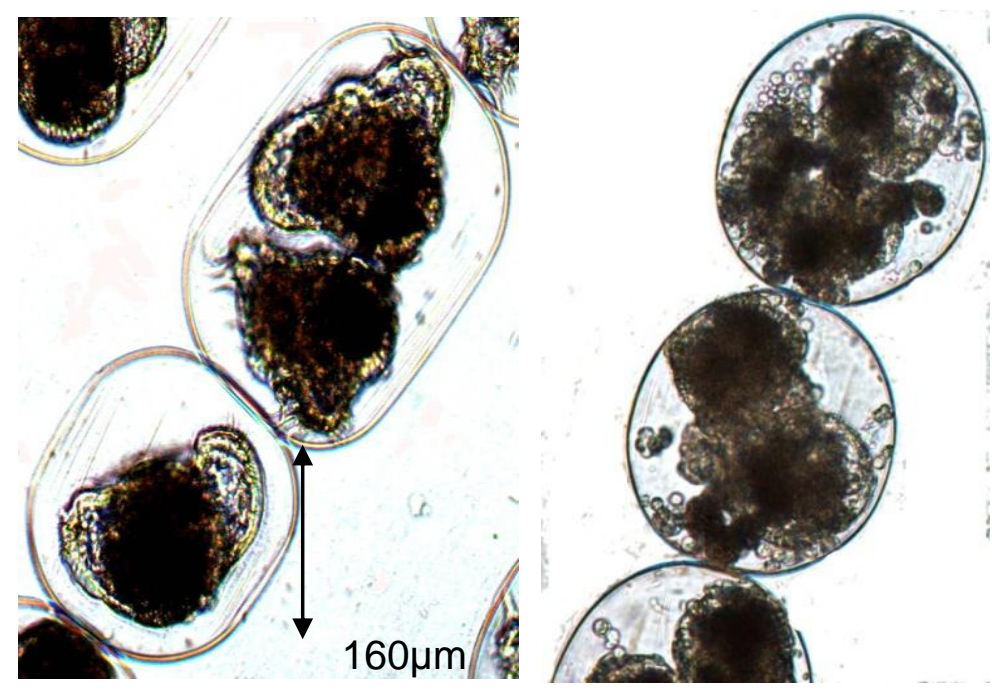

Figure 2.7 Examples of viable (left) and inviable (right) embryos of Pleurobranchaea maculata after 5 consecutive days (press) in the control (35\%, left) and low salinity (20\%, right) treatment.

Egg masses with $<100 \%$ of inviable embryos were maintained in dishes of filtered sea water (FSW; filtered with a 1- $\mu$ m mesh size filter) and hatching success was recorded for each egg mass by checking the dishes daily for hatched larvae. "Success" was constituted when at least 100 larvae had hatched from the egg mass in the dish and "failure" was constituted when no 
larvae had hatched within 14 days after the completion of the experiment. The embryos in the egg mass were then discarded. If larvae hatched, they were preserved in $4 \%$ buffered formalin for measuring. Shell lengths of 21 larvae per treatment and per replicate egg mass were measured using a Zeiss compound microscope equipped with an ocular micrometer at 100x magnification (Fig 2.8).

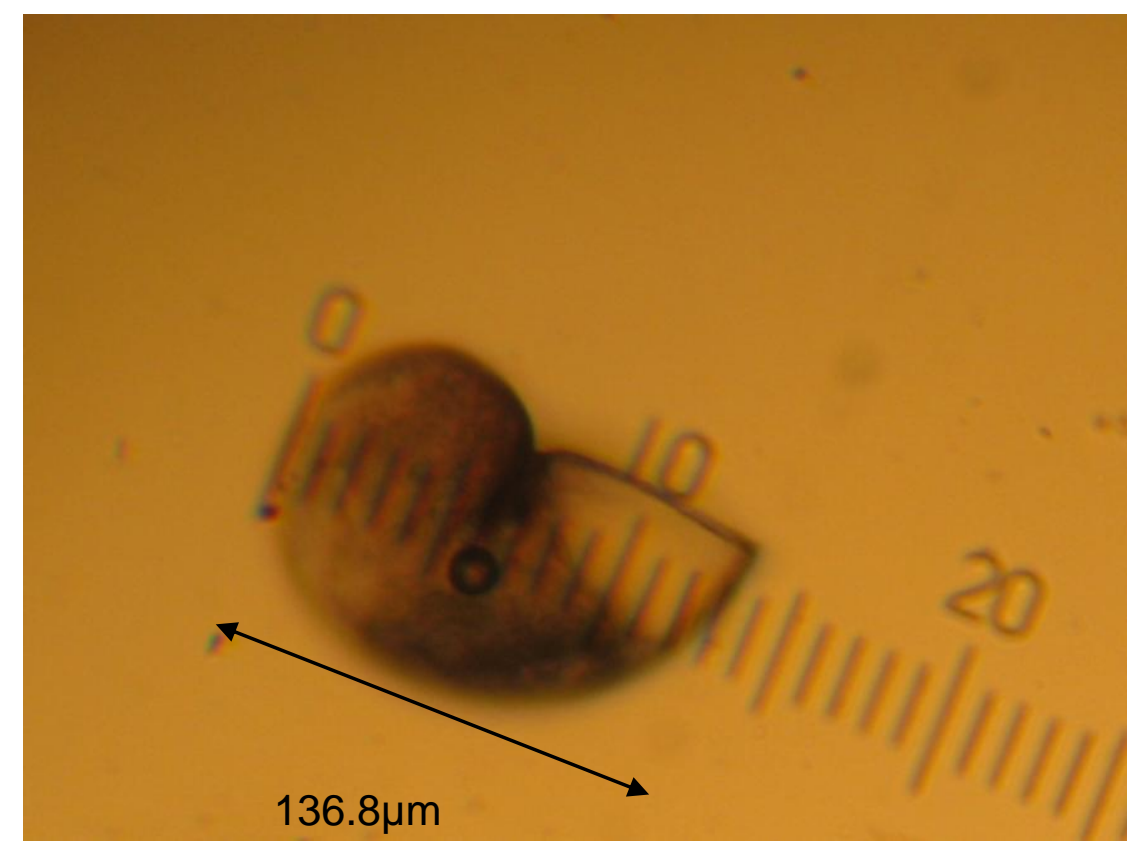

Figure 2.8 Shell length of a newly hatched Siphonaria australis larva being measured under the microscope (100x magnification).

\section{Experiment Two- Pulse}

This experiment was designed to examine the effects of short-term periodic changes in salinity on mortality, hatching success and larval size at hatching for one intertidal (S. australis) and two subtidal (P. maculata, $A$. juliana) species. Similar to the press experiment, for each species, six freshly deposited egg masses were collected from the tanks in the lab and cut into five sections of approximately equal size. Salinity levels were the same as in the press experiment $(20 \%, 25 \%, 30 \%, 35 \%$ (control) and $40 \%$ ), but egg masses were only exposed to these treatments for 4 hours a day (11:00-15:00) for five consecutive days. When not in salinity treatments, egg masses were 
maintained at the control salinity (35\%). Mortality, hatching success, and larval size were measured as described above for experiment one.

The pulse experiments were conducted between the $3^{\text {rd }}$ and $8^{\text {th }}$ of December 2010 for Siphonaria australis, the $10^{\text {th }}$ and $21^{\text {st }}$ of August 2010 for $P$. maculata and the $8^{\text {th }}$ and $17^{\text {th }}$ of May 2010 for $A$. juliana.

\subsubsection{Temperature}

As egg masses are only laid in spring and summer, low temperatures are not a concern and therefore not of interest in this study. Temperature measurements in small intertidal pools during low tide in February 2010 ranged from $20.7-25.2^{\circ} \mathrm{C}$; and between $18.8-22.4^{\circ} \mathrm{C}$ in the subtidal zone ( $\mathrm{n}=30$ pools). Temperature of the open water ranged between $12^{\circ} \mathrm{C}$ and $17^{\circ} \mathrm{C}$.

\section{Experiment One: Press}

This experiment was designed to examine the effects of chronic exposure to high temperature on mortality, hatching success and larval size of one intertidal ( $S$. australis) and one subtidal ( $P$. maculata) species. For both species six freshly deposited egg masses were collected from the tanks in the lab. Each egg mass was cut into three sections of approximately equal size. Each section from each egg mass was placed into a glass dish filled with 100 $\mathrm{ml} \mathrm{FSW}$ and exposed to one of the following temperatures for 5 consecutive days: $15^{\circ} \mathrm{C}$ (control), $20^{\circ} \mathrm{C}$ and $25^{\circ} \mathrm{C}$. In the control treatment, the dishes were placed into a sea table with flowing seawater $\left(15^{\circ} \mathrm{C}\right)$ and temperature was measured twice a day; heater bars in two glass tanks filled with water were used to elevate the temperature to $20^{\circ} \mathrm{C}$ and $25^{\circ} \mathrm{C}$ respectively for the stress treatments. Mortality, hatching success, and larval size were measured as described for previous experiments. This experiment was conducted between the $4^{\text {th }}$ and $9^{\text {th }}$ of November 2011 for S. australis and $22^{\text {th }}$ and $30^{\text {th }}$ of October 2010 for $P$. maculata. 


\section{Experiment Two- Pulse}

This experiment was designed to test for the effects of periodic high temperature on embryonic mortality, hatching success and larval size at hatching of three species: intertidal $S$. australis and subtidal $A$. juliana and $D$. wellingtonensis. For each species, six freshly deposited egg masses were collected from the tanks in the lab. Each egg mass was cut into three sections of approximately equal size. Each section from each egg mass was placed into a glass dish filled with $100 \mathrm{ml} \mathrm{FSW}$ and exposed to one of the following temperatures for 4 hours per day for 5 consecutive days: $15^{\circ} \mathrm{C}$ (control), $20^{\circ} \mathrm{C}$ and $25^{\circ} \mathrm{C}$. Temperature treatments were created using the same methods as described for the press experiment above.

After 4 hours, the FSW was replaced in all dishes and the dishes returned to the control sea table. Temperatures in each stress tank were confirmed with a thermometer. Mortality, hatching success, and larval size were measured as described for previous experiments.

This experiment was conducted between the $22^{\text {nd }}$ of October and the $27^{\text {th }}$ of November 2010 for S. australis, $4^{\text {th }}$ and $8^{\text {th }}$ of April 2010 for A. juliana, and the $22^{\text {nd }}$ and $30^{\text {th }}$ of October 2010 for Doris wellingtonensis.

\subsubsection{UV-B radiation}

\section{Experiment - Press}

UV-B radiation levels were measured using a UV-B sensor radiometer (Skye, SpectroSense2+) on several sunny cloudless days in February 2010. UV-B radiation can reach $1.7 \mathrm{~W} \mathrm{~m}^{-2} \mathrm{~s}^{-1}$ and higher in summer, compared to $0.88 \mathrm{~W} \mathrm{~m}^{-2} \mathrm{~s}^{-1}$ in winter (own unpublished data).

This experiment was designed to test for the effects of chronic harmful UV-B on mortality, hatching success and larval size of the intertidal species $S$. australis. Six freshly deposited $S$. australis replicate egg masses were 
collected from the tank in the lab. Each egg mass was cut into three sections, of approximately equal size. One section from each egg mass was placed in a small glass dish with FSW in a temperature controlled room (set to $20^{\circ} \mathrm{C}$, this temperature was used because of logistical constraints of other users) and exposed to one of the following UV-B treatments for 12 hours (this time was chosen to simulate night and day) daily for 5 consecutive days: $1.7 \mathrm{~W} \mathrm{~m}^{-2} \mathrm{~s}^{-}$ ${ }^{1}$ (high), $1.5 \mathrm{~W} \mathrm{~m}^{-2} \mathrm{~s}^{-1}$ (medium) and shade/ control $\left(0.015 \mathrm{~W} \mathrm{~m}^{-2} \mathrm{~s}^{-1}\right)$. UV-B lights (Philips UVB Broadband TL 20W/12) were used and UV-B intensity was measured and calibrated using a UV-B sensor radiometer (Skye, SpectroSense2+). The shade treatment was created by blocking UV light with a large plastic cloth that did not permit light transmission. The lamps were covered in polyvinyl chloride (PVC) to filter out short wavelengths that are not reaching Earth's surface.

After 12 hours the UV-B lamps were switched off, the dishes remained in the temperature controlled room. Salinity was controlled for by replacing the FSW twice a day. Salinity and temperature were confirmed by using a refractometer and thermometer. After 5 days, each egg mass and hatching larvae were examined as previously described in this chapter. The press experiment was conducted between the $7^{\text {th }}$ and $12^{\text {th }}$ of December 2011.

\section{Experiment Two- Pulse}

This experiment was designed to examine the effects of short-term periodic high UV-B on mortality, hatching success and larval size at hatching of one intertidal gastropod species (S. australis). Six freshly deposited egg masses were collected from the tank in the lab and each cut into three sections of approximately equal size. UV-B levels were the same as in the press experiment $\left(1.7 \mathrm{Wm}^{-2} \mathrm{~s}^{-1}, 1.5 \mathrm{Wm}^{-2} \mathrm{~s}^{-1}\right.$ and shade), egg masses were exposed to these treatments for 4 hours (11:00-15:00) per day for five consecutive days. After four hours the egg masses were removed from the UV-B lights and maintained in the shade in the temperature controlled room. After 5 days, each 
egg mass was examined for embryonic mortality, hatching success and hatching larvae from each treatment as previously described in this chapter. The pulse experiment was conducted between the 7 th and $11^{\text {th }}$ of December 2011.

\subsubsection{Statistical Analysis}

Separate mixed model ANOVAs were used for each press and pulse experiment, with stressor (i.e. salinity, temperature or UVR) as a fixed factor and egg mass nested within the stressor as a random factor to examine the treatment effects on embryonic mortality and larval size at hatching for each species. Significant results were further examined by post hoc tests. The percentage of inviable embryos in the egg mass was assumed to be equal to embryonic mortality. When the percentage data of embryonic mortality or the larval size at hatching data violated the ANOVA assumptions, the data were arc-sine square-root transformed for the mortality data and log10 transformed for the larval size data to improve normality. All statistical analyses were carried out using PASW 18.0 software. While transformed data were used for the analyses, raw data were plotted for easier interpretation.

\subsection{RESULTS}

\subsubsection{Salinity}

\section{Experiment One- Press}

Chronic salinity had a significant effect on the mean embryonic mortality of one intertidal species, $S$. australis $\left(\mathrm{F}_{4,25}=2.983, \mathrm{p}=0.038\right)$. The embryonic mortality was 10 times higher at $20 \%$ than at all the other treatments, none of which were significantly different from each other (pairwise comparisons, $p<$ 0.05 , Fig 2.9 ) and in which mortality was low (less than $3 \%$ compared to $22 \%$ in $20 \%$ ). The intertidal $E$. felina was not affected by salinity $\left(F_{4,25}=0.351\right.$, 
$p=0.841$ ) and mortality was uniformly low (less than $2 \%$ ) for all treatments (Fig 2.9).

Embryonic mortality was highly affected by salinity for the subtidal $P$. maculata $\left(\mathrm{F}_{4,25}=29.451, \mathrm{p}<0.001\right)$. Mean embryonic mortality was lowest at $35 \%$ and $40 \%$ (on average $2 \%$ mortality across these treatments), and increased with decreasing salinity with being relatively low at $30 \%$ (17\%) and with reaching very high mortality at $25 \%$ and $20 \%$ o (84-100\%), which were significantly different from the other treatments (pairwise comparisons, $p<$ 0.001 , Fig 2.9). Salinity also had a significant effect on the subtidal $A$. juliana $\left(F_{4,25}=3.057, p=0.035\right.$, Fig 2.9). Embryonic mortality was relatively high in all treatments compared to the other species, and significantly higher in the lowest salinity treatment (86\%) than at $35 \%$ and $40 \%$ o (pairwise comparisons, $p<$ 0.05).

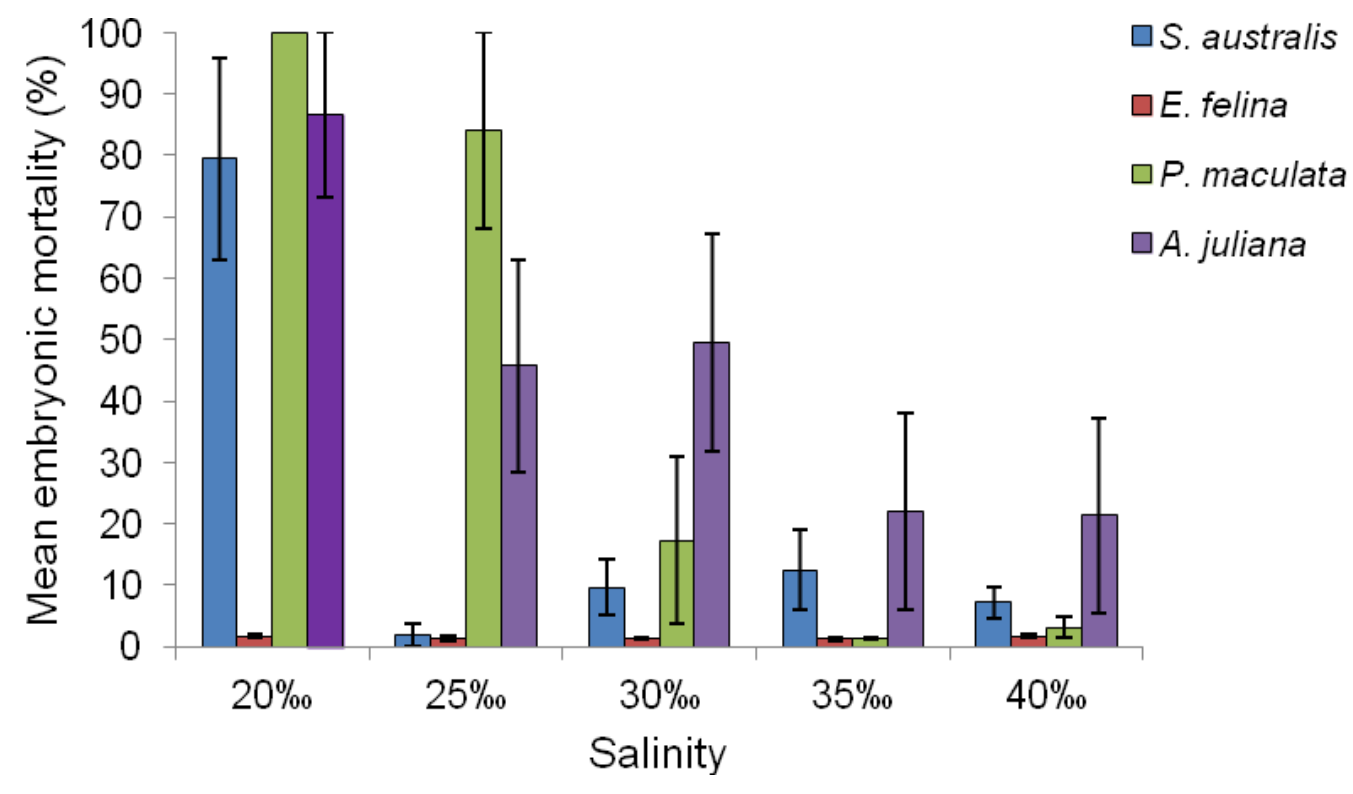

Figure 2.9 Mean percentage of embryonic mortality in egg masses for two intertidal and two subtidal species with mixed development subjected to different levels of chronic salinity for a period of 5 days $( \pm S E), n=6$ for each species. 
Hatching success varied between the intertidal and subtidal species in the salinity treatments. The intertidal E. felina and $S$. australis had high hatching success throughout all levels of salinity (Table 2.1). The subtidal species $P$. maculata and $A$. juliana both showed none or very low hatching success in $20 \%$ and increasingly higher success in higher salinity levels. There was no discrepancy in days till hatching for $S$. australis, E. felina, and A. juliana larvae between the different levels of salinity (Table 2.1). Days till hatching were higher at low salinity for $P$. maculata larvae. The variation between the egg masses was large (up to 11 days for $P$. maculata and up to five days for $A$. juliana) in the subtidal species.

Table 2.1 Hatching success (in \%) and days till hatching ( \pm SD) of each species in response to chronic salinity treatments. Hatching success and days till hatching were scored out of 6 egg masses for each species

\begin{tabular}{l|lccccc} 
& Salinity & $20 \%$ & $25 \%$ o & $30 \%$ & $35 \%$ & $40 \%$ \\
\hline S. australis & Success & 100 & 100 & 100 & 100 & 100 \\
& Days & $11.1 \pm 0.4$ & $10.6 \pm 0.8$ & 10 & 10 & $10.5 \pm 0.8$ \\
\hline E. felina & Success & 100 & 100 & 100 & 100 & 100 \\
& Days & $7.3 \pm 0.5$ & $7.3 \pm 0.5$ & 7 & $6.3 \pm 1$ & 7 \\
\hline P. maculata & Success & 0 & 16 & 83 & 100 & 100 \\
& Days & - & 29 & $17.4 \pm 9.5$ & $8.1 \pm 1.6$ & $13.5 \pm 8.9$ \\
\hline A. juliana & Success & 16 & 66 & 66 & 83 & 83 \\
& Days & 13 & $18.2 \pm 6.1$ & $13.5 \pm 0.5$ & $15.4 \pm 4.2$ & $16 \pm 1$ \\
\hline
\end{tabular}

Larval size at hatching was not significantly different between the five levels of salinity for $S$. australis $\left(F_{4,23}=0.509, p=0.73\right.$; mean size $0.141 \mathrm{~mm}, \pm$ $0.009 \mathrm{SD})$, or for $E$. felina $\left(\mathrm{F}_{4,5}=2.456, \mathrm{p}=0.176\right.$; mean size $0.109 \mathrm{~mm}, \pm 0.01$ $\mathrm{SD})$. Because of failure to hatch, hatching size could only be examined from 3 salinity treatments for $P$. maculata (30, 35 and 40\%). Salinity had a significant effect on $P$. maculata larval size at hatching $\left(F_{2,12}=37.094, p<0.001\right.$, Fig 2.10). Larvae hatched at the control salinity (35\%) were larger than those at either 
$30 \%$ or $40 \%$ (pairwise comparisons, $p<0.001$ ), but the magnitude of the effect was small (mean size of $0.158 \mathrm{~mm}$ vs. $0.128 \mathrm{~mm}$ ). Salinity did not affect larval size at hatching for $A$. juliana $\left(\mathrm{F}_{3,12}=1.738, \mathrm{p}=0.209\right.$; mean size $0.122 \mathrm{~mm}, \pm$ 0.011 SD).

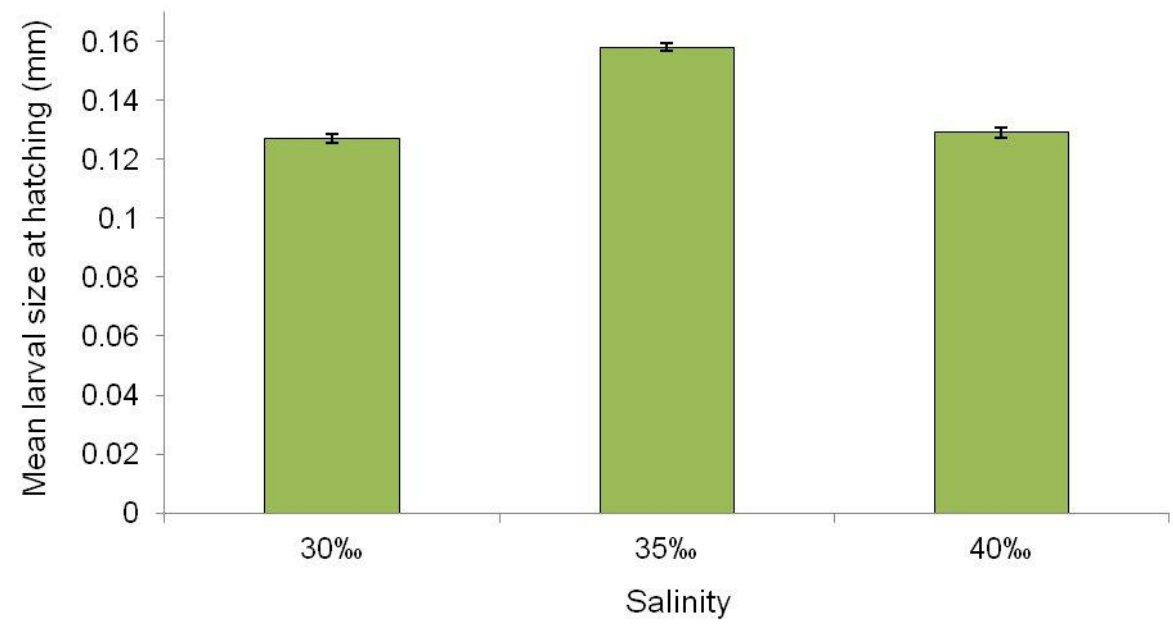

Figure 2.10 Mean Pleurobranchaea maculata larval size $(\mathrm{mm})$ at hatching after being subjected to different levels of chronic salinity for a period of 5 days $( \pm S E), n=21$ for each treatment per egg mass.

\section{Experiment Two- Pulse}

Periodic exposure to variable salinity had a significant effect on embryonic mortality of the intertidal $S$. australis $\left(\mathrm{F}_{4,25}=28.87, \mathrm{p}<0.001\right)$. However, the mean embryonic mortality was overall very low across the treatments (less than $4 \%$ ). Mortalities at $25 \%$ and $30 \%$ as well as $20 \%$ and $35 \%$ did not differ from each other; all other combinations were significantly different from each other (pairwise comparisons, $p \leq 0.001$, Fig 2.11).

Periodic salinity changes also had a significant effect on the mean mortality of embryos in egg masses of the subtidal $P$. maculata $\left(\mathrm{F}_{4,25}=6.65\right.$, $p=0.001$ ). Mortality was generally high and significantly higher at $20 \%$ and $25 \%$ o than the other treatments (pairwise comparisons, $\mathrm{p}<0.05$, Fig 2.11). 
The subtidal $A$. juliana was also significantly affected by salinity $\left(\mathrm{F}_{4,25}=\right.$ $11.138, p<0.001)$. Embryonic mortality was highest in $20 \%$ o $(100 \%)$ and differed significantly from the other treatments (pairwise comparisons, $p<0.01$ ). Mortality was also higher at $25 \%$ than at $35 \%$ and $40 \%$ (pairwise comparisons, $\mathrm{p}<0.05$, Fig 2.11).

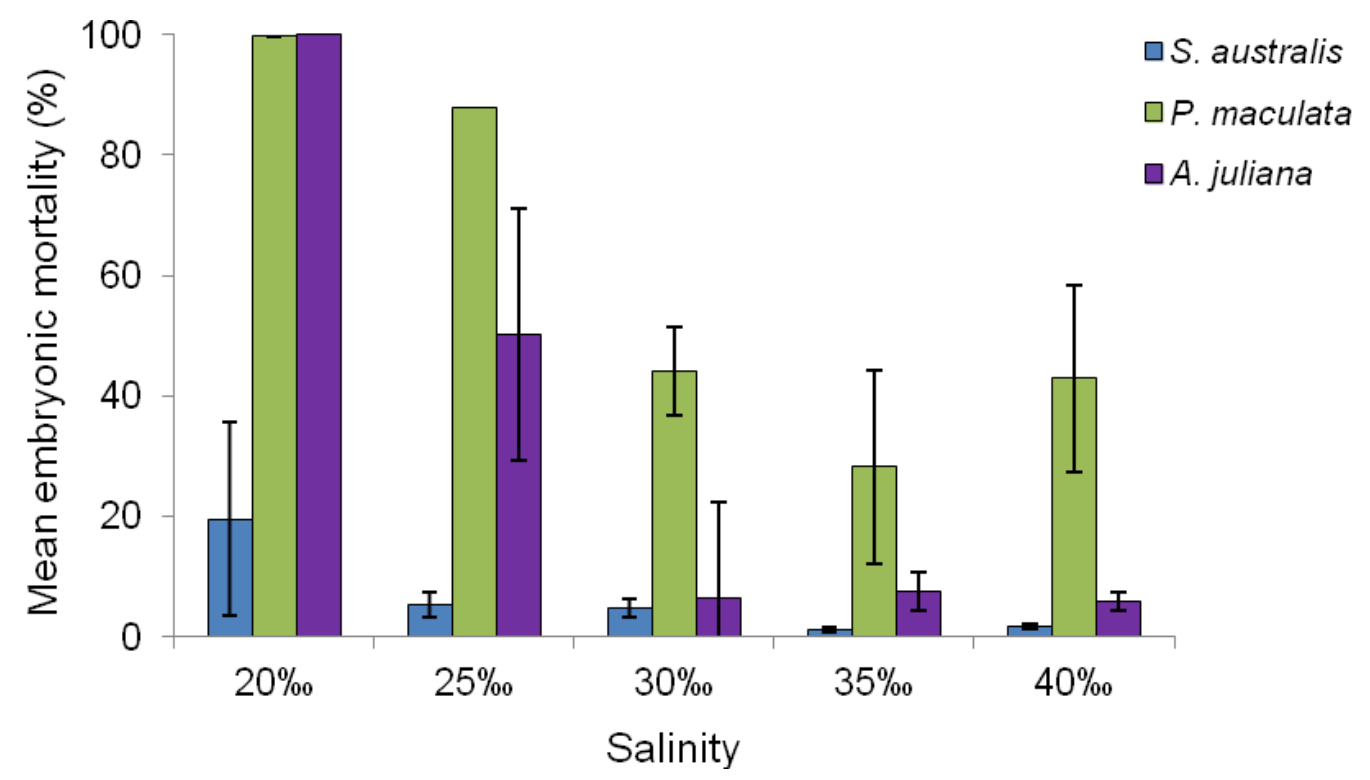

Figure 2.11 Mean percentage of embryonic mortality in egg masses for 3 different species subjected to different levels of periodic salinity for 4 hours/ day for 5 days $( \pm S E), n=6$ for each species.

Hatching success varied highly between the intertidal and subtidal species in the salinity treatments. S. australis had a 100\% hatching success throughout all levels of salinity whereas the subtidal species $P$. maculata and $A$. juliana had no hatching success at very low salinity. $P$. maculata larvae failed to hatch at $25 \%$ and showed lower overall hatching success than $A$. juliana whose larvae hatched in $25 \%$ and had a $100 \%$ success in the higher salinity ranges (Table 2.2). There was no difference in days till hatching for larvae of each species between the different levels of salinity (Table 2.2). 
Table 2.2 Hatching success (in \%) and days till hatching ( \pm SD) of each species in response to periodic salinity treatments. Hatching success and days till hatching were scored out of 6 egg masses for each species

\begin{tabular}{l|lccccc} 
& Salinity & $20 \%$ & $25 \%$ & $30 \%$ & $35 \%$ & $40 \%$ \\
\hline S. australis & Success & 100 & 100 & 100 & 100 & 100 \\
& Days & $6.6 \pm 2.3$ & $6.5 \pm 2.4$ & $6.1 \pm 2.6$ & $6.1 \pm 2.6$ & $6.1 \pm 2.6$ \\
\hline P. maculata & Success & 0 & 0 & 33 & 50 & 66 \\
& Days & - & - & 8 & $8.3 \pm 0.5$ & $8 \pm 0.8$ \\
\hline A. juliana & Success & 0 & 50 & 100 & 100 & 100 \\
& Days & - & $9.6 \pm 5.5$ & $9.6 \pm 4.8$ & $8.5 \pm 3.3$ & $10.3 \pm 3.3$ \\
\hline
\end{tabular}

Press salinity treatments had no significant effect on the larval size at hatching for $S$. australis $\left(F_{4,25}=1.036, p=0.408\right.$; mean larval size $0.147 \mathrm{~mm} \pm$ $0.01 \mathrm{SD}), P$. maculata $\left(\mathrm{F}_{2,6}=1.361, \mathrm{p}=0.326\right.$; mean larval size $0.127 \mathrm{~mm} \pm$ $0.014 \mathrm{SD}$, only three levels of salinity could be included due to the low hatching success), and $A$. juliana $\left(\mathrm{F}_{3,15}=0.401, \mathrm{p}=0.754\right.$; mean larval size $0.111 \mathrm{~mm} \pm$ 0.016 SD).

\subsubsection{Temperature}

\section{Experiment One- Press}

Chronic high temperature had a highly significant effect on the mean embryonic mortality of $S$. australis $\left(F_{2,15}=369.986, p<0.001\right)$. The embryonic mortality was over 100 times higher at $25^{\circ} \mathrm{C}$ and significantly different than at the other temperatures (pairwise comparisons, $p<0.001$, Fig 2.12). Embryonic mortality of $P$. maculata was also highly affected by temperature $\left(\mathrm{F}_{2,15}=\right.$ 76.333, $\mathrm{p}<0.001)$. Mean mortality was low at the control temperature $(0.5 \%)$ but very high at both $20^{\circ} \mathrm{C}(80 \%)$ and $25^{\circ} \mathrm{C}(100 \%)$, and significantly different among all three (pairwise comparisons, $\mathrm{p}<0.001$, Fig 2.12). 


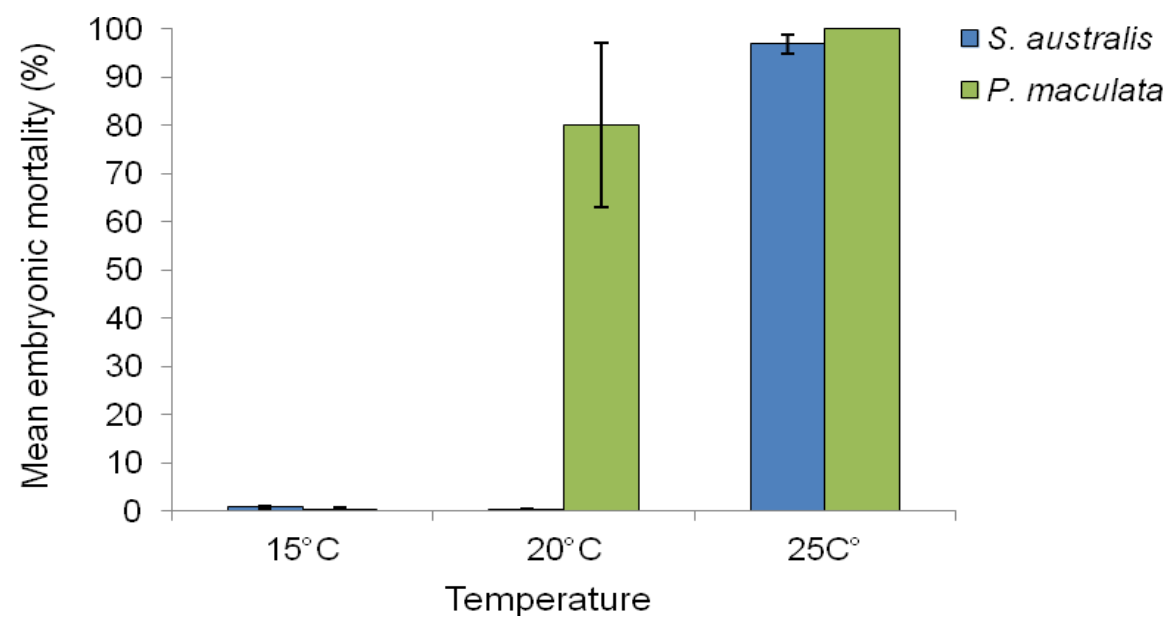

Figure 2.12 Mean percentage of embryonic mortality in egg masses for one intertidal and one subtidal species subjected to different levels of chronic temperature for a period of 5 days $( \pm S E), n=6$ for each species.

The hatching success between the intertidal and subtidal species varied highly in the temperature treatments. S. australis had a $100 \%$ hatching success at $15^{\circ} \mathrm{C}$ and $20^{\circ} \mathrm{C}$ and a relatively high hatching success at $25^{\circ} \mathrm{C}$ whereas the subtidal species $P$. maculata had a very high hatching success at $15^{\circ} \mathrm{C}$ but relatively low success in $20^{\circ} \mathrm{C}$ and no success at $25^{\circ} \mathrm{C}$ (Table 2.3). Days till hatching were longer at $20^{\circ} \mathrm{C}$ and $25^{\circ} \mathrm{C}$ than at $15^{\circ} \mathrm{C}$ for both $S$. australis and $P$. maculata (Table 2.3X).

Table 2.3 Hatching success (in \%) and days till hatching ( \pm SD) of each species in response to chronic temperature treatments. Hatching success and days till hatching were scored out of 6 egg masses for each species

\begin{tabular}{l|lccc} 
& Temperature & $15^{\circ} \mathrm{C}$ & $20^{\circ} \mathrm{C}$ & $25^{\circ} \mathrm{C}$ \\
\hline S. australis & Success & 100 & 100 & 66 \\
& Days & $9.1 \pm 1.8$ & $8.1 \pm 3.4$ & $16.25 \pm 3.2$ \\
\hline P. maculata & Success & 100 & 16 & 16 \\
& Days & $8.1 \pm 1.6$ & 16 & 25 \\
\hline
\end{tabular}


While there was no effect of temperature on larval size at hatching for $P$. maculata larvae $\left(\mathrm{F}_{1,5}=0.614 \mathrm{p}=0.469\right.$; however only one egg mass hatched in $20^{\circ} \mathrm{C}$ and none in $25^{\circ} \mathrm{C}$ ), S. australis larval size at hatching was affected by temperature $\left(F_{2,13}=3.969, p=0.045\right)$. Larvae were larger when hatching at the control temperature $(0.153 \mathrm{~mm} \pm 0.004 \mathrm{SD})$ than at $20^{\circ} \mathrm{C}(0.147 \mathrm{~mm} \pm 0.004$ $\mathrm{SD}$ ) or $25^{\circ} \mathrm{C}(0.145 \mathrm{~mm} \pm 0.004 \mathrm{SD})$, (pairwise comparisons, $\mathrm{p}<0.05$, Fig 2.13); there was no difference between larvae hatching at $20^{\circ} \mathrm{C}$ and $25^{\circ} \mathrm{C}$.

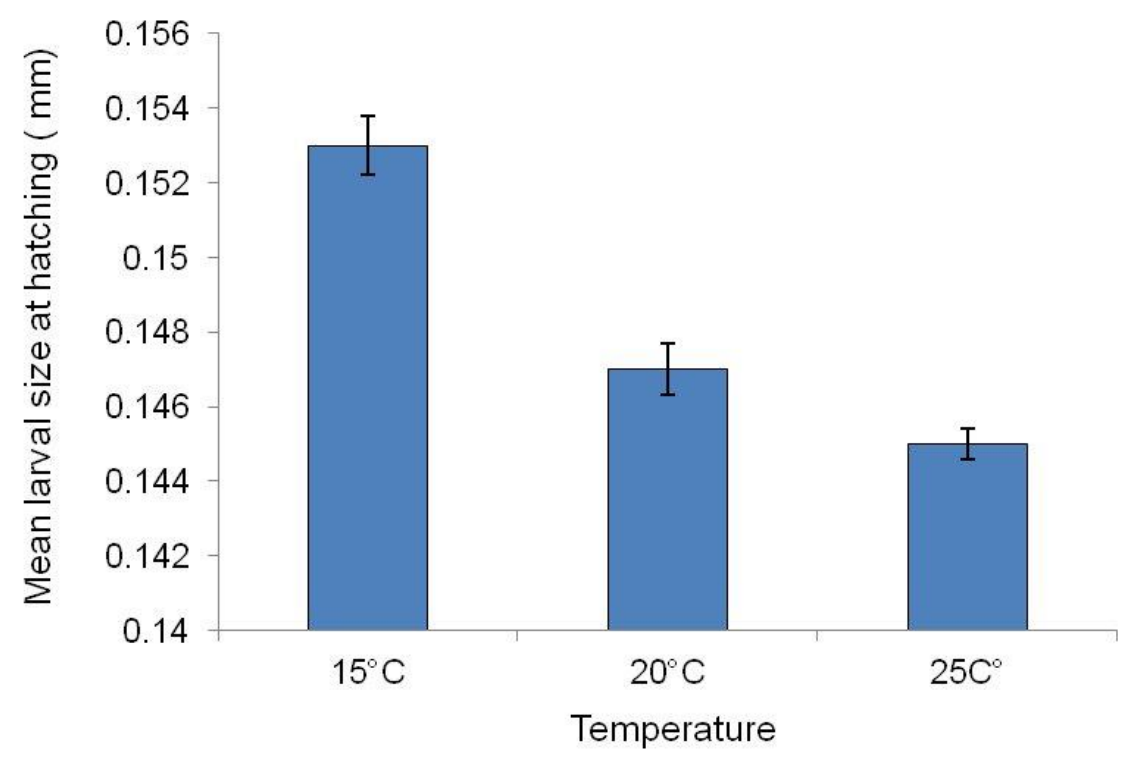

Figure 2.13 Mean Siphonaria australis larval size $(\mathrm{mm})$ at hatching after being subjected to different levels of chronic temperature for a period of 5 days $( \pm S E), n=21$ for each treatment per egg mass.

\section{Experiment Two- Pulse}

Periodic exposure to increased temperature had no significant effect on embryonic mortality of $S$. australis $\left(F_{2,15}=0.859, p=0.443\right.$, Fig 2.14). There was a trend for higher mean mortality at both $20^{\circ} \mathrm{C}$ and $25^{\circ} \mathrm{C}$ than in the control treatment but the variation was high (Fig 2.14). Pulsed temperature increases had a significant effect on $A$. juliana embryonic mortality $\left(F_{2,15}=9.618, p=\right.$ $0.002)$. Mortality was significantly higher at $20^{\circ} \mathrm{C}(83 \%)$ and $25^{\circ} \mathrm{C}(68 \%)$ than in the control treatment (pairwise comparison, $\mathrm{p}<0.05$ ). Embryonic mortality was 
also significantly affected by temperature for $D$. wellingtonensis $\left(F_{2,15}=11.806\right.$, $p=0.001$, Fig 2.14 ), with $20^{\circ} \mathrm{C}$ causing four times higher mortality than the control temperature and $25^{\circ} \mathrm{C}$ causing complete mortality (pairwise comparisons, $p<0.05)$.

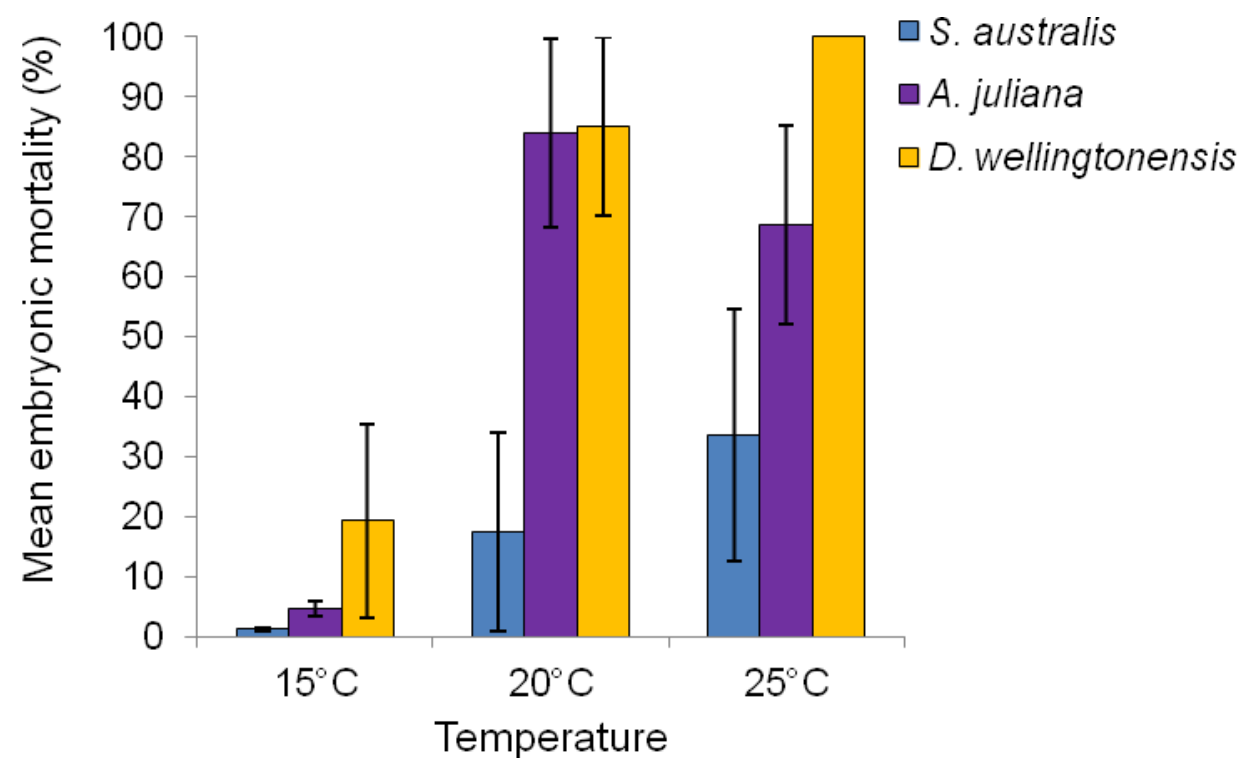

Figure 2.14 Mean percentage of embryonic mortality in egg masses for one intertidal and two subtidal species subjected to different levels of periodic temperature for $4 \mathrm{hrs} /$ day over 5 days $( \pm S E), n=6$ for each species.

Hatching success varied between the three (Table 2.4). In all cases, hatching success was greatest in the control treatment (50-100\%) and for $S$. australis (66-100\%). For $D$. wellingtonensis, larvae only hatched from the control treatment, and $A$. juliana also had lower success in the two increased temperature treatments. By contrast, hatching success for the intertidal $S$. australis was still relatively high in the elevated temperature treatments (Table 2.4). Days till hatching were highly variable within $S$. australis but there was no difference between temperature levels (Table 2.4). On average, it took $A$. juliana larvae longest to hatch in $20^{\circ} \mathrm{C}$. 
Table 2.4 Hatching success (in \%) and days till hatching ( \pm SD) of each species in response to periodic temperature treatments. Hatching success and days till hatching were scored out of 6 egg masses for each species

\begin{tabular}{l|lccc} 
& Temperature & $15^{\circ} \mathrm{C}$ & $20^{\circ} \mathrm{C}$ & $25^{\circ} \mathrm{C}$ \\
\hline S. australis & Success & 100 & 83 & 66 \\
& Days & $13.8 \pm 7.3$ & $12.8 \pm 5.8$ & $14.25 \pm 8.9$ \\
\hline A. juliana & Success & 50 & 16 & 33 \\
& Days & $18.6 \pm 3.5$ & 24 & $20 \pm 1.4$ \\
\hline D. wellingtonensis & Success & 100 & 0 & 0 \\
& Days & $10.6 \pm 1$ & - & - \\
\hline
\end{tabular}

Temperature did not have a significant effect on larval size at hatching for $S$. australis $\left(F_{2,11}=0.056, p=0.946\right.$; mean larval size $\left.0.147 \mathrm{~mm} \pm 0.012 S D\right)$. Temperature also had a nearly significant effect on hatching size of $A$. juliana larvae $\left(F_{2,3}=7.672, p=0.066\right.$, Fig 2.15). Higher periodic temperature resulted in larger $A$. juliana larvae at hatching. Due to no hatching success of $D$. wellingtonensis in the higher temperatures the effect of temperature on larval size could not be tested for this species (mean larval size in control temperature $0.147 \mathrm{~mm} \pm 0.011 \mathrm{SD}$ ). 


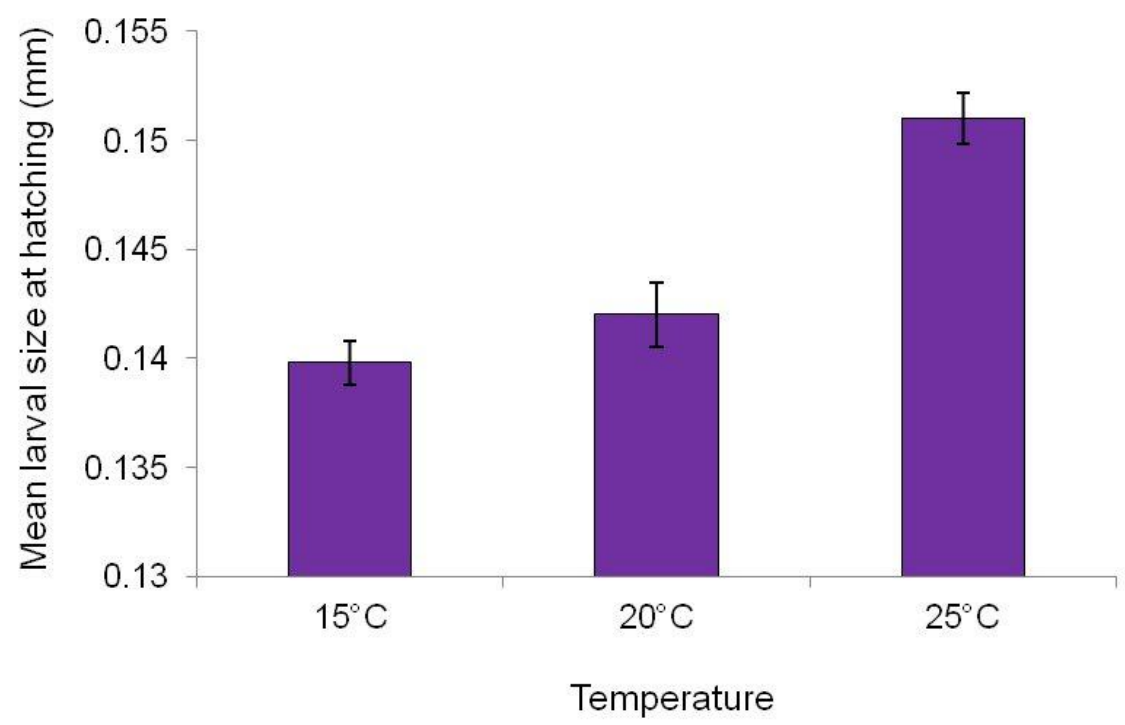

Figure 2.15 Mean Aplysia juliana larval size $(\mathrm{mm})$ at hatching after being subjected to different levels of periodic temperature for a period of $4 \mathrm{hrs} /$ day over 5 days $( \pm \mathrm{SE})$, $\mathrm{n}=21$ for each treatment per egg mass.

\subsubsection{UV-B radiation}

\section{Experiment One- Press}

Chronic daily UV-B had a highly significant effect on the mean embryonic mortality of $S$. australis $\left(F_{2,15}=46.363, p<0.001\right)$. The embryonic mortality was very low in the shaded control treatment $(0.2 \%)$ and very high in the $1.5 \mathrm{~W} \mathrm{~m}^{-2} \mathrm{~s}^{-1}(71.8 \%)$ treatment, reaching $99.3 \%$ in the $1.7 \mathrm{~W} \mathrm{~m}^{-2} \mathrm{~s}^{-1}$ treatment. All treatments differed significantly from each other with respect to embryonic mortality (pairwise comparisons, $\mathrm{p}<0.001$, Fig 2.16). 


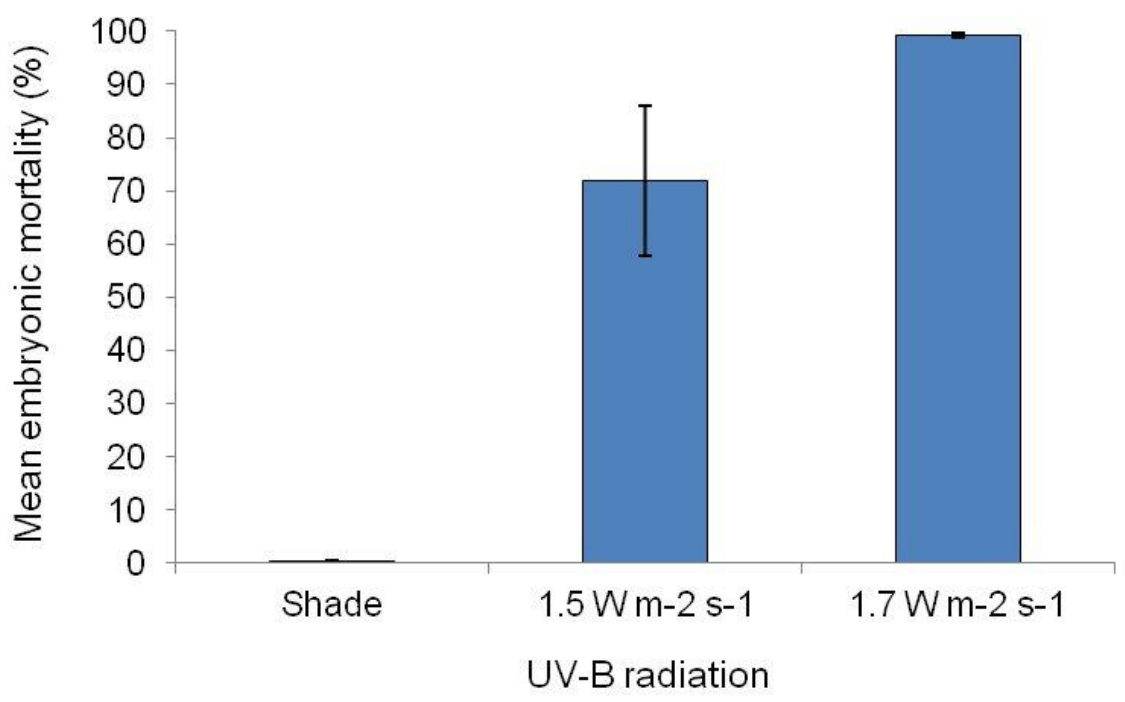

Figure 2.16 Mean percentage of embryonic mortality in Siphonaria australis egg masses subjected to different levels of chronic UV-B radiation for $12 \mathrm{hrs} /$ day over a period of 5 days $( \pm S E), n=6$ for each species.

Hatching success for $S$. australis was highest in shade and decreased with increasing UV-B intensity (Table 2.5). Days till hatching increased slightly at 1.5 and $1.7 \mathrm{~W} \mathrm{~m}^{-2} \mathrm{~s}^{-1}$ UVR.

Table 2.5 Hatching success (in \%) and days till hatching ( \pm SD) of Siphonaria australis in response to chronic UV-B treatments. Hatching success and days till hatching were scored out of 6 egg masses

\begin{tabular}{l|lccc} 
& UV-B & Control (shade) & $1.5 \mathrm{~W} \mathrm{~m}^{-2} \mathrm{~s}^{-1}$ & $1.7 \mathrm{~W} \mathrm{~m}^{-2} \mathrm{~s}^{-1}$ \\
\hline S. australis & Success & 100 & 66 & 33 \\
& Days & $7.1 \pm 1.3$ & $10.7 \pm 2.2$ & $10.5 \pm 0.7$ \\
\hline
\end{tabular}

UV-B radiation did not have an effect on the size of hatching larvae $\left(F_{2,9}\right.$ $=0.449, p=0.652$, mean larval size $0.139 \mathrm{~mm} \pm 0.038 \mathrm{SD})$. 


\section{Experiment Two- Pulse}

Periodic UV-B had no significant effect on embryonic mortality of $S$. australis $\left(\mathrm{F}_{2,15}=2.466, \mathrm{p}=0.119\right.$, Fig 2.17). The mean mortality was highest in $1.7 \mathrm{~W} \mathrm{~m}^{-2} \mathrm{~s}^{-1}(33.17 \%)$ and $1.5 \mathrm{~W} \mathrm{~m}^{-2} \mathrm{~s}^{-1}(7.33 \%)$ compared to shade (0\%) but there was large variation in the embryonic mortality within the egg masses for the two higher intensities.

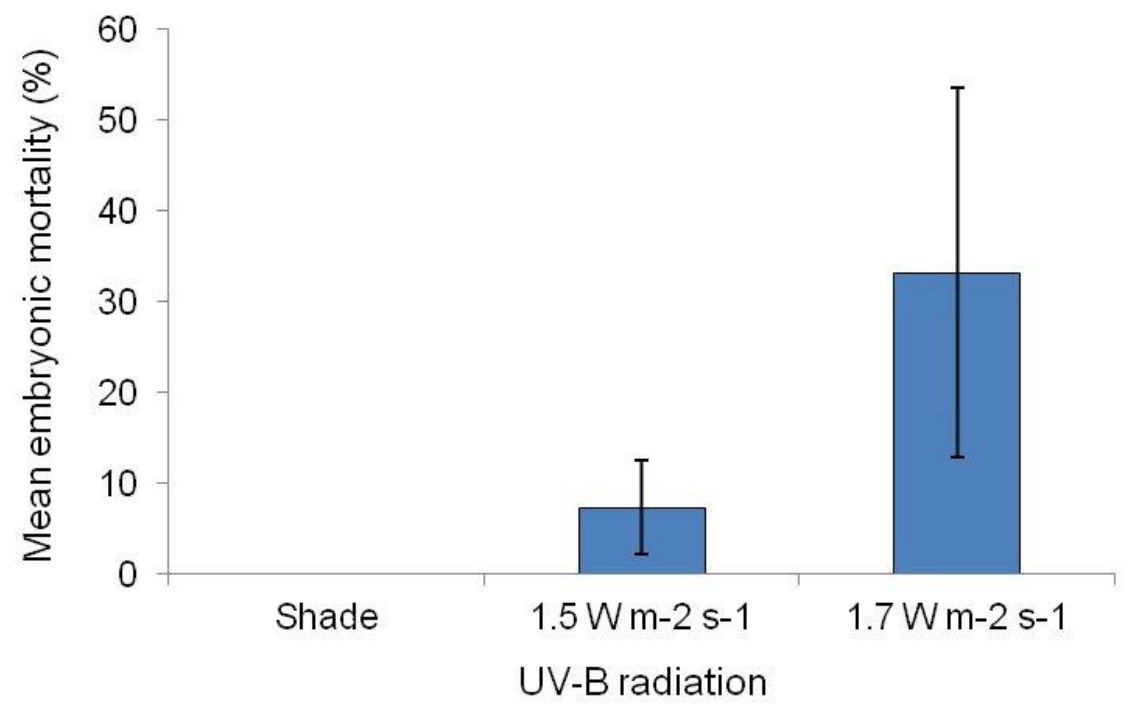

Figure 2.17 Mean percentage of embryonic mortality in Siphonaria australis egg masses subjected to different levels of periodic UV-B radiation for $4 \mathrm{hrs} /$ day over a period of 5 days $( \pm S E), n=6$ for each species.

Hatching success was very high in all treatments (Table 2.6). Days till hatching increased as UV-B intensity increased. Larval size at hatching did not differ between the UV-B treatments $\left(F_{2,15}=1.075, p=0.366\right.$; mean larval size $0.143 \mathrm{~mm} \pm 0.006 \mathrm{SD})$. 
Table 2.6 Hatching success (in \%) and days till hatching ( \pm SD) of Siphonaria australis in response to periodic UV-B radiation treatments. Hatching success and days till hatching were scored out of 6 egg masses

\begin{tabular}{l|lccc} 
& UV-B & Control (shade) & $1.5 \mathrm{~W} \mathrm{~m}^{-2} \mathrm{~s}^{-1}$ & $1.7 \mathrm{~W} \mathrm{~m}^{-2} \mathrm{~s}^{-1}$ \\
\hline S. australis & Success & 100 & 100 & 100 \\
& Days & $5.5 \pm 1.5$ & $9.1 \pm 0.7$ & $9.6 \pm 3.3$ \\
\hline
\end{tabular}

\subsection{DISCUSSION}

All responses to stress treatments were species-specific but the magnitude of responses tended to be larger for the subtidal species, whereas the intertidal species were more tolerant. Low salinity, high temperature and high UV-B were the most stressful levels for embryonic development; the magnitude of the press responses were larger than the pulse responses and the responses were species-specific. Although embryonic development was affected by these environmental stressors, hatching success was generally high for $S$. australis, suggesting that embryos surviving stressful conditions may be unaffected, however indirect (carry-over) effects may only show in later life stages and this will be tested in a later chapter (Chapter 4).

Chronic low salinity did not affect embryonic mortality for the intertidal $E$. felina but the intertidal $S$. australis was negatively affected by chronic and periodic low salinity, chronic high temperature and chronic high UV-B. Hatching success was lowered in chronic and periodic higher temperature and chronic high UV-B. Larval size at hatching was negatively affected by chronic higher temperature. Embryonic mortality of all subtidal species ( $P$. maculata, $A$. juliana and $D$. wellingtonensis within the experiments they were included in) increased at chronic and periodic low salinity, and at high temperature. Hatching success was lower at low salinity and at higher temperature. Chronic high temperature increased the time till larval hatching for $S$. australis, $P$. maculata and $A$. juliana, whereas periodic high temperature did not affect the time till hatching. $P$. maculata larvae hatched faster and larval size at hatching was smaller in 
lower or higher salinity treatments, and $A$. juliana larvae at hatching were slightly larger when exposed to high temperature. In general, salinity and UVR affected embryonic mortality but not growth as much across all species whereas temperature affected larval size for some species.

\subsubsection{Salinity}

Low salinity resulted in high mortality for three out of four species. The species not affected, the sacoglossan E. felina, can be found in ephemeral tide pools, one of the most variable marine environments where salinity can reach high and low extremes. The species must therefore be very tolerant to changes in salinity. In a previous study, E. felina adults tolerated salinity up to $55 \%$ before showing signs of stress, such as decreased tenacity and swelling of body tissues (Trowbridge, 1994). Unfortunately due to their ephemeral nature, egg masses of $E$. felina were only available for the chronic salinity experiment and their response to temperature and UVR could not be tested at all.

S. australis had relatively high embryonic mortality in chronic low salinity but coped well with low salinity when exposed to it for short time periods. The hatching success from all treatments shows how resilient this species is to variability in salinity, which is to be expected for an organism that occupies habitats on the high shore. The development of embryos within the gelatinous egg mass is asynchronous, with outer layers of embryos developing and hatching before the inner layers develop (Chaffee \& Strathmann, 1984). This may be a mechanism of protecting a high amount of embryos from stress (Pechenik, 1979, 1982; Pechenik et al. 2001).

As embryonic mortality was still relatively low in $20 \%$ salinity, the threshold of $S$. australis embryos to low salinity may have not been reached. Embryos of the estuarine gastropod Crepipatella dilatata survived short-term exposure to $10 \%$ salinity and even lower salinities when maternal protection was provided in a study by Chaparro et al. (2008), and embryos of 
Melanochlamys diomedea, a gastropod living on tidal flats and in the shallow subtidal, have been reported to survive well in $10 \%$ salinity and have surviving embryos after short-term exposure to $5 \%$ and $0 \%$ salinities (Woods \& DeSilets, 1997). Early life stages of gastropods have been shown to recover from salinity stress within a few days, suggesting if early life stages survive stressful conditions they can successfully become adults (Diederich, et al. 2011).

As hypothesized, the subtidal species $P$. maculata and $A$. juliana both had high mortality in low salinity. Subtidal species do not frequently encounter low salinity whereas embryos of species depositing their egg masses throughout the intertidal have become adapted to tolerate wide ranges of salinity (Woods \& DeSilets, 1997). However the egg masses and adults of $P$. maculata and $A$. juliana can be found in very shallow water where they can occasionally be exposed to low salinity water after heavy rainfall where the freshwater layer can extend down substantially (Witman \& Grange, 1998).

In contrast to the high mortality of $P$. maculata and $A$. juliana in this study, the subtidal gastropod Thais haemastoma canaliculata has been reported to successfully develop in a range of $15-35 \%$ salinity (Roller \& Stickle, 1989). The literature on subtidal gastropod embryos and their responses to low salinity remains scarce.

The intertidal S. australis (and E. felina) had lower overall mortality throughout both stress treatments compared to the subtidal species which do not encounter low salinity events as often in the subtidal as intertidal (Pechenik, 1979, 1983; Roller \& Stickle, 1989; Pechenik et al. 1998; Witman \& Grange, 1998; Pechenik, et al. 2003;Barry, et al. 2008). Hatching success was much lower in low salinity water for the subtidal species than for the intertidal species, suggesting that subtidal species are not able to recover even from periodic salinity stress as well as the intertidal species. A. juliana showed similar embryonic mortality in $25 \%$ and $30 \%$ when exposed to chronic and periodic salinity and coped better in $25 \%$ than in $20 \%$ when exposed to periodic stress, 
whereas $P$. maculata was not able to cope better with $25 \%$ in the periodic than in the chronic treatment.

Previous research has shown that salinity extremes cause embryonic mortality in egg masses (Struhsaker \& Costlow 1969, Pechenik 1982, Woods \& DeSilets 1997, reviewed in Przeslawski, 2004). Three hours in very low salinity $(0 \%$ ) caused a $75 \%$ drop in embryonic survival for the intertidal and shallow subtidal Melanochlamys diomedea compared to survival in 5-30\% salinity (Woods \& DeSilets, 1997). Scheltema (1965) observed that after 4 hours in $20 \%$ salinity both adult and larvae of the mudsnail Ilyanassa obsolete decreased activity. Pechenik $(1982,1983)$ however, observed that I. obsolete embryonic mortality was below $25 \%$ when exposed to $5 \%$ o for 10 hours; by contrast, intertidal Nucella spp. had generally very low mortality. Exposing the subtidal gastropod Thais haemastoma canaliculata to $12.5 \%$ salinity till hatching resulted in abnormal or retarded development and longer time till hatching compared to at higher salinity (Roller \& Stickle, 1989).

Allen and Pechenik (2010) investigated the effects of low salinity events on fertilization success and early development of a subtidal echinoderm, the sand dollar Echinarachnius parma, and discovered that fertilized eggs fail to cleave in low salinity. The role that gelatinous egg masses may play in the protection against salinity has been discussed in the past but has not been confirmed (Pechenik, 1979, 1982; Przeslawski, 2004). The egg capsules may buffer the rate at which the osmotic concentration inside the capsule decreases, not the actual magnitude of decrease itself (Pechenik, 1982, 1983).

Literature on the effects of salinity on the hatching success and larval size at hatching remains scarce. In a study on estuarine invertebrates and their responses to salinity fluctuations, Richmond and Woodin (1996) found that chronic reduced salinity (10\%) resulted in longer time till hatching and smaller larval size at hatching for the intertidal mudsnail $I$. obsolete and the polychaete Arenicola cristata compared to at the control salinity. The larvae of only one 
species, $P$. maculata, were affected by salinity, with smaller larvae hatching in $30 \%$ and $40 \%$ salinity than in the control salinity.

The intertidal species were much more tolerant to low salinity than the subtidal species. Even short-term exposure to low salinity can have large impacts on the embryonic mortality and hatching success of subtidal invertebrates with embryonic development in egg masses. Lower hatching success of larvae has direct effects on the population dynamics of affected species (Gaudy, et al. 1982; Qiu \& Qian, 1999).

\subsubsection{Temperature}

Chronic high temperature had a significant effect on embryonic mortality for both species examined. The intertidal $S$. australis had very low mortality at $20^{\circ} \mathrm{C}$ but the mean mortality at $25^{\circ} \mathrm{C}$ was over $90 \%$, suggesting the threshold must be between these two temperatures. As $S$. australis is often found in high temperatures on the shore during high tide, it is more adapted to increased temperature than the subtidal $P$. maculata which had very high mortality in both elevated temperatures.

While periodic high temperature was not a significant factor for embryonic mortality for $S$. australis, the mean mortality was higher at $20^{\circ} \mathrm{C}$ and $25^{\circ} \mathrm{C}$ than in $15^{\circ} \mathrm{C}$. There was, however, large variation between the egg masses. For the subtidal $A$. juliana and $D$. wellingtonensis, high temperatures resulted in very high mortality. Surprisingly, $A$. juliana had higher mortality at $20^{\circ} \mathrm{C}$ than at $25^{\circ} \mathrm{C}$ which then resulted in higher hatching success at $25^{\circ} \mathrm{C}$ than at $20^{\circ} \mathrm{C}$; however this can be explained by one egg mass which had $100 \%$ mortality at $20^{\circ} \mathrm{C}$ but only $2 \%$ at $25^{\circ} \mathrm{C}$.

The size at hatching of $S$. australis larvae was influenced by the temperature treatments. Mean larval size at hatching was highest at $15^{\circ} \mathrm{C}$ and higher at $25^{\circ} \mathrm{C}$ than at $20^{\circ} \mathrm{C}$, although there was large variation in the larvae 
hatched at $25^{\circ} \mathrm{C}$. This large variation is due to one egg mass in $25^{\circ} \mathrm{C}$ which hatched as large larvae. Whether larvae hatched at $25^{\circ} \mathrm{C}$ were as viable as larvae hatched from $20^{\circ} \mathrm{C}$ could not be established however. Larger size at hatching may give the larvae an advantage (swimming, feeding) but may have compromised development in other areas.

Most of the literature on the effects of temperature on embryonic development involves the impacts of chronic temperature on very young embryos ( $<48$ hours) through to hatching. There seems to be a lack of research comparing chronic vs. periodic exposures of embryos to temperature changes.

Temperature has long been recognized to be an important factor on the early development of marine invertebrates (Costlow, et al. 1960; Struhsaker \& Costlow, 1969; Wollmuth \& Crawshaw, 1988; Anil et al. 1995; Hoegh-Guldberg \& Pearse, 1995; Bryars \& Havenhand, 2006; Grubert \& Ritar, 2004a; Przeslawski, 2004) and can have important consequences on later life stages (Yoshida et al. 2004; Clemens-Seely \& Phillips, 2011). As temperature increases within a species' tolerance range, developmental rate accelerates and time spent within the egg mass generally decreases (Spight, 1975; Cancino et al. 2003; Pechenik, et al. 2003; Watt \& Aiken, 2003; Clemens-Seely \& Phillips, 2011). This may be beneficial to embryos in egg masses as shorter encapsulation time means faster hatching time and therefore less predatory pressure (Spight, 1975; Garton \& Stickle, 1980; Rawlings, 1990; Qiu \& Qian, 1999;).

Increases in temperature have also been shown to accelerate larval growth in copepods (IMcLaren \& Corkett, 1981; McLaren, Seviguy, \& Corkett, 1988) and adult growth in barnacles (Qiu \& Qian, 1999). Yoshida et al. (2004) examined temperature effects on egg development in Antarctic krill (Euphausia sp.) and found that development time decreased as temperature increased; hatching success was however not related to temperature in the range tested for. Qiu and Qian (1999) subjected adults and embryos of a barnacle (Balanus sp.) to high temperature and found that adults had more moulting stages at 
high temperature than at the control temperature. Embryo survival was not affected in the high temperature and time to metamorphosis decreased in high temperature for larvae. Cancino et al. (2003) exposed embryos of the marine gastropod Chorus giganteus to three temperatures $\left(12,15\right.$ and $\left.18^{\circ} \mathrm{C}\right)$ and concluded that increased temperature reduced the time till hatching but neither embryonic survival nor shell length was affected by raised temperature. Raised temperature also accelerated the development of embryos for the gastropod Nassarius obsoletus and time of hatching decreased in a study by Scheltema (1967).

Once the temperature exceeds a tolerable threshold for a species however, mortality increases and high temperature becomes detrimental. Somero (2002) found that high temperatures can increase the heart rate, impair protein synthesis, membrane consistency, neural functions and mitochondrial functions, and induce heat shock proteins in adult marine crabs and snails. Any cellular damage caused by thermal stress requires repair and has a very high energetic cost on adults that could have otherwise been used for growth or reproductive output (Tomanek \& Helmuth, 2002). At higher temperatures, metabolic rate increases (Anger \& Dawirs, 1981; Anil et al. 2001) and reduced oxygen distribution to tissues has been suggested to be responsible for the intolerance of egg masses to high temperatures (Deschaseaux, et al. 2010).

Early embryos have been reported to be most vulnerable to heat stress (Kennedy et al. 1974), which may be due to the lack of heat shock proteins which develop in advanced stages (Podolsky \& Hofmann, 1998; Podolsky, 2000). Pechenik et al. (2003) exposed embryos of the estuarine mudsnail Amphibola crenata to a range of temperatures $\left(15,20\right.$ and $\left.25^{\circ} \mathrm{C}\right)$ and found that embryonic survival was lowest in $25^{\circ} \mathrm{C}$ and that developmental rate increased and days till hatching decreased in 20 and $25^{\circ} \mathrm{C}$. In a study by Watt and Aiken (2003) on embryos of the intertidal nudibranch Dendronotus frondosus to different temperatures $\left(5,11\right.$ and $\left.15^{\circ} \mathrm{C}\right)$, embryos developed faster at $11^{\circ} \mathrm{C}$ than at $5^{\circ} \mathrm{C}$ and did not develop until hatching stages in $15^{\circ} \mathrm{C}$. 
The species-specific thresholds and ability to cope with high temperatures of adults is one of the factors contributing to intertidal zonation and the vertical distribution of species (Connell, 1961b; Paine \& Levin, 1981). The rate of embryonic development and hatching success are important factors contributing to recruitment success of a population (Yoshida et al. 2004)

\subsubsection{UV-B radiation}

Even though overall mortality for $S$. australis was lower in the periodic high UV-B radiation treatments, both the chronic and periodic exposure resulted in much higher mortality than the shade treatment. However, although the embryonic mortality in chronic high UV-B $\left(1.7 \mathrm{~W} \mathrm{~m}^{-2} \mathrm{~s}^{-1}\right)$ was close to $100 \%$, two out of 6 egg masses managed to hatch. This shows how resilient $S$. australis embryos are and that they are able to recover to some extent from stressful events. Reduction in embryonic or larval survival due to UVR exposure may have important impacts on population persistence (Bancroft et al. 2008).

Russell and Phillips (2009a) exposed embryos of two intertidal gastropods, $S$. australis and Benhamina obliquata, to different natural light treatments in summer, for 3 hours daily and found embryonic mortality to be highest in full sun exposure for both species. Both species were highly vulnerable to UVR and at risk of high embryonic mortality, especially on sunny days during low tide when temperature was high (Russell \& Phillips, 2009a). The embryonic mortality in $S$. australis egg masses submerged in full sun in September was similar to the results of the pulse treatment in this study; however the mortality in submerged full sun exposure in February was a lot higher than this study. In a similar study on UVR and two Haminoea species, embryonic mortality was also highest in full sun and desiccated conditions but the results showed species-specific responses between the two congeners in terms of which conditions were most stressful, suggesting differences in the vulnerability to environmental stressors (Russell \& Phillips, 2009b). 
Unfortunately no egg masses of subtidal species were available for my UV-B radiation experiments. In a study by Bischof et al. (1998), the response to UV-B radiation was compared between algae from different zones on the shore. The shallow-water algae were least affected by UV-B radiation, followed by the algae found in the slightly deeper waters. The algae from the lower subtidal were extremely sensitive to UV-B exposure (Bischof et al. 2006). A study by van de Poll et al. (2001) supported these findings by showing that the position on the shore was significantly correlated to the inhibition of growth induced via UV-B exposure. Algal species living in the intertidal zone need to be able to adapt to rapidly and widely fluctuating environmental conditions. The same holds true for the intertidal $S$. australis which may explain the high tolerance to UV-B radiation in the pulse experiment.

Przeslawski (2005) exposed the egg masses of three intertidal gastropods to different light and desiccation treatments for 3 days and examined embryonic mortality and development rates. Bembicium nanum and Siphonaria denticulata are often exposed on rocks whereas Dolabrifera brazieri can be found in the shade and submerged. Embryonic mortality was higher in UV blocked light than full sun exposure for $S$. denticulata after being desiccated and developmental rate increased in the light treatments compared to the dark for $B$. nanum. Embryonic mortality increased for $D$. brazieri in visible light and desiccation and was generally higher than for the other two species (Przeslawski, 2005). These results support my general hypothesis that species which are frequently exposed to stressful conditions have lower embryonic mortalities than species which are usually shaded or submerged. To examine the synergistic effects of stressors, Przeslawski et al. (2005) subjected the embryos of the same three species to combinations of UVR, temperature and salinity and concluded that UVR was the factor contributing most to elevated mortality, but all three stressors were acting synergistically to increase embryonic mortality. Although this response was the same for all three species, the magnitude of the response was species-specific and highest for $D$. brazieri. In a study on a large variety of intertidal mollusc species, Przeslawski et al. 
(2004) concluded that embryonic mortality is generally high in egg masses from shaded habitats and low in egg masses from sunny habitats.

\subsubsection{Summary}

Chronic low salinity was more stressful than increased salinity for all subtidal species and for the intertidal $S$. australis. Periodic low salinity was stressful for the subtidal species whereas $S$. australis was able to tolerate short term low salinity well. Increases in chronic and periodic high temperature $\left(25^{\circ} \mathrm{C}\right)$ were highly stressful for both the intertidal and the subtidal species. However, the intertidal $S$. australis was able to recover from stressful low salinity and high temperature and had high larval hatching success. UV-B radiation only affected $S$. australis in the press treatment.

These results suggest that marine gastropods occupying the intertidal seem to cope better with ranges in salinity, temperature and UV-B radiation, especially when those stressors are relatively short in duration. The pulse treatments are ecologically more realistic than the press treatments as shortterm stress is more likely to be common for the egg masses of subtidal species and likely for intertidal species to occur daily, especially when low tides are occurring at midday during summer, when various stressors can act synergistically. 


\section{CHAPTER 3}

\section{Effects of timing of single and multiple stressors on the early development of encapsulated intertidal and subtidal marine gastropods}

\subsection{ABSTRACT}

Environmental stressors can cause high embryonic mortality in developing benthic egg masses of intertidal and shallow subtidal gastropod species. I investigated the effects of stressful levels of salinity, temperature and UV-B radiation, each as a single stressor, during different times of embryonic development (early and late) for 3 days. I then exposed embryos to 24 hours of stressful conditions on different days of embryonic development. The effects of multiple stressors were also examined by subjecting embryos to combinations of temperature and salinity for different lengths of time (chronic and periodic) and at different times of embryonic development. The species used in these experiments were $S$. australis, A. juliana and $P$. maculata.

Three-day exposure to low salinity $(20 \%)$ caused high embryonic mortality in egg masses for $A$. juliana during early and late embryonic development but did not affect $S$. australis. 24-hour exposure to low salinity caused significantly greater embryonic mortality in $A$. juliana egg masses on day 1 and day 2 of development.

High temperature $\left(25^{\circ} \mathrm{C}\right)$ caused much higher embryonic mortality on day 1 of embryonic development for $S$. australis and during early embryonic development for $A$. juliana, with day 1 and 2 being most vulnerable to high temperature. S. australis had much higher embryonic mortality on day 1 when exposed to high UV-B radiation. 
In both chronic and periodic exposure to multiple stressors, embryonic mortality was highest when high temperature $\left(25^{\circ} \mathrm{C}\right)$ was combined with both high (45\%) and low (20\%) salinity for $S$. australis. Embryonic mortality for $A$. juliana was highest in periodic exposure to low (20\%) and high salinity (45\%o) and was higher in combination with high temperature $\left(25^{\circ} \mathrm{C}\right)$ than control temperature $\left(15^{\circ} \mathrm{C}\right)$.

The exposure to high temperature and low salinity caused highest embryonic mortality on day 1 during early embryonic development, and did not affect mortality on any other day during early embryonic development for $S$. australis. The hatching success for all species mirrored the effects on embryonic mortality.

Overall, these results suggest that embryos are most vulnerable to different stressors during early embryonic development. Encapsulated embryos of intertidal egg masses appear to tolerate stressful conditions better as development progresses. Further, combinations of simultaneous multiple stressors can act synergistically to increase embryonic mortality.

\subsection{INTRODUCTION}

It has been widely acknowledged that stressful abiotic factors can affect early life stages of intertidal gastropods (Pechenik, 1979; Little et al. 1984; Pechenik et al. 2003; Przeslawski, 2004, 2005; Przeslawski et al. 2004, 2005; Chaparro et al. 2008; Russell \& Phillips, 2009a, b; Allen \& Pechenik, 2010). Embryonic, larval and adult life stages have been examined for their responses to environmental stress (Struhsaker \& Costlow, 1969; Davis, 2000;

Deschaseaux et al. 2011; Diederich et al. 2011), however the effect of stressors occurring at particular times during embryonic development has not been extensively investigated. This may indicate whether embryos' vulnerability to environmental stressors is heightened during certain times of development (Richmond \& Woodin, 1996). 
Previous studies have investigated the effects of environmental stressors on the embryonic development of echinoderms (Adams \& Shick, 2001; Lamare \& Hoffmann, 2004; Lesser et al. 2004; Lesser et al. 2006; Lamare et al. 2007; Nahon et al. 2009; Allen \& Pechenik, 2010), bivalves (Kennedy et al. 1974), ascidians (Bingham \& Reyns, 1999) and amphibians (Blaustein et al. 1997; Blaustein et al. 1998; Smith et al. 2000).

Marine invertebrates with planktonic embryos have been shown to be vulnerable to environmental stressors and show abnormal development, differences in sizes or sex ratios and halted development in response to stressful conditions (Coglianese \& Martin, 1981; Coglianese, 1982; Epel et al. 1999; Lee et al. 2003; Brennand et al. 2010). The majority of studies on embryonic development have focused on long-term exposure to stressors rather than focusing on the timing of stress within embryonic development (Adams \& Shick, 2001; Lee et al. 2003; Lamare et al. 2007).

Different embryonic development stages of sea urchins exposed to UVR were all negatively affected by UVR; development was frequently abnormal and delayed at all stages (Lesser et al. 2004), however freshly fertilized embryos were the most vulnerable stage (Lesser \& Barry, 2003; Nahon et al. 2009). Another study on early sea urchin embryos observed the effects of UV-B radiation after 24 and $48 \mathrm{hrs}$ of fertilization and also concluded that embryos were most vulnerable to radiation in the early stages of development (Bonaventura et al. 2006). Early embryos of amphibian egg clutches have been shown to have reduced survival rates, frequently abnormal development, and reduced hatching success when exposed to UVR during embryonic development (Smith et al. 2000; Pahkala et al. 2002) but the timing of when embryonic susceptibility to UVR is highest has been suggested to be speciesspecific (Castanaga et al. 2009).

For benthic species with mixed life histories, very little is known about how environmental stressors affect them at different times of embryonic development. The first aim of this study was to examine vulnerability of 
embryos to stress during different times of development, and to examine this for both short and long durations of stress.

Temperature and salinity change simultaneously in coastal habitats (Thiyagarajan et al. 2003), particularly in tidal pools (Trowbridge, 1994). Egg masses in tide pools are likely to be exposed to high temperatures and salinity variation simultaneously in the field (i.e. on hot summer days water can either evaporate thereby increasing salinity, or following rain events, salinity can decrease) (Rose, 1986; Miliou \& Moraitou-Apostolopoulou, 1991; Davis, 2000; Pechenik et al. 2003; Li \& Brawley, 2004; Deschaseaux et al. 2010). Therefore a second aim of this study was to examine the effects of temperature and salinity simultaneously on embryonic development, with a focus on duration and timing of exposures.

I hypothesised that (1) stressors are causing higher mortality during early than during late embryonic development, and (2) temperature and salinity simultaneously increase embryonic mortality.

\subsection{METHODS}

\section{Study Species}

The species used in the following experiments are all hermaphroditic marine gastropods; they are Siphonaria australis, Aplysia juliana and Pleurobranchaea maculata. For further information on the study species please refer to Chapter 2. Egg masses were obtained from adults maintained in the laboratory as described in Chapter 2. Due to the availability of egg masses and limited time, not all species were used in each experiment (Table 3.1). 
Table 3.1 Species used in the single and multiple stressor experiments in this chapter and the dates during which these experiments were conducted.

\begin{tabular}{|c|c|c|c|}
\hline Species & Experiment & Stressor(s) & Date \\
\hline \multirow[t]{10}{*}{ S. australis } & Early vs. late exposure & Salinity & 8th- 22nd Oct. 2010 \\
\hline & & Temperature & 7th- 13th Nov. 2011 \\
\hline & & UV-B & 19th- 25th Dec. 2011 \\
\hline & 24-hour exposure & Salinity & 3rd- 7th Nov. 2011 \\
\hline & & Temperature & 4th- 22nd Nov. 2011 \\
\hline & & UV-B & 19th- 23rd Dec. 2011 \\
\hline & Chronic exposure & Temperature $\mathrm{x}$ Salinity & 21st- 26th Nov. 2011 \\
\hline & Pulse exposure & Temperature $x$ Salinity & 3rd- 8th Nov. 2011 \\
\hline & Early vs. late exposure & Temperature $\mathrm{x}$ Salinity & 24th- 30th Nov. 2011 \\
\hline & 24-hour exposure & Temperature $\mathrm{x}$ Salinity & 23rd- 27th Nov. 2011 \\
\hline \multirow[t]{4}{*}{ A. juliana } & Early vs. late exposure & Salinity & 8th- 18th May 2010 \\
\hline & 24-hour exposure & Salinity & 4th- 8th April 2011 \\
\hline & & Temperature & 14th- 18th April 2011 \\
\hline & Pulse exposure & Temperature $\mathrm{x}$ Salinity & 4th- 8th April 2010 \\
\hline P. maculata & Early vs. late exposure & Salinity & 18th - 26th May 2010 \\
\hline
\end{tabular}

\subsubsection{Timing and Duration of exposure to single stressors}

\subsubsection{Early vs. late exposure to single stressors}

To examine whether vulnerability to single stressors depends on developmental stage, a series of experiments were conducted using 3 separate stressors (high temperature, low salinity, high UV-B); with egg masses of different species (Table 3.1) being exposed for 3 days either early or late in development. In all experiments, 6 freshly deposited egg masses $(\leq 24 \mathrm{~h}$ post spawning) were collected from the tanks and cut into 3 equal sized pieces, such that there was one replicate piece of each egg mass in each of three treatments: control, early exposure (exposure to stressor for 3 days, then into 
FSW for 3 days) and late exposure (in FSW for 3 days, then exposed to stressor for 3 days). The water in all treatments was replaced daily (with either FSW or low salinity mixture). All dishes were kept in a large sea table with flowing seawater to keep the temperature as constant as possible $\left(15^{\circ} \mathrm{C}\right)$.

The salinity treatment used was $20 \%$ because this was the most stressful level in the previous experiments (see Results Chapter 2). Salinity was established by adding appropriate amounts of Instant Ocean ® salt to distilled water. The salinity was confirmed with a refractometer. The temperature treatment used was $25^{\circ} \mathrm{C}$ because it was the most stressful temperature in the previous experiments (see Results Chapter 2), and was established in a tank filled with water using heater bars. The control temperature was established by placing dishes into a large sea table with flowing seawater (ambient temperature $15^{\circ} \mathrm{C}$ ). The temperature was confirmed with a thermometer. The UV-B treatment used was $1.7 \mathrm{~W} \mathrm{~m}^{-2} \mathrm{~s}^{-1}$ as this was the most stressful UV-B level in the previous experiment (see Results Chapter 2) and was established by using UV-B lamps (see Chapter 2 for details) in a temperature controlled room (set to $20^{\circ} \mathrm{C}$ ). Shade was established by shielding the dishes from UV-B with a large black plastic cover. UV-B radiation was confirmed using a UV-B sensor radiometer (Skye, SpectroSense2+).

After six days each egg mass section from each treatment was examined under 100x magnification and 100 embryos were scored (recorded as percentage) as either viable (alive and appearing to be developmentally normal) or inviable (dead or severely abnormal in appearance) to measure mortality.

Egg masses with $<100 \%$ of inviable embryos were maintained in dishes of filtered seawater (FSW) and hatching success was recorded for each egg mass by checking the dishes daily for hatched larvae. "Success" was constituted when at least 100 larvae had hatched from the egg mass in the dish and "failure" was constituted when no larvae had hatched within 14 days after the completion of the experiment. The embryos in the egg mass were then 
discarded. If larvae hatched, they were preserved in $4 \%$ buffered formalin for measuring. Shell lengths of 21 larvae per treatment and per replicate egg mass were measured using a Zeiss compound microscope with an ocular micrometer, at $100 x$ magnification.

3.3.1.2 24-hour exposure to single stressors at different days after deposition

This experiment was designed to examine the effects of one-day exposure to stressors (low salinity, high temperature, high UV-B) to identify the most vulnerable ages of embryos in egg masses for different species (Table 3.1). Six replicate freshly deposited egg masses were divided into 6 pieces and exposed to stressors on either day 1, 2, 3 or 4 of development, or control conditions. After being exposed to the stressor, egg mass pieces were maintained in FSW under control conditions for the remaining duration of the experiment. Salinity, high temperature and UV-B radiation treatments were established as described in the previous series of experiments.

After the fifth day, embryonic mortality was recorded as in the previous experiment, and all egg masses placed in FSW for hatching. Hatching success and larval size at hatching were measured as described for the previous experiments.

\subsubsection{Effects of timing and duration of exposure to two stressors simultaneously}

\subsubsection{Chronic exposure to high temperature and variable salinity}

This experiment was designed to test for the interactive effects of chronic temperature and salinity stress on mortality, hatching success and larval size of $S$. australis. Six freshly deposited egg masses were collected from the tank in the lab. Each egg mass was cut into six sections of approximately equal size. One section from each egg mass was placed into a glass dish and each exposed to a factorial combination of two temperatures (control $\left(15^{\circ} \mathrm{C}\right)$ 
and $25^{\circ} \mathrm{C}$ ) and three levels of salinity (control (35\%o), 20\%o and 45\%o) for five consecutive days. Salinity was established as described previously. The dishes were then placed into one of three tanks filled with water in which the temperature was heated by temperature bars to $20^{\circ} \mathrm{C}$ and $25^{\circ} \mathrm{C}$, respectively. The control temperature treatment was established using a sea table with flowing seawater $\left(15^{\circ} \mathrm{C}\right)$. The water in the dishes was replaced daily.

After 5 days, embryonic mortality was recorded and all egg masses placed at the control salinity (FSW) and temperature, and left to hatch. Hatching success was recorded as previously described in this chapter. Larval size at hatching was not a variable in the temperature and salinity combination experiments.

\subsubsection{Periodic exposure to high temperature and variable salinity}

This experiment was designed to test the interactive effects of exposure to periodic temperature and salinity stress on mortality, hatching success and larval size of $S$. australis and $A$. juliana (Table 3.1). Egg masses were collected and cut into 6 pieces as described previously. The temperature and salinity combinations used were the same as described for the previous experiment, only the duration was different. Egg mass pieces in this experiment were exposed to the stress treatments 4 hours per day for five consecutive days. After exposure, the egg masses were placed at control temperature and control salinity for the remainder of the day. The control salinity and temperature were established as in the previous experiments. Salinity and temperature were confirmed by using a refractometer and a thermometer.

After 5 days, embryonic mortality was recorded and all egg masses left at control salinity (FSW) and control temperature and left to hatch. Hatching success was recorded as previously described in this chapter. 


\subsubsection{Early vs. late exposure to high temperature and low salinity}

To examine whether vulnerability to two stressors depends on developmental stage, this experiment used a combination of high temperature and low salinity, exposing $S$. australis egg masses for 3 days either early or late in development. The temperature and salinity levels in this experiment were $25^{\circ} \mathrm{C}$ and $20 \%$ because this was the most stressful combination in the previous experiments (see Results). Six replicate egg masses were cut into 3 approximately equal pieces and assigned to one of 3 treatments: 1 ) control conditions for 6 days, 2) early exposure to stressful temperature and salinity for 3 days followed by 3 days in control conditions, and 3 ) control conditions for 3 days followed by stressful temperature and salinity for 3 days. High temperature and low salinity were established as described previously. Control conditions were established by placing dishes into a large sea table with flowing seawater (ambient temperature $\left(15^{\circ} \mathrm{C}\right)$ in FSW $(35 \%)$. Temperature and salinity were confirmed with a thermometer and refractometer. The water in all treatments was replaced daily.

After six days the egg masses were examined as previously described and all dishes were left in FSW in the control temperature to hatch. Hatching success was recorded as previously described.

3.3.2.4 24-hour exposure to high temperature and low salinity at different days after deposition

This experiment was designed to examine the effects of one-day exposure to two simultaneous stressors (low salinity: 20\%, high temperature: $25^{\circ} \mathrm{C}$ ) on $S$. australis embryos, to identify the most vulnerable ages. Six replicate freshly deposited egg masses were divided into 6 pieces and exposed to stressors on either day 1, 2, 3 or 4 of development or control conditions. After being exposed to the stressors, egg mass pieces were maintained in FSW under control conditions for the remaining duration of the experiment. 
After the fifth day, embryonic mortality was recorded as described previously, and all egg masses left in FSW at the control temperature for hatching. Hatching success was recorded as described for the previous experiments.

\subsubsection{Statistical Analysis}

Mixed model ANOVAs were used with stressor (i.e. salinity, temperature, UV-B, temperature and salinity, plus the interaction between the two) as a fixed factor and egg mass nested within each stressor as a random factor to examine the treatment effects on embryonic mortality (and larval size at hatching for the single stressor experiments) for each species. Significant results were further examined by pairwise comparisons to compare between groups. The percentage of inviable embryos in the egg mass was assumed to be equal to embryonic mortality. When the percentage data of embryonic mortality (or the larval size at hatching for the single stressor experiments) violated the ANOVA assumptions, the data were arc-sine square-root (or log10 for the size respectively) transformed to improve normality. All statistical analyses were carried out using PASW 18.0 software.

While transformed data were used for the analysis, raw data were plotted for easier interpretation.

\subsection{RESULTS}

\subsubsection{Timing and Duration of exposure to single stressors}

\subsubsection{Early vs. late exposure to single stressors}

The timing of stressful salinity $(20 \%)$ was not a significant factor for mean embryonic mortality for $S$. australis $\left(F_{2,15}=1.534, p=0.248\right)$. Mortality was relatively low overall, although there was a trend for higher mortality in late stressful salinity $(20.17 \%)$ than in the other two treatments $(1.5-1.83 \%$, Fig 
3.1). The timing of stressful treatment was also not a significant factor for mean embryonic mortality of $A$. juliana $\left(\mathrm{F}_{2,15}=1.975, \mathrm{p}=0.173\right.$, Fig 3.1), however mortality for this species was relatively high across all treatments (69-97\%). There was a significant effect of timing for $P$. maculata, $\left(F_{2,15}=46.725\right.$, $p<0.001$, Fig 3.1 , where mean embryonic mortality was highest in the early exposure treatment $(100 \%)$, intermediate in the late exposure treatment $(39 \%)$ and very low in the control treatment (1.17\%), with all treatments being significantly different from each other (pairwise comparisons, $\mathrm{p}<0.005$, Fig 3.1). The variation in $S$. australis and $A$. juliana egg masses was high.

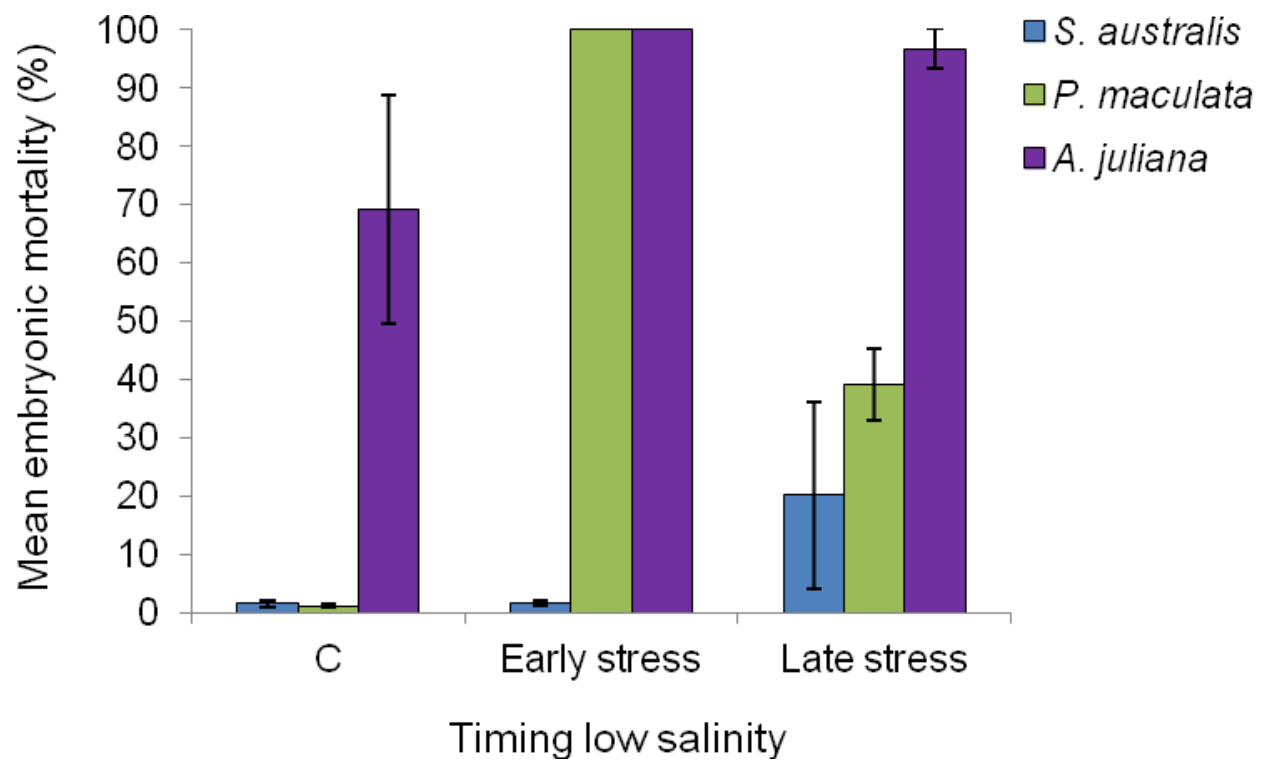

Figure 3.1 Mean percentage of embryonic mortality in egg masses of 1 intertidal and 2 subtidal species subjected to 3-day exposure to low salinity at different times of development $( \pm S E), n=6$ for each species.

S. australis hatching success was equally high in all treatments $(100 \%$, Table 3.2). Hatching success was high in P. maculata in the control treatment and when embryos were stressed late in their development. No larvae hatched from the early stress treatment. Hatching success was generally low for $A$. juliana but even lower in both stress treatments. 
Table 3.2 Hatching success (in \%) of each species in response to 3-days of low salinity at two different developmental stages and in control $(C)$ salinity. Hatching success was scored out of 6 egg masses for each species.

\begin{tabular}{|cccc|}
\hline Timing of low & & & \\
salinity (20 \%) & S. australis & P. maculata & A. juliana \\
C & 100 & 100 & 33 \\
Early & 100 & 0 & 16 \\
Late & 100 & 66 & 16 \\
\hline
\end{tabular}

Salinity did not have a significant effect on larval size at hatching between the different treatments for $S$. australis $\left(F_{2,15}=1.322, p=0.296\right)$. Mean larval size was $0.141 \mathrm{~mm}( \pm 0.011 \mathrm{~mm} S D)$. There was also no difference in size for $P$. maculata $\left(\mathrm{F}_{1,10}=0.098, \mathrm{p}=0.761\right)$ and $A$. juliana $\left(\mathrm{F}_{1,1}=0.069, \mathrm{p}=0.837\right)$ larvae hatching in the different treatments.

The timing of 3-day exposure to high temperature had a significant effect on mortality for $S$. australis embryos $\left(F_{2,15}=3.861, p=0.044\right.$, Fig 3.2). Mean embryonic mortality was higher under early (83.33\%) and late (47.5\%) temperature stress than at the control temperature (18.5\%). However, only mortality in the early treatment was significantly different from the control treatment (pairwise comparisons, $\mathrm{p}=0.014$ ). One egg mass had $100 \%$ mortality (and thus no larval hatchlings) across all treatments which may explain the high variation in the egg masses. 


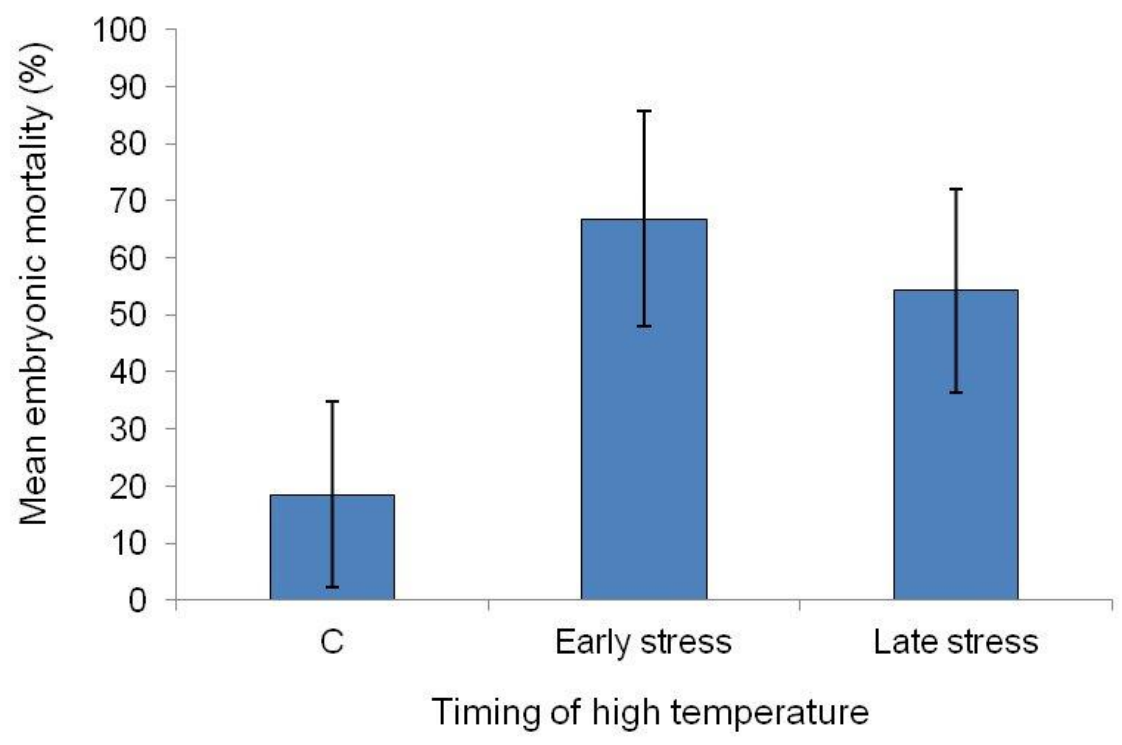

Figure 3.2 Mean percentage of embryonic mortality in Siphonaria australis egg masses subjected to 3-day exposure to high temperature at different times of development and in control temperature $(C)$ for six days $( \pm S E), n=6$.

Hatching success was high in the control temperature and late stressful exposure (both $83 \%$ ), and low in early stressful exposure (16\%). Larval size at hatching was not different between the treatments $\left(F_{2,8}=0.429, p=0.665\right.$, mean larval size $0.149 \mathrm{~mm} \pm 0.007 \mathrm{SD}$ ).

The timing of high UV-B radiation had a significant effect on the mortality of $S$. australis embryos $\left(F_{2,15}=10.098, p=0.002\right)$. Early exposure to high UV-B caused significantly higher embryonic mortality $(57 \%)$ than late $(8 \%)$ or control (shade, $3 \%$ ) exposure (pairwise comparisons, $p<0.005$, Fig 3.3). 


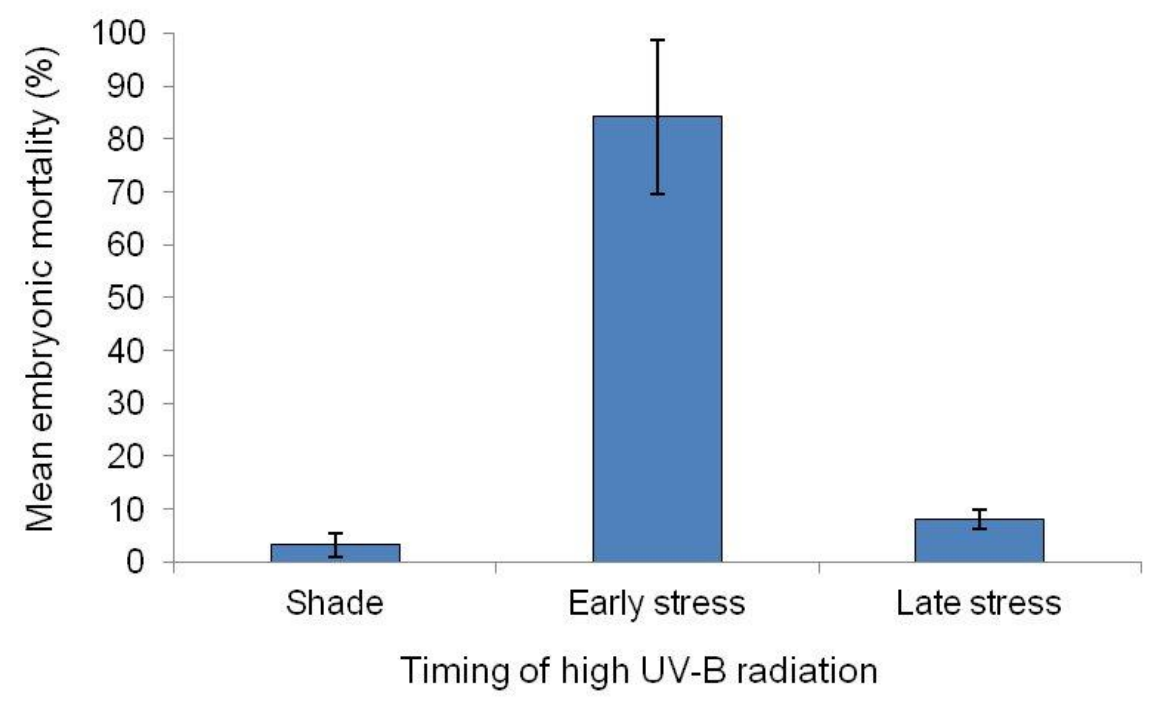

Figure 3.3 Mean percentage of embryonic mortality in Siphonaria australis egg masses subjected to 3-day exposure to high UV-B radiation at different times of development $( \pm S E), n=6$.

Hatching success was high overall (100\% in late and control exposure), and $66 \%$ in early exposure. There was no effect of timing of UV-B exposure and size at hatching $\left(F_{2,13}=0.072, p=0.931\right)$. The mean larval size at hatching was $0.139 \mathrm{~mm}( \pm 0.008 \mathrm{SD})$.

3.4.1.2 24-hour exposure to single stressors at different days after deposition

Timing of 24 hours of low salinity had a significant effect on $A$. juliana embryonic mortality $\left(\mathrm{F}_{4,25}=2430, \mathrm{p}<0.001\right)$. Mortality was high on all days of stressful salinity (100\%) and low in the control salinity (3.33\%). Timing of 1 day exposure to low salinity did not significantly affect $S$. australis embryos $\left(F_{4}\right.$, $\left.{ }_{25}=0.701, p=0.598\right)$, and mortality was low across all treatments $(1.83-5 \%$, Fig 3.4). 


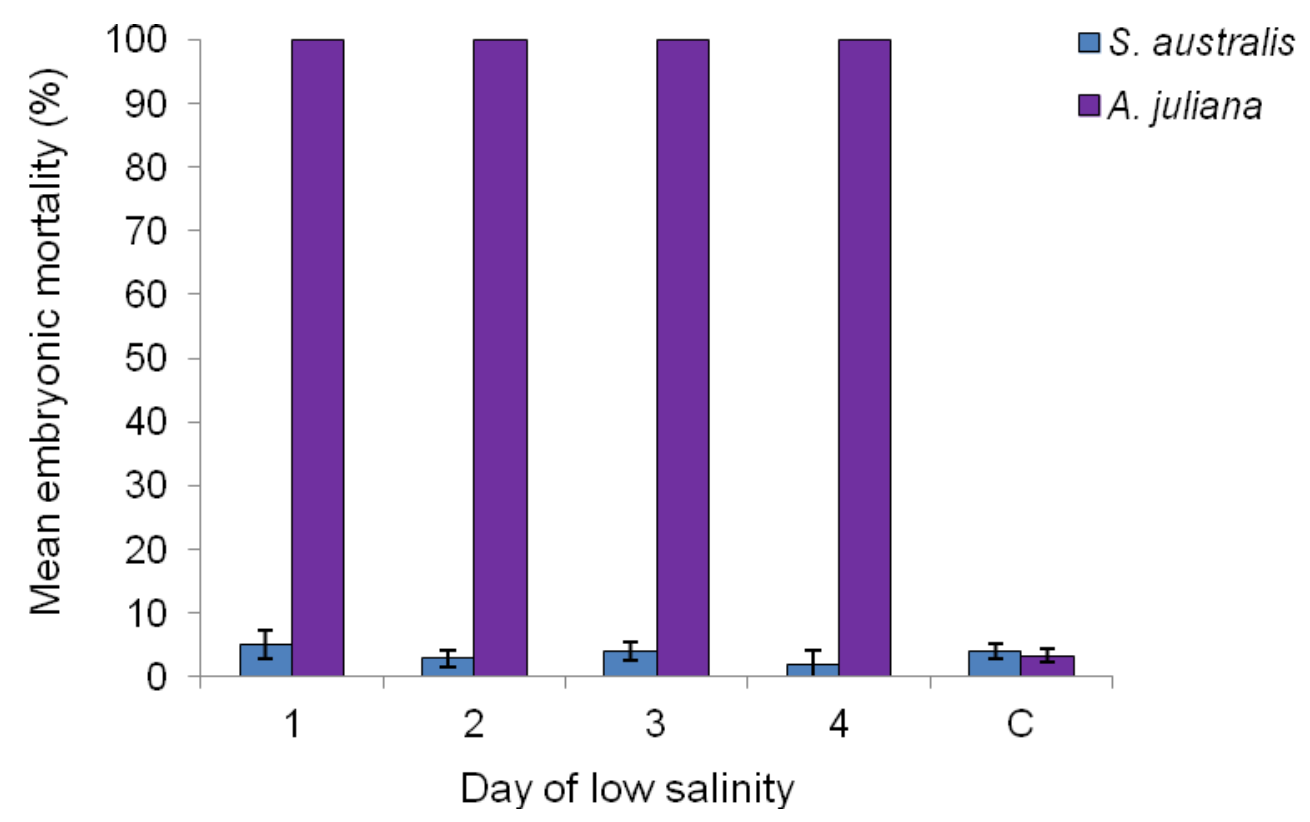

Figure 3.4 Mean percentage of embryonic mortality in egg masses of 1 intertidal and 1 subtidal species subjected to 1-day exposure to low salinity at different days of embryonic development and five days in control salinity $(C)( \pm S E), n=6$ for each species.

Hatching success was high in all treatments for $S$. australis (100\%). A. juliana larvae only hatched from the control treatment. Larval size at hatching was significantly different between the treatments for $S$. australis larvae $\left(F_{4}\right.$, ${ }_{25}=2.829, p=0.046$ ). Larvae hatching at the control salinity were larger than larvae hatching at any of the stress treatments $(0.1599 \mathrm{~mm} \pm 0.007 \mathrm{SD}$ vs. $0.1537 \mathrm{~mm} \pm 0.007 \mathrm{SD}$; pairwise comparisons, $\mathrm{p}<0.05$ ). Larval size differences could not be tested for $A$. juliana larvae as there were no hatchlings in any of the stress treatments; the mean larval size from the control treatment was $0.133 \mathrm{~mm}( \pm 0.012 \mathrm{~mm} \mathrm{SD})$.

Timing of the 1 day of exposure to high temperature had a significant effect on embryonic mortality for both species $S$. australis $\left(\mathrm{F}_{4,25}=5.951\right.$, $\mathrm{p}=0.002)$ and $A$. juliana $\left(\mathrm{F}_{4,25}=15.363, \mathrm{p}<0.001\right.$, Fig 3.5). For $S$. australis the embryonic mortality was significantly higher on the first day of development to high temperature exposure $(50.83 \%)$ than on any of the other days $(1-4 \%$, 
pairwise comparisons, $\mathrm{p} \leq \mathrm{0.001)}$. For $A$. juliana embryonic mortality was higher in the early days of development ( 1 and 2, 99-100\%) than the later days, however mortality in the third day of exposure was still higher than at day 4 (pairwise comparisons, $p<0.05$ ).

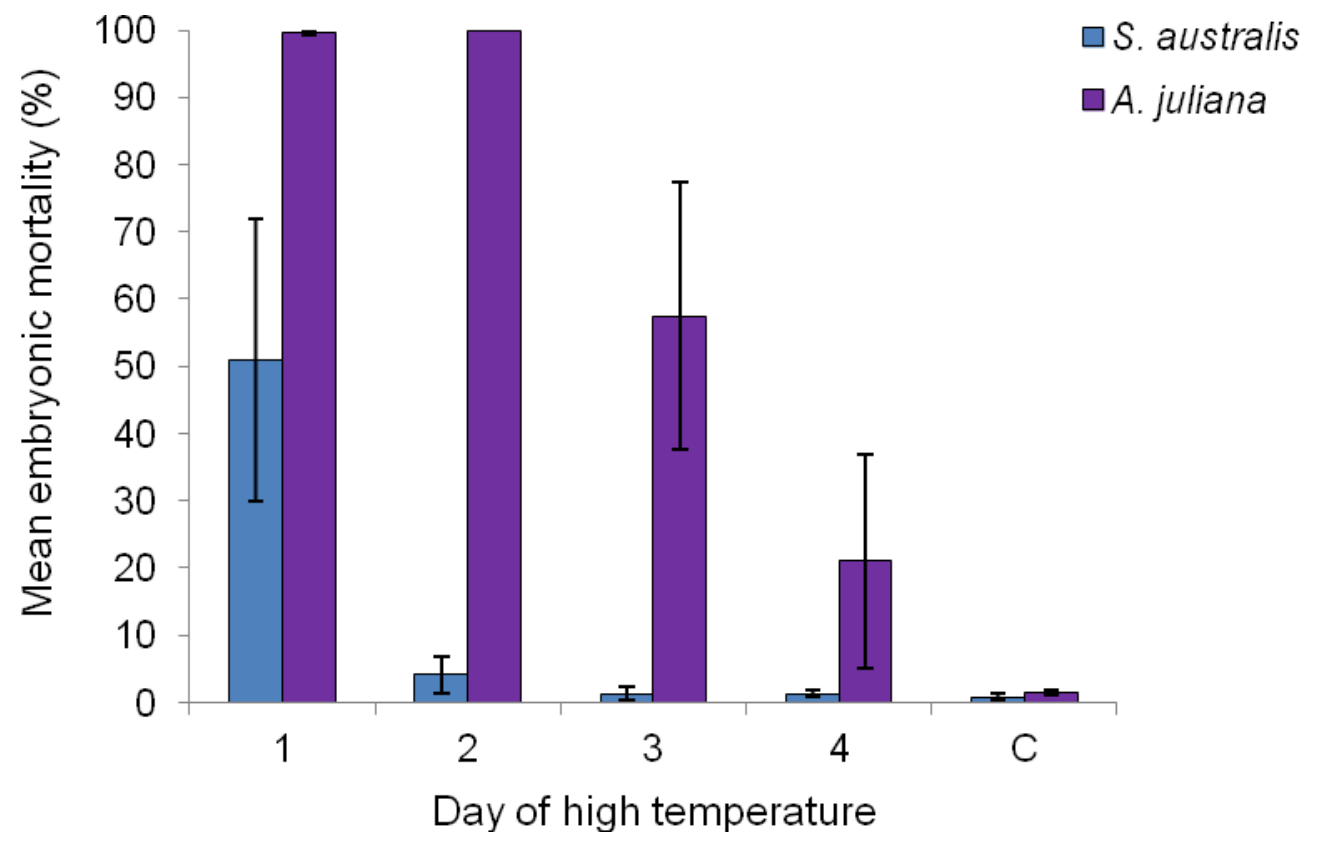

Figure 3.5 Mean percentage of embryonic mortality in egg masses of 1 intertidal and 1 subtidal species subjected to 1-day exposure to high temperature at different days of embryonic development $( \pm S E), n=6$ for each species.

Hatching success was very high for $S$. australis (Table 3.3). The hatching success for $A$. juliana larvae was lowest in egg masses exposed to stress on the second day, but low when the stress was applied on the first day. It increased when stress was applied on the third and fourth days. 
Table 3.3 Hatching success (in \%) of each species in response to $24 \mathrm{hrs}$ at high temperature. Hatching success was scored out of 6 egg masses for each species

\begin{tabular}{|ccc|}
\hline Day of high temperature exposure $\left(\mathbf{2 5}^{\circ} \mathbf{C}\right)$ & S. australis & A. juliana \\
1 & 83 & 16 \\
2 & 100 & 0 \\
3 & 100 & 33 \\
4 & 100 & 50 \\
C & 100 & 66 \\
\hline
\end{tabular}

There was no difference in larval size between the treatments for either S. australis larvae $\left(\mathrm{F}_{4,25}=0.559, \mathrm{p}=0.694\right)$ or $A$. juliana $\left(\mathrm{F}_{3,5}=1.223, \mathrm{p}=\right.$ $0.393)$ larvae. Mean size at hatching was $0.146 \mathrm{~mm}( \pm 0.01 \mathrm{SD})$ for $S$. australis and $0.137 \mathrm{~mm}( \pm 0.009 \mathrm{SD})$ for $A$. juliana.

The day of exposure to stressful UV-B radiation had a significant effect on $S$. australis embryonic mortality $\left(\mathrm{F}_{4,25}=4.12, \mathrm{p}=0.011\right.$, Fig 3.6). Mortality was at least twice as high when exposed to high UV-B on day $1(60 \%)$ of development than on any other day during development (0.5 - 26\%) and embryonic mortality was higher on day 1 then on days 3 , or 4 , or in the control treatment (pairwise comparisons, $\mathrm{p} \leq 0.005$ ). Embryonic mortality decreased as developmental days increased. 


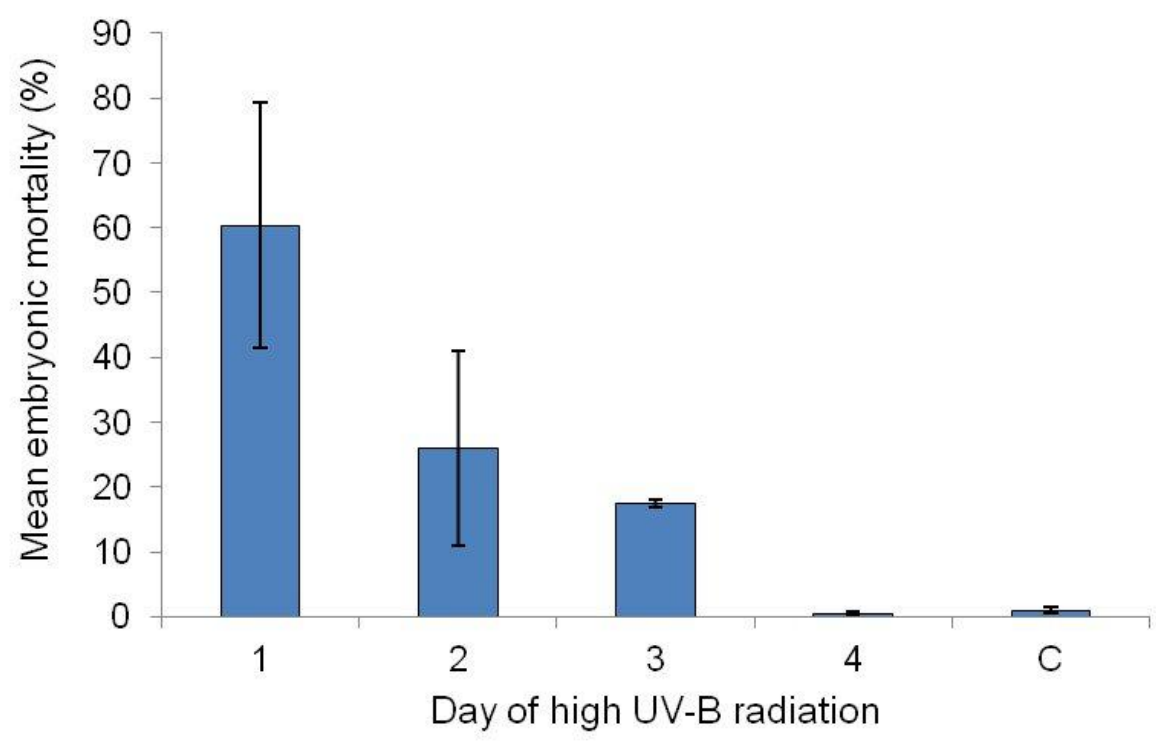

Figure 3.6 Mean percentage of embryonic mortality in Siphonaria australis egg masses subjected to 1-day exposure to high UV-B radiation at different days of embryonic development $( \pm S E), n=6$.

Hatching success was high overall across the treatments (66-100\%, Table 3.4).

Table 3.4 Hatching success (in \%) of $S$. australis in response to high UV-B radiation treatments. Hatching success was scored out of 6 egg masses.

\begin{tabular}{|cc|}
\hline Day of stressful UV-B radiation $\left(\mathbf{1 . 7} \mathbf{W m}^{-\mathbf{2}} \mathbf{s}^{-1}\right)$ & S. australis \\
1 & 66 \\
2 & 83 \\
3 & 100 \\
4 & 83 \\
C & 100 \\
\hline
\end{tabular}

There was no effect on larval size at hatching of the day of stressful UVB exposure $\left(F_{4,21}=0.498, p=0.738\right)$. The mean larval size at hatching was $0.142 \mathrm{~mm}( \pm 0.007 \mathrm{SD})$. 


\subsubsection{Effects of timing and duration of exposure to two stressors simultaneously}

3.4.2.1 Chronic exposure to high temperature and variable salinity

Temperature $\left(\mathrm{F}_{1,4}=573.93, \mathrm{p}<0.001\right)$ and salinity $\left(\mathrm{F}_{2,10}=4.752, \mathrm{p}=\right.$ 0.035 ) had significant effects on the embryonic mortality of $S$. australis, but the interaction of the two factors was also significant $\left(F_{2,12}=4.614, p=0.031\right)$. In general, mortality was much higher in all high temperature treatments compared to all treatments at control temperatures (Fig 3.7), however the significant interaction arose because high temperature resulted in higher embryonic mortality when coupled with both low (99\%) and high salinity (98\%) compared to high temperature at the control salinity $(75 \%)$.

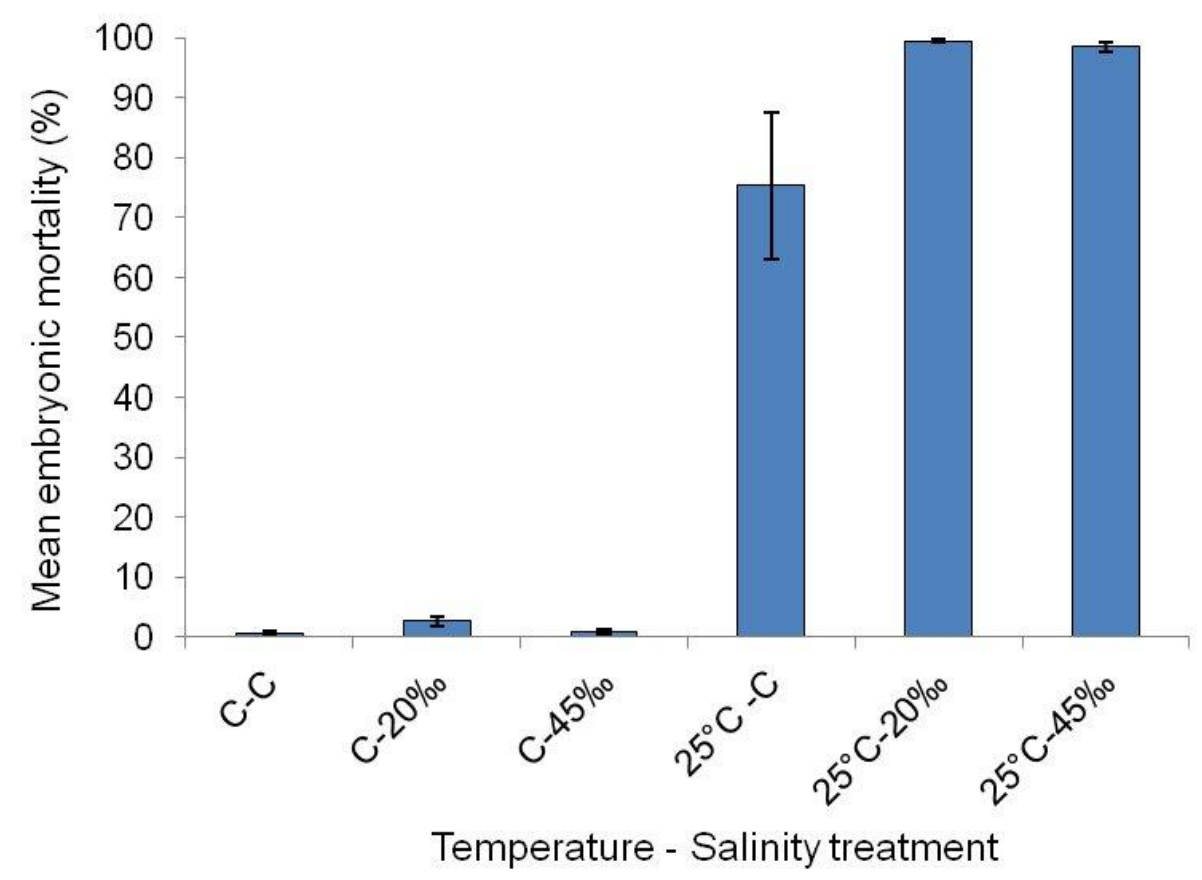

Figure 3.7 Mean percentage of embryonic mortality in Siphonaria australis egg masses subjected to different combinations of chronic temperature and salinity over a period of 5 days $( \pm S E), n=6$.

Hatching success was very high in the control temperature treatments and very low in the high temperature treatments (Table 3.5). 
Table 3.5 Hatching success (in \%) of $S$. australis in response to chronic temperature and salinity treatments. Hatching success was scored out of 6 egg masses.

\begin{tabular}{|cc|}
\hline Temperature (in ${ }^{\circ} \mathrm{C}$ )- Salinity (in \%o) combinations & S. australis \\
C - C & 100 \\
C - 20\%o & 100 \\
C - 45\% & 100 \\
$25^{\circ} \mathrm{C}-\mathrm{C}$ & 16 \\
$25^{\circ} \mathrm{C}-20 \%$ & 0 \\
$25^{\circ} \mathrm{C}-45 \% \circ$ & 0 \\
\hline
\end{tabular}

\subsubsection{Periodic exposure to high temperature and variable salinity}

Temperature $\left(\mathrm{F}_{1,10}=71.245, \mathrm{p}<0.001\right.$, $\left.\mathrm{Fig} 3.8\right)$ and salinity $\left(\mathrm{F}_{2,20}\right.$ $=11.096, p=0.001)$ had a significant effect on the embryonic mortality of $S$. australis in periodic exposure, however the interaction between temperature and salinity was also significant $\left(F_{2,20}=11.096, p=0.001\right)$. High temperature resulted in higher embryonic mortality when coupled with both low (99\%) and high salinity (98\%) compared to high temperature at the control salinity $(75 \%)$.

Temperature did not have a significant effect on embryonic mortality for A. juliana $\left(\mathrm{F}_{1,15}=3.675, \mathrm{p}=0.074\right.$, $\left.\mathrm{Fig} 3.8\right)$; Salinity was significant $\left(\mathrm{F}_{2,15}\right.$ $=8.755, p=0.003)$, but so was the interaction $\left(F_{2,15}=6.621, p=0.009\right)$. Embryonic mortality at $45 \%$ salinity was higher when coupled with high temperature $(73 \%)$ than with the control temperature (38\%). Mortality at $20 \%$ was lower at high temperature $(72 \%)$ than at the control temperature $(100 \%)$. This may be explained due to one egg mass with a very low mortality (3\%). 


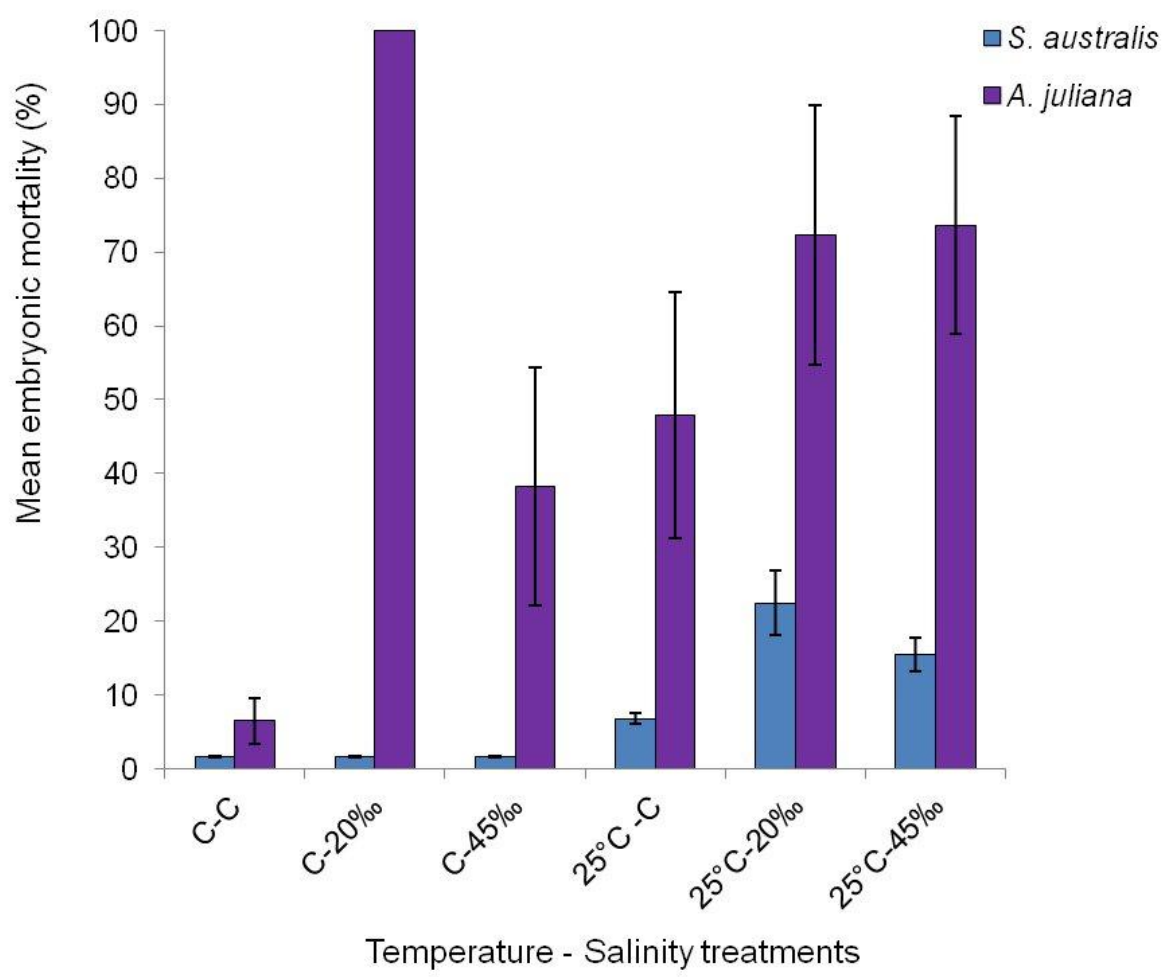

Figure 3.8 Mean percentage of embryonic mortality in egg masses of one intertidal and one subtidal species subjected to different combinations of periodic temperature and salinity for 4 hours/ day over a period of 5 days ( $\pm S E$ ), $n=6$ for each species.

Hatching success was very high for $S$. australis across all combinations of temperature and salinity (Table 3.6). A. juliana larvae were able to hatch from the control treatment and had relatively high success at control temperature and $45 \%$ salinity, as well as at high temperature and control salinity. Success was low at high temperature and low salinity, and no larvae hatched in the high temperature and high salinity treatments. 
Table 3.6 Hatching success (in \%) of S. australis in response to periodic temperature and salinity treatments. Hatching success was scored out of 6 egg masses for each species

\begin{tabular}{|ccc|}
\hline $\begin{array}{c}\text { Temperature (in }{ }^{\circ} \mathrm{C} \text { )- Salinity (in \%o) } \\
\text { combinations }\end{array}$ & S. australis & A. juliana \\
$\mathrm{C}-\mathrm{C}$ & 100 & 100 \\
$\mathrm{C}-20 \%$ - & 100 & 0 \\
$\mathrm{C}-45 \%$ - & 100 & 66 \\
$25^{\circ} \mathrm{C}-\mathrm{C}$ & 100 & 66 \\
$25^{\circ} \mathrm{C}-20 \%$ & 100 & 16 \\
$25^{\circ} \mathrm{C}-45 \%$ & 100 & 0 \\
\hline
\end{tabular}

3.4.2.3 Early vs. late exposure to high temperature and low salinity

The timing of high temperature and low salinity had a significant effect on the mortality of $S$. australis embryos $\left(F_{2,15}=10.031, p=0.002\right.$, Fig 3.9). Early exposure to stressful temperature and salinity caused more than ten times higher embryonic mortality (67\%) than late exposure or control conditions (pairwise comparisons, $p=0.001$ and $p=0.002$ ). Mean embryonic mortality was higher with late exposure $(6 \%)$ than under control conditions $(1.67 \%)$, but there was no statistical difference between the two treatments. 


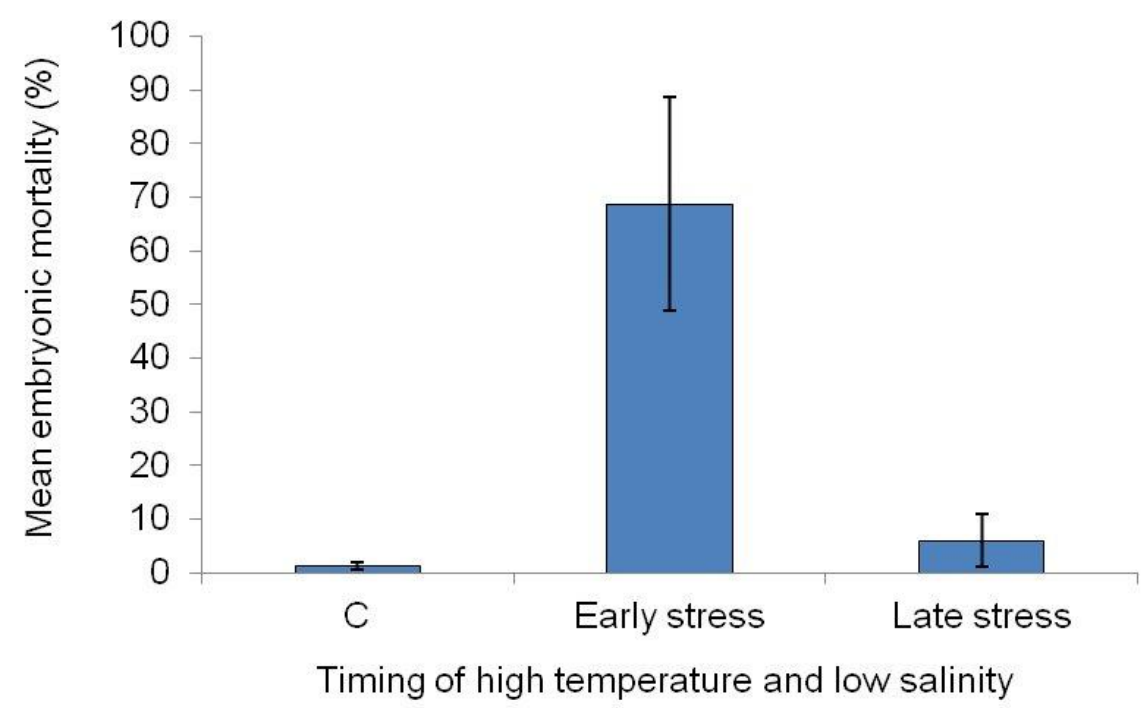

Figure 3.9 Mean percentage of embryonic mortality in Siphonaria australis egg masses subjected to 3-day exposure to high temperature and low salinity at different times of development $( \pm S E), n=6$ for each species.

Hatching success was high in the control conditions (100\%) and relatively high in late exposure (66\%) but low in the early exposure treatments (33\%).

3.4.2.4 24-hour exposure to two stressors at different days after deposition

The day of high temperature $\left(25^{\circ} \mathrm{C}\right)$ and low salinity $(20 \%)$ exposure had a highly significant effect on embryonic mortality for $S$. australis $\left(\mathrm{F}_{4,25}\right.$ $=348.682, p<0.001$, Fig 3.10). Mortality was very high on day $1(97 \%)$ and significantly higher than on any other day (pairwise comparisons, $p<0.001$ ). Mortality on all other days was uniformly low (0-1.3\%), with mortality on day 2 $(1.33 \%)$ being statistically higher than in the control treatment $(0 \%)$ (pairwise comparisons, $\mathrm{p}=0.026)$. 


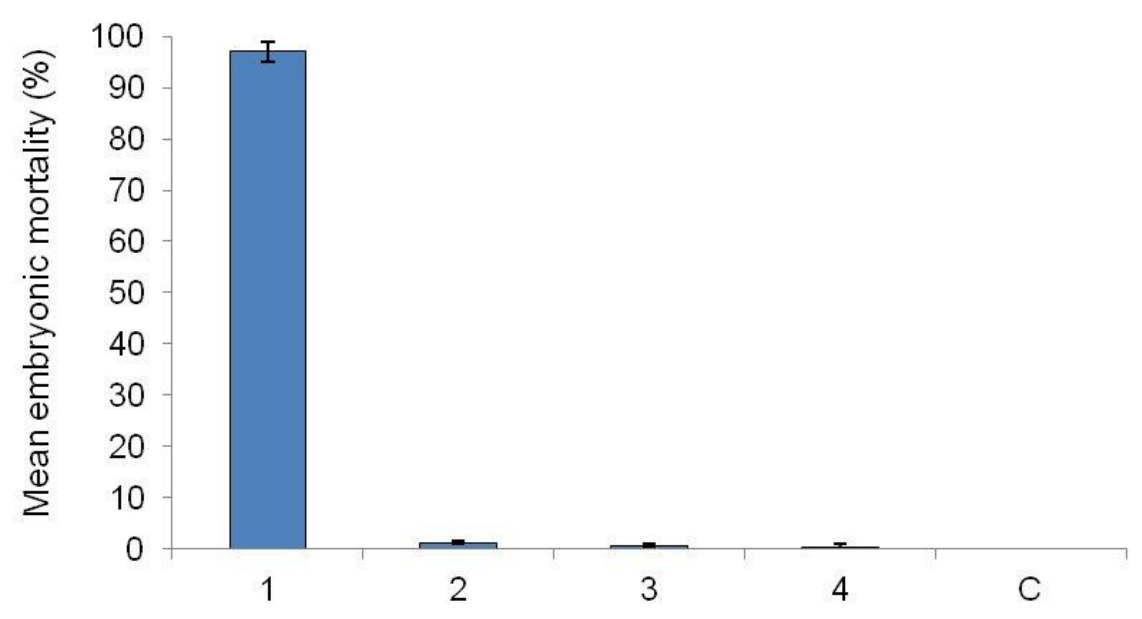

Day of high temperature and low salinity

Figure 3.10 Mean percentage of embryonic mortality in Siphonaria australis egg masses subjected to 1-day exposure to high temperature and low salinity at different days of embryonic development $( \pm S E), n=6$ for eac species.

Hatching success was low in egg masses stressed on day 1 (33\%), high in egg masses stressed on day 2 (83\%) and very high in egg masses stressed on day 3 and 4 , as well as in the control treatment (100\%).

\subsection{DISCUSSION}

\subsubsection{Single stressors}

Exposure to single stressors had strong species-specific effects on embryonic mortality that were mediated by the duration and timing of exposure. In general, for all species examined, 3-day exposure caused higher embryonic mortality than 24-hour exposure and embryos at earlier stages of development were more vulnerable to exposure to stress than later stages, but results were different for each species and stressor.

Aplysia juliana had high embryonic mortality when exposed to low salinity on each of 4 days of development, but vulnerability to high temperature decreased with age. P. maculata embryos were more vulnerable to low salinity 
during early stages of embryonic development. For $S$. australis, low salinity caused the highest mean embryonic mortality during late exposure, however there was no significant effect for either 3-day or 1-day exposure. Vulnerability to high temperature and to high UV-B radiation was highest on day 1 of embryonic development and decreased significantly as development progressed.

Various studies suggest that low salinity may affect the fertilization success and early development of free-spawning marine invertebrates. While fertilized sand dollar eggs and polychaete eggs have been shown to fail to cleave in low salinity (Allen \& Pechenik, 2010; Pechenik et al. 2007), there appears to be an overall lack of research in the literature regarding the most vulnerable time to salinity stress during embryonic development in egg masses.

S. australis embryos were most vulnerable to high temperature on day 1 after egg mass deposition and became more tolerant to high temperature as development increased. Previous research has suggested that early embryonic development in molluscs is less tolerant to temperature increases than later larval stages (Pelseneer 1901 as cited in Kennedy et al. 1974). Kennedy et al. (1974) exposed bivalve embryos of different developmental stages to a large range of temperatures and concluded that early embryonic stages were more sensitive to temperature extremes than later stages.

UV-B radiation resulted in high embryonic mortality during day 1 of embryonic development of $S$. australis; this is consistent with the effects of UVR on early development in echinoderms (Lesser \& Barry, 2003). Investigations from a range of studies found that freshly fertilized embryos of sea urchins were most vulnerable to UVR exposure compared to later developmental stages (Lesser et al. 2003; Nahon, et al. 2009). Another study on early sea urchin embryos observed the effects of UV-B radiation $24 \mathrm{~h}$ and $48 \mathrm{~h}$ post fertilization, and concluded that embryos were most vulnerable to radiation in the very early stages of development (Bonaventura et al. 2006). 
A decrease in survival, abnormalities and delays in development, and cell death as a response to UVR in early embryonic stages have been observed in a range of studies on echinoderms (Lesser \& Barry, 2003; Lesser, et al. 2003; Lesser et al. 2004; Lesser et al. 2006; Tauchman \& Pomorya, 2011), but the exact timing of when UVR is most damaging during embryonic development remains unclear. In contrast to the studies on echinoderms, UVR caused malformations and delayed development in all embryonic stages in amphibian embryos, but the early embryonic stages were less vulnerable than later embryonic stages (Castanaga et al. 2009).

In this study, hatching successes of $S$. australis, $A$. juliana and $P$. maculata generally mirrored those of embryonic mortality, and there were little to no effects of exposure to stress on larval size. On the contrary, Richmond and Woodin (1996) exposed estuarine mud snail (Ilyanassa obsolete) embryos to reduced salinity for either 2 or 4 days at either early or late embryonic development, and examined hatching time and larval size. Longer exposure to low salinity resulted in later hatching of larvae compared to short-term low salinity. Larvae were smaller at hatching when the salinity had been reduced for 2 days during late development. These results are consistent with the larval response in this study for $S$. australis; larvae at the control salinity were larger than larvae hatching at low salinity on any other day after 24 hours of exposure. However, there was no difference of mean larval size at hatching between 3day exposures.

Thomas and McClintock (1990) studied the effects of temperature on the embryonic development of the freshwater gastropod Physella cubensis. Development time and time till hatching decreased as temperature increased and higher temperature also increased larval size. As shown in the previous experiments (Chapter 2), increases in temperature and stressful salinity and UV-B levels increased time till hatching and while there was no effect of temperature on larval size for any of the species in this study, temperature can be an important factor in regulating and affecting development. 


\subsubsection{Multiple stressors}

For S. australis, the exposure to stressful temperature and salinity simultaneously caused high embryonic mortality, whereby chronic exposure had a much larger impact on embryonic mortality than periodic exposure. The simultaneous exposure to two stressors caused higher embryonic mortality than either high temperature or low salinity by themselves, suggesting that the two stressors acted synergistically. Temperature seemed to be the main factor for high embryonic mortality in both chronic and periodic exposures, as high temperature caused high embryonic mortality by itself but the effect was magnified when combined with stressful salinity.

Temperature and salinity have both been negatively associated with development, growth and survival of gastropods, and in many benthic invertebrates the effects of salinity and temperature have been shown to vary between developmental stages, body sizes and exposure times (Pechenik et al. 2003; Przeslawski et al. 2005). Whether salinity, temperature or the combination of both is mainly responsible for negative impacts on early life stages is still debatable and is probably species-specific (Deschaseaux et al. 2010).

Deschaseaux et al. (2011) exposed encapsulated embryos of gastropod species from the high, mid and low intertidal to combinations of temperature and salinity levels for 3 days to evaluate the effects of multiple stressors on embryonic mortality. High temperature and both low and high salinity increased embryonic mortality. The response intensity was species-specific, and no clear patterns as to which species was most sensitive to temperature and salinity changes could be established. In a study by Pechenik et al. (2003), Amphibola crenata embryos were subjected to various salinity and temperature combinations. The embryonic mortality was highest at high temperature and survival was highest at intermediate salinity. 
The response to temperature and salinity also appeared to be speciesspecific in this study. The mortality of the subtidal $A$. juliana embryos with periodic exposure to temperature and salinity was highest at both high and low salinity, with temperature magnifying the response. Embryonic mortality for the intertidal $S$. australis was highest at high temperature, and both high and low salinity magnified the response. It thus appears that, for the subtidal $A$. juliana, salinity was the main factor driving high embryonic mortality.

The one-day exposure to high temperature and low salinity was only detrimental to $S$. australis embryos on day 1 after egg mass deposition. This ties in with the results for high temperature as a single stressor, which was also only stressful on day 1 . With the single stressor salinity having no effect on embryonic mortality during one-day exposure, this suggests that temperature is most likely the cause of high embryonic mortality in the multiple stressor experiments.

Przeslawski (2005) and Przeslawski et al. (2005) exposed intertidal gastropods to several stressors known to be common in the intertidal, including different levels of light exposure, desiccation, temperature and salinity and showed that the effects of multiple stressors simultaneously can be dramatically amplified compared to single stressors. Russell and Phillips (2009a) examined the effects of UVR and tide pool conditions on intertidal gastropod egg masses and found that UVR caused highest embryonic mortality when combined with another stressor, and that the response was speciesspecific.

The synergistic effects of stressors on embryonic development have been widely acknowledged for a range of species including amphibians, echinoderms, fish and molluscs. Overall, the studies have overall suggested that a stressor which may or may not have caused elevated mortality on its own will act synergistically in the presence of another stressor, magnifying the effect of a single stressor (Wang et al. 1985; Kazlauskiene \& Stasiunaite, 1999; Davis, 2000; Pahkala et al. 2002; Huff et al. 2004; Sih et al. 2004; Przeslawski, 
2005; Przeslawski et al. 2005; Bancroft et al. 2008; Brennand et al. 2010; Hu et al. 2010;)

\subsubsection{Summary}

Timing and duration of single stressors had an effect on embryonic mortality. The 3-day exposure caused generally higher embryonic mortality than 1-day exposure. While the timing of low salinity exposure did not impact $S$. australis, embryos were most vulnerable to high temperature and UV-B radiation on day 1 after spawning; $A$. juliana and $P$. maculata embryos were also most vulnerable to stress during their early development. Temperature and salinity combined acted synergistically and caused higher embryonic mortality in S. australis egg masses than each of the stressors on its own. Embryos were most vulnerable to the stressful combination of high temperature and low salinity during early embryonic development.

These results suggest that the timing of stressful conditions in benthic egg masses is important for the reproductive success and population dynamics of species. Environmental conditions such as temperature and salinity in coastal areas are likely to change as a consequence of global climate change but this research suggests that embryos can tolerate short-term stress during late embryonic development without significant consequences during the embryonic life stage and immediate impacts on the larval stage. 


\section{CHAPTER 4}

\section{Effects of intertidal stressors on embryos of an intertidal gastropod and carry-over effects on later life stages}

\subsection{ABSTRACT}

The environmental stressors salinity, temperature and UV-B radiation can cause high embryonic mortality in intertidal gastropod egg masses, particularly when these multiple stressors act simultaneously. I examined the effects of simulated tide pool conditions on embryos in benthic egg masses of the intertidal gastropod Siphonaria australis by either stressing or not stressing egg masses for 4 hours daily for 5 consecutive days. Larvae hatching from stressed and unstressed egg masses were then exposed to different temperature and light levels for ten days and examined every 3 days.

Simulated tide pool conditions caused high embryonic mortality in $S$. australis egg masses. There was no difference in the mean time till hatching, larval size at hatching or cilia length at hatching between the egg mass treatments.

Larval survival was only affected by egg mass and/ or larval treatment from day 7 after hatching, when survival was low under UV-B exposure regardless of temperature. Carry-over effects became most apparent when larvae were shaded from UV-B; in shaded treatments larvae from stressed egg masses had higher mortality when they were exposed to warm temperatures than larvae from unstressed egg masses. 
UV-B radiation had a strong effect on larval growth, where larvae of both stressed and unstressed egg masses were smaller and increased little in size from hatching. An effect of egg mass treatment was only evident for larvae shaded from UV-B, when larvae from stressed egg masses were smaller than those from unstressed egg masses by day 10 . UV-B radiation resulted in shorter cilia for larvae from both egg mass treatments on day 10 compared to the other larval treatments.

Overall these results suggest that UV-B radiation can cause high mortality during the embryonic and larval stages; and that stress experienced during embryonic development in the egg mass can result in sub-lethal damage that increases vulnerability to one stressor and decreases vulnerability to another stressor experienced in the larval stage.

\subsection{INTRODUCTION}

It has been recognized that environmental stressors can cause high embryonic mortality in intertidal gastropod egg masses (Przeslawski, 2004, 2005; Przeslawski, et al. 2004; Russell \& Phillips, 2009a). Previous chapters in this thesis have already explored the response of encapsulated Siphonaria australis embryos to the intertidal stressors salinity, temperature, and UV-B radiation, and the effects of salinity and temperature acting simultaneously (see Chapters 2 and 3), and have shown that these stressors can cause high mortality during early development.

While the embryonic mortality in response to abiotic factors has been established, those larvae surviving stressful conditions within egg masses and successfully hatching are far from being out of danger. The larval stage is also exposed to stressors, which will be a main focus in this chapter. Larvae and gametes of many benthic marine invertebrates can be found in near-surface waters where UVR is high (Lesser \& Barry, 2003). These larvae and gametes 
are exposed to high doses of UVR which may affect the development and fertilization success in the case of species with gametes (Adams \& Shick, 2001). Invertebrate predators have also been suggested to be responsible for an upward movement of zooplankton during daylight hours, thus exposing the zooplankton to high UVR. While some organisms try to migrate vertically to avoid the surface radiation, the exposure remains excessive on sunny days (Häder et al. 2007).

Larval history and especially nutritional condition during the larval stage have been shown to strongly affect growth, performance in juveniles and adults, and delayed metamorphosis, thus ultimately affecting survival in a large range of marine invertebrates (Pechenik et al. 1998; Marshall et al. 2003). One way nutritional stress can impact on juvenile performance is by negatively affecting the development of feeding structures (Wendt, 1996), resulting in a depletion of nutrient reserves which are necessary for completing metamorphosis (Pechenik et al. 2001).

Larval history and especially nutritional condition have been shown to strongly affect adult performance in a large range of marine organisms (Marshall et al. 2003). For planktotrophic larvae, the amount of food available in the plankton affects their growth and ultimately their survival as juveniles and adults (Pechenik et al. 1998; Phillips, 2002, 2004). Delayed attachment, sublethal salinity and nutritional stress, and the initial provisioning for lecithotrophic larvae affect post-metamorphic performances of marine invertebrates (Marshall et al. 2003).

The quality of larvae settling on the benthos can be strongly linked to recruitment success in the adult population, affecting fitness, i.e. survival, growth and reproduction of the adults (Pechenik, 1999). These effects, where experiences in early life stages strongly affect the performance in later life stages, are called "carry-over" effects and have been observed across a variety of developmental modes and phyla (Marshall et al. 2003; Marshall \& Keough, 2004). The relationship between larval history and juvenile/ adult performance 
has recently become recognised as important, as several studies have suggested that the linkage is substantial (Pechenik et al. 1998; Qiu \& Qian, 1999; Smith, et al., 2000; Pahkala et al. 2001; Ankley et al. 2002; Blaustein \& Belden, 2003; Marshall \& Keough, 2006; Tauchman \& Pomorya, 2011). Therefore any stressful experiences and rates of mortality during both embryonic and larval stages can have important implications for reproductive success, recruitment and population dynamics.

Previous research has primarily focused on whether size and performance as adults is influenced by events during the larval phase of development. It has been found that events in early life stages highly influence their size as adults (Marshall \& Keough, 2006). Carry-over effects have also been studied in terrestrial invertebrates and fish with pelagic development, and mainly focused on size and associated reproductive values and fitness (e.g. Moran \& Emlet, 2001; Sponaugle \& Grorud-Colvert, 2006). For marine invertebrates with benthic development and complex life histories, there is still a lack of informative research on this subject.

Marine invertebrates with mixed development can be exposed to stress during both embryonic development in benthic egg masses and the larval stage in the water column, and early exposure to stress may affect later larval responses. Most studies to date look at larval stress and post-metamorphic carry-over effects rather than egg mass stress and effects on the larval stage (Wendt, 1996; Pechenik, et al. 1998; Qiu \& Qian, 1999; Marshall \& Keough, 2003a, 2006; Green \& Fisher, 2004; Diederich et al. 2011; McDonald \& Gruenbaum, 2011; but Chan et al. 2008).

In this chapter, I exposed the egg masses of the intertidal gastropod $S$. australis to multiple stressors (i.e. high salinity, high temperature and UV-B radiation), simulating tide pool conditions on a summer day at low tide. I then examined the effects of stressful conditions (high temperature and UV-B radiation) in the larval stages, for larvae hatching from stressed and unstressed egg masses. It was hypothesised that (1) larvae hatching from egg masses that 
experienced stress are fitter than larvae hatching from previously unstressed egg masses because only the fittest larvae hatched from the stressed egg masses ("hatching of the fittest") and (2) UV-B radiation will have a negative impact on larval development. In addition to examining larval survival and larval sizes in response to stress in both the egg mass and larval stage, cilia lengths (in larvae, cilia are used for swimming and part of the feeding structure [the velum] (Strathmann, 1987)) were also measured as a possible indication of a sub-lethal effect.

\subsection{METHODS}

\subsubsection{Simulated tide pool conditions}

Siphonaria australis adults were collected and maintained in aquaria as described in Chapter 2. Six freshly deposited (<24 h post spawning) egg masses were collected and cut into two pieces of approximately equal size. I then assigned each piece to one of two egg mass treatments: "stressed" or "unstressed". In the "stressed" treatment the egg masses were subjected to three environmental stressors simultaneously, simulating tide pool conditions: high temperature $\left(20^{\circ} \mathrm{C}\right)$, high salinity $(45 \%)$ and high UV-B radiation $\left(1.7 \mathrm{~W} \mathrm{~m}^{-}\right.$ $\left.{ }^{2} \mathrm{~s}^{-1}\right)$. In the "unstressed" treatment, the egg masses were placed in control conditions, i.e. shade, ambient sea temperature (approximately $15^{\circ} \mathrm{C}$ ), and salinity (35\%o). In the shade treatment, dishes were placed on a rack in the cold room and shielded from UV-B with a large black plastic cloth that did not permit light transmission.

The egg masses were exposed to the treatments for 4 hours daily for 5 consecutive days. After being in the tide pool conditions for 4 hours, the stressed egg masses were placed into control conditions and water was replaced in all dishes with FSW. 
After 5 days, all egg masses were examined as described in chapters 2 and 3; embryonic mortality was recorded and all egg masses were left in control conditions until larvae hatched. Hatching success was recorded and ten hatched larvae per egg mass were measured (recorded as day 1).

\subsubsection{Larval exposure}

The hatched larvae from all stressed egg masses were mixed together and then redistributed into nine $500 \mathrm{ml}$ beakers. Then the hatched larvae from all unstressed egg masses were mixed together and redistributed into nine $500 \mathrm{ml}$ beakers. The beakers were filled with FSW and assigned to one of three larval treatments for 12 hours daily for ten days (with three replicate beakers each for the larvae from stressed and unstressed egg masses): 1) high temperature $\left(20^{\circ} \mathrm{C}\right)$ and high UV-B $\left.\left(1.7 \mathrm{~W} \mathrm{~m}^{-2} \mathrm{~s}^{-1}\right), 2\right)$ high temperature $\left(20^{\circ} \mathrm{C}\right)$ and shade, and 3 ) control temperature (ambient sea water $\sim 15^{\circ} \mathrm{C}$ ) and shade (control). After being in different treatments for 12 hours, all beakers were placed into control conditions for the next 12 hours of the day.

I placed sixty larvae (based on recommended density (Strathmann, 1987)) in every beaker; the FSW was replaced every 3 days and larvae were fed with Isochrysis galbana cells (100,000 cells/ ml). Larval mortality, larval size and velar cilia length were assessed every 3 days, i.e. on day 1 (day of hatching), day 4, day 7 , day 10 .

To measure larval mortality, all larvae were assessed in a Bogorov tray under a dissecting microscope and scored as live (body within shell and cilia movement) or dead (no body within shell or no cilia movement) and the percentage of live larvae was recorded. On days 1, 4, 7 and 10, ten larvae from each beaker were inspected under a compound microscope. I measured shell length (as in the previous chapters) and I measured three cilia per larva, whereby the mean of those three values was recorded as a single measure of 
cilia length per larva. The cilia were measured under the compound microscope when cilia were extended (Fig 4.1).

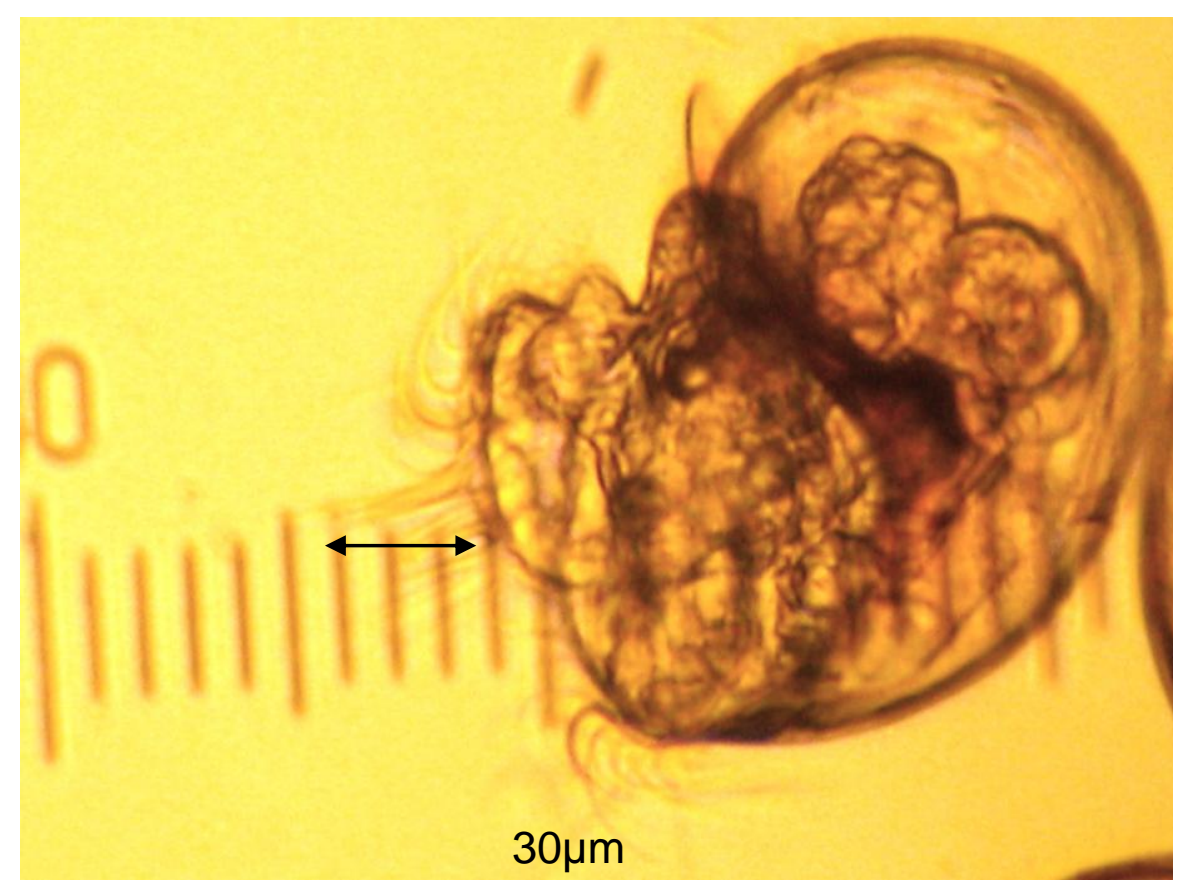

Figure 4.1 Cilia length (in $\mu \mathrm{m}$ ) of a newly hatched Siphonaria australis larva being measured under the microscope (400x magnification).

\subsubsection{Statistical Analysis}

A mixed model ANOVA was used for the tide pool conditions experiment with egg mass treatment as a fixed factor and egg mass nested within the treatment as a random factor, to examine the treatment effects on embryonic mortality, cilia length and larval size at hatching for $S$. australis. Significant results were further examined by posthoc tests.

Separate mixed model ANOVAs were then used for each day of larval assessment $(4,7$, and 10) for the subsequent larval experiment with egg mass treatment, larval treatment, and the interaction term as fixed factors and replicate beaker nested within the egg mass treatment as a random factor, to examine the effects on larval survivorship, larval size and cilia length. Significant results were further examined by posthoc tests. When data violated 
the ANOVA assumptions, the data were log10 transformed to improve normality. All statistical analyses were carried out using PASW 18.0 software. While transformed data were used for the analyses, raw data were plotted for easier interpretation.

\subsection{RESULTS}

\subsubsection{Simulated tide pool conditions}

Simulated tide pool conditions had a highly significant effect on the mean embryonic mortality of the intertidal $S$. australis $\left(F_{1,10}=46.312, p<\right.$ 0.001). The embryonic mortality was 75 times higher in tide pool conditions than in control conditions, where there was almost no mortality (Fig 4.2).

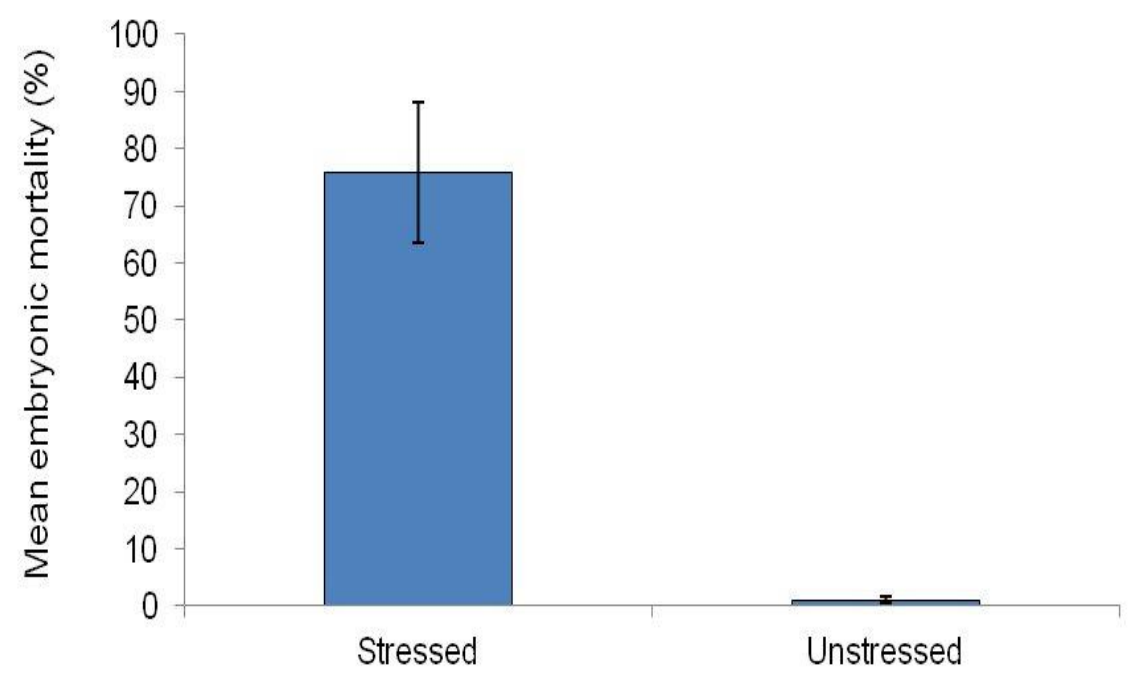

Egg mass treatment

Figure 4.2 Mean percentage of embryonic mortality in Siphonaria australis egg masses subjected to stressed (simulated tide pool) conditions and unstressed (control) conditions for 4hours/ day over 5 consecutive days $( \pm S E), n=6$.

The egg mass treatments had no effect on hatching success with all egg masses hatching in both treatments $(100 \%)$. There was no difference between the mean time till hatching and the egg mass treatment with 6.83 days $( \pm 0.4$ 
SD) for both stressed and unstressed egg masses. Five out of 6 egg masses hatched after 7 days and one egg mass hatched after 6 days.

Egg mass treatment had no effect on larval size at hatching (Day 1) $\left(\mathrm{F}_{1}\right.$, $4=0.019, p=0.898)$. The mean larval size at hatching was $0.1378 \mathrm{~mm}( \pm 0.006$ $\mathrm{SD})$ in stressed egg masses and $0.1371 \mathrm{~mm}( \pm 0.008 \mathrm{SD})$ in unstressed egg masses. At hatching, there was no significant difference of cilia length between larvae hatched from the stressed egg masses (mean length $0.03 \mathrm{~mm} \pm 0.004$ $\mathrm{SD}$ ) and larvae hatched from unstressed egg masses (mean length $0.032 \mathrm{~mm} \pm$ $\left.0.003 \mathrm{SD} ; \mathrm{F}_{1,4}=5.004, \mathrm{p}=0.089\right)$.

\subsubsection{Larval exposure}

\section{Larval survival}

On day 4 of the larval treatment, there was no significant effect on survivorship of either egg mass treatment $\left(F_{1,4}=1.185, p=0.338\right)$ or between larval treatments $\left(F_{2,8}=1.765, p=0.232\right)$. There was also no interaction effect $\left(F_{2,8}=1.018, p=0.404\right.$, Fig 4.3). 


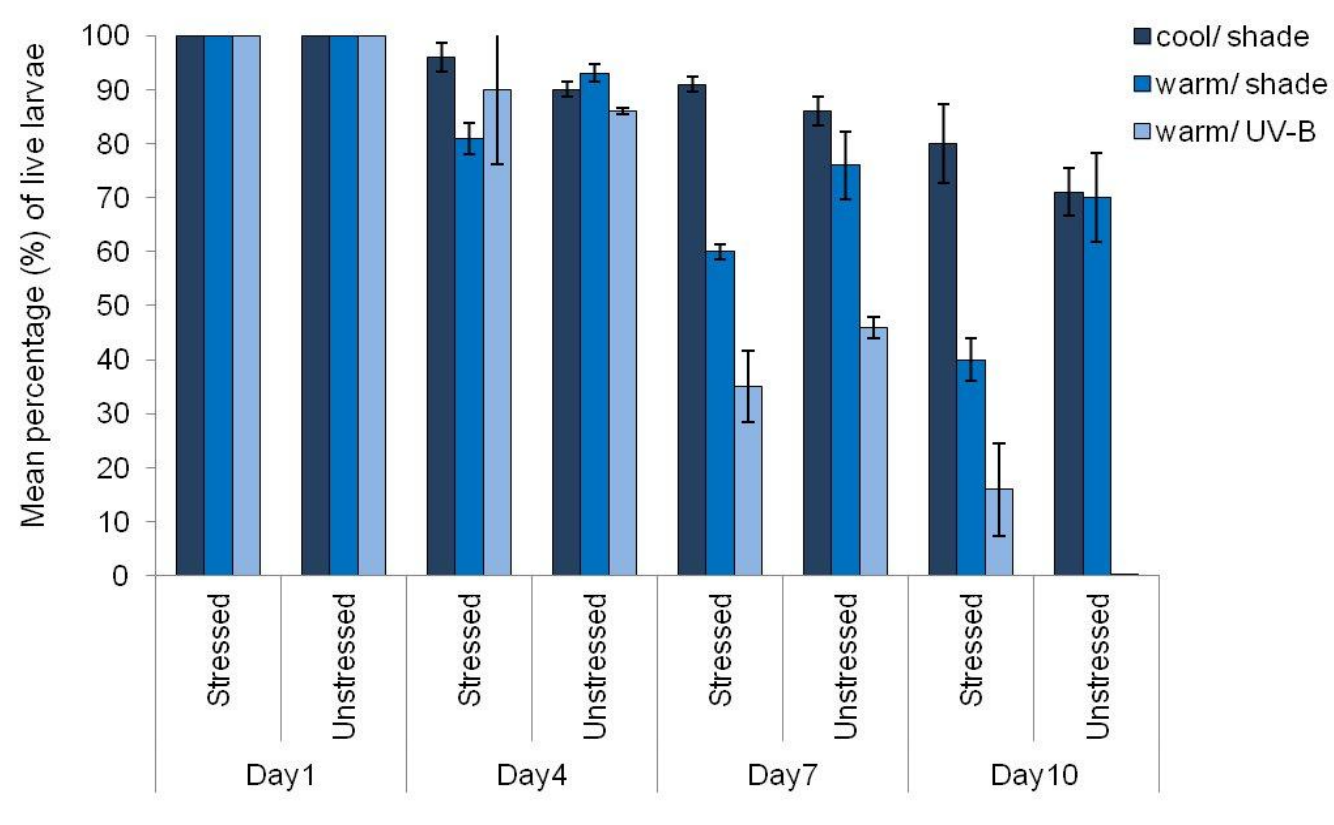

Larval Treatment

Figure 4.3 Mean percentage of live Siphonaria australis larvae from stressed or unstressed egg masses subjected to three temperature and UV-B treatments after different days of exposure ( $\pm S E), n=60$ for each replicate treatment.

On day 7 of the larval treatment, egg mass had a significant effect on the mean percentage of live larvae $\left(F_{1,4}=5.001, p=0.045\right)$. Larvae from unstressed egg masses had higher survivorship than larvae from stressed egg masses (pairwise comparisons, $p=0.045$, Fig 4.3). Larval treatment also had a significant effect on the mean percentage of live larvae $\left(F_{2,8}=40.49, p<0.001\right)$ with higher survivorship in the cool/ shade treatment than either of the other treatments $(p<0.013$ in both cases). Survivorship in the warm/ shade treatment was also significantly higher than in the warm/ UV-B treatment $(p<0.001)$. There was no interaction effect between egg mass and larval treatments $\left(F_{2,8}=\right.$ 2.638, $p=0.112$ ).

On day 10 of the larval treatment, there was no effect of egg mass treatment on larval survivorship $\left(F_{1,4}=3.587, p=0.131\right)$, although there was of larval treatment $\left(F_{2,8}=117.152, p<0.001\right.$, Fig 4.3), and there was a significant interaction effect between egg mass treatment and larval treatment $\left(F_{2,8}=\right.$ 
18.039, $p=0.001$ ). Survival was highest overall in the cool/ shade larval treatment in both stressed and unstressed egg masses. However, larvae in the warm/shade treatment had higher survival from unstressed egg masses, whereas larvae in the warm/ UV-B treatment had higher survival from stressed egg masses.

\section{Larval size}

On day 4 both egg mass treatment $\left(F_{1,4}=30.346, p=0.005\right)$ and larval treatment $\left(F_{2,174}=22.669, p<0.001\right)$ had a significant effect on larval size (Fig 4.4). Within each larval treatment, larvae from unstressed egg masses were larger than larvae from stressed egg masses (pairwise comparisons, $p=0.005$ ). Larval sizes differed between all three larval treatments for both stressed and unstressed egg masses; larvae from the warm/ shade treatment were largest followed by larvae from the control treatment, and larvae from the warm/ UV-B treatment were smallest (pairwise comparisons, $p<0.005$ ). The interaction term was not significant $\left(F_{2,174}=1.077, p=0.343\right)$.

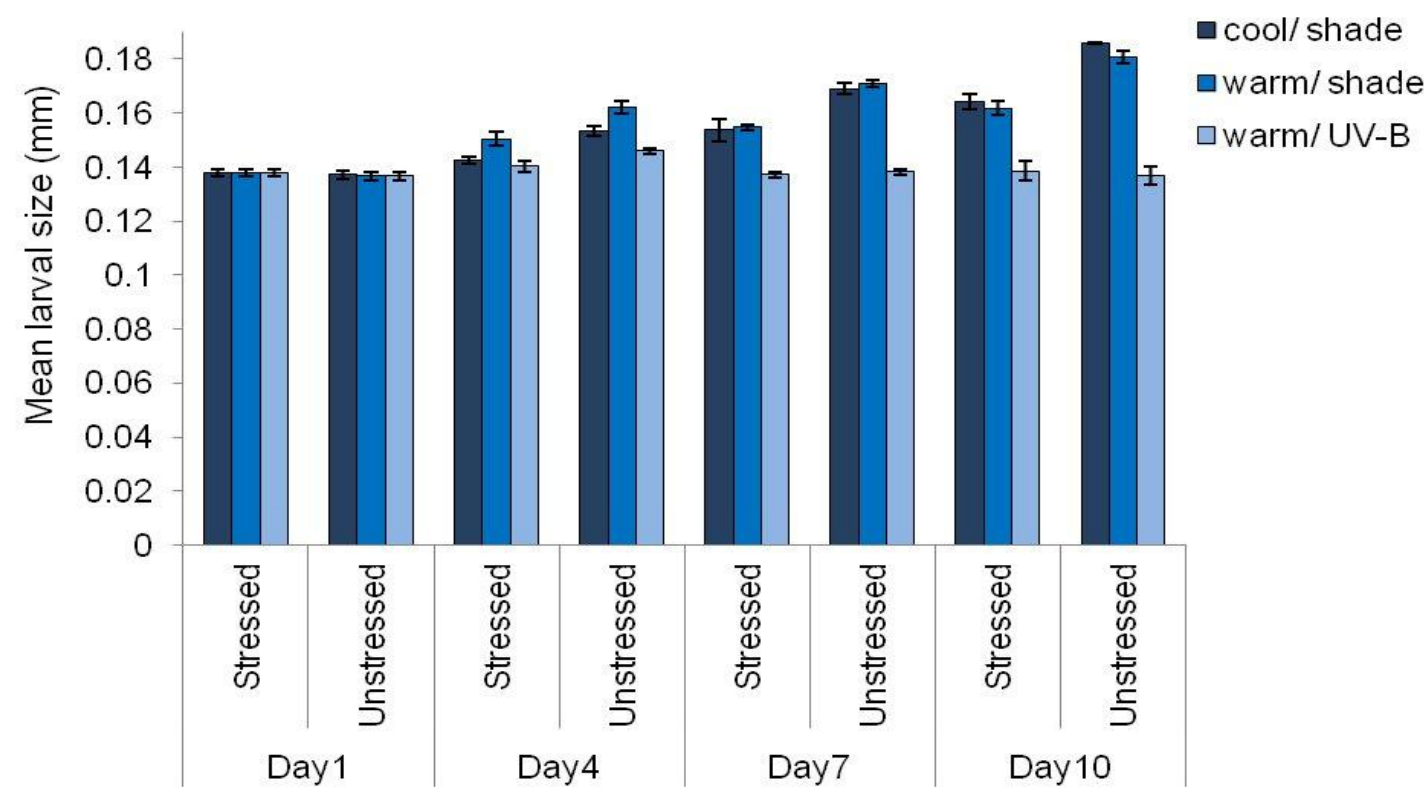

Larval treatment

Figure 4.4 Mean Siphonaria australis larval size $(\mathrm{mm})$ from stressed or unstressed egg masses subjected to three temperature and UV-B light treatments after different days of exposure $( \pm \mathrm{SE}), \mathrm{n}=10$ larvae for each replicate treatment. 
On day 7 , both egg mass treatment $\left(F_{1,4}=39.612, p<0.001\right)$ and larval treatment $\left(F_{2,174}=90.14, p<0.001\right)$ had a significant effect on larval size, however the interaction term was also significant $\left(F_{2,174}=7.883, p=0.001\right.$, Fig 4.4). Larvae from stressed and unstressed egg masses in the warm/ UV-B treatment were similar in size and smaller than larvae in the other treatments. However in the cool/ shade and warm/ shade larval treatments, larvae from unstressed egg masses were larger (mean size $0.169 \mathrm{~mm} \pm 0.01 \mathrm{SD}$ and $0.171 \mathrm{~mm} \pm 0.007 \mathrm{SD}$ ) than larvae from stressed egg masses (mean size $0.153 \mathrm{~mm} \pm 0.02 \mathrm{SD}$ and $0.154 \mathrm{~mm} \pm 0.006 \mathrm{SD})$.

On day 10 both egg mass treatment $\left(F_{1,143}=16.807, p<0.001\right)$ and larval treatment $\left(F_{2,143}=44.856, p<0.001\right)$ had a significant effect on larval size. The interaction term was also significant $\left(F_{2,143}=3.484, p=0.033\right.$, Fig 4.4). Larvae in the warm/ UV-B treatment, regardless of egg mass treatment, were small and had not grown since Day 1. Larvae in the cool/ shade and warm/ shade treatments were larger from unstressed egg masses (mean size $0.185 \mathrm{~mm} \pm 0.013 \mathrm{SD}$ and $0.18 \mathrm{~mm} \pm 0.012 \mathrm{SD}$ ) than stressed egg masses (mean size $0.164 \mathrm{~mm} \pm 0.016 \mathrm{SD}$ and $0.161 \mathrm{~mm} \pm 0.014 \mathrm{SD}$ ).

\section{Cilia length}

On day 4 , mean cilia length was affected by egg mass treatment $\left(F_{1,4}=\right.$ 11.137, $\mathrm{p}=0.029$, Fig 4.5). Larval treatment had no effect on cilia length $\left(F_{2}\right.$, $530=2.144, p=0.118)$, however the interaction term was significant $\left(F_{2,530}=\right.$ $6.818, p=0.001)$. The interaction arose because larvae in the warm/ shade treatment had longer cilia if they were from unstressed egg masses (mean length $0.035 \mathrm{~mm} \pm 0.005 \mathrm{SD}$ ) than stressed egg masses (mean length $0.03 \mathrm{~mm}$ $\pm 0.006 \mathrm{SD}$ ), whereas cilia lengths from all other treatment combinations were similar. 


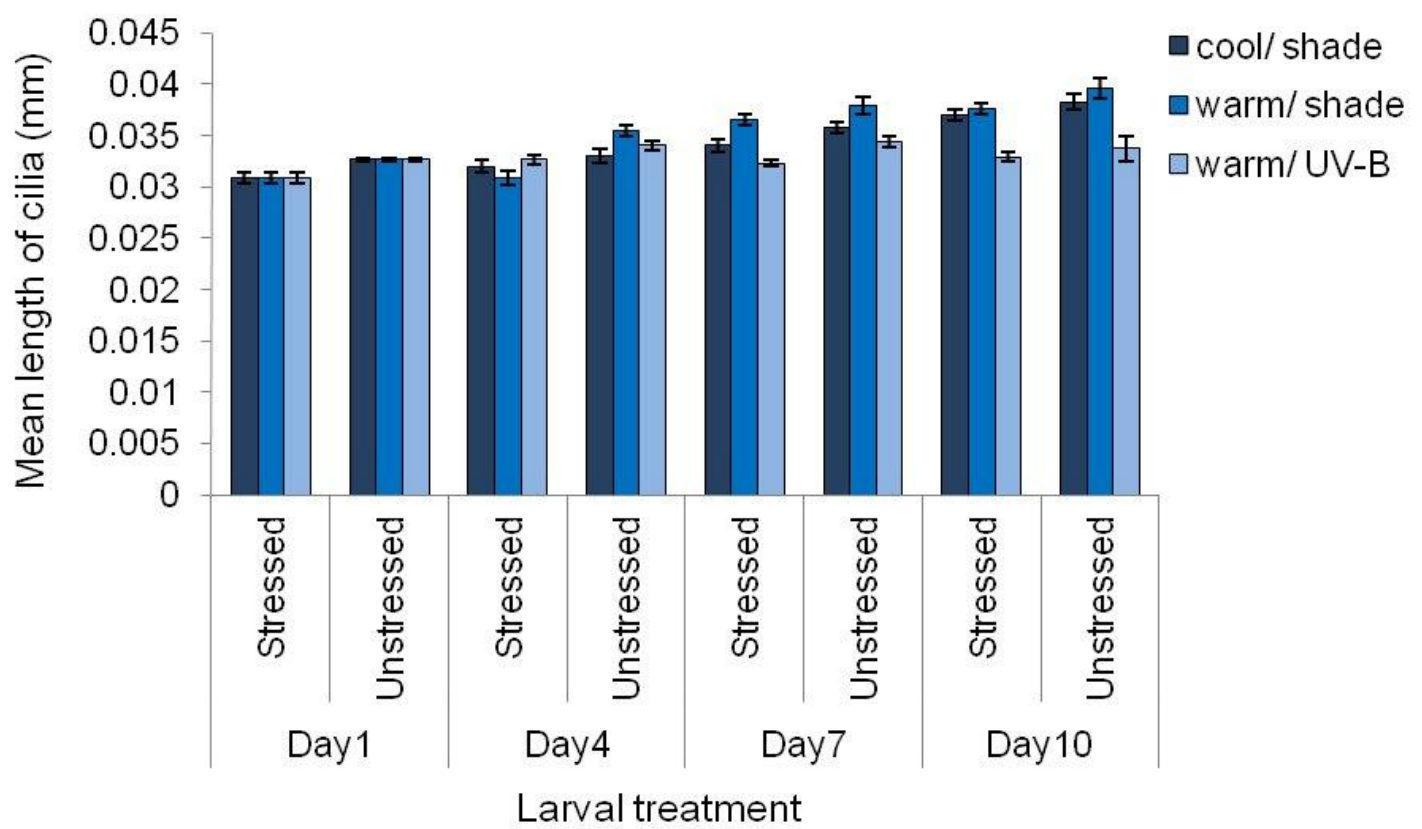

Figure 4.5 Mean length of cilia $(\mathrm{mm})$ of Siphonaria australis larvae from stressed or unstressed egg masses subjected to three temperature and UV-B treatments after different days of exposure $( \pm S E), n=10$ larvae in each replicate treatment.

On day 7 , both initial egg mass treatment $\left(F_{1,4}=9.007, p=0.04\right)$ and larval treatment $\left(F_{2,530}=20.437, p<0.001\right)$ had a significant effect on cilia length (Fig 4.5). Within each larval treatment, larvae hatched from unstressed egg masses had longer cilia than those from stressed egg masses (pairwise comparisons, $p=0.04$ ). Cilia length was longer in the warm/ shade treatment than in the control (pairwise comparisons, $p<0.001$ ) which was also longer than the warm/ UV-B treatment (pairwise comparisons, $p<0.02$ ). The interaction term was not significant $\left(F_{2,530}=0.567, p=0.568\right)$.

On day 10 the initial egg mass treatment had no effect on mean cilia length $\left(F_{1,4}=2.472, p=0.117\right.$, Fig 4.5). However the cilia length was significantly different between the larval treatments $\left(F_{2,441}=13.214, p<0.001\right)$. There was no difference between the control and the warm/ shade treatments, but both were significantly longer than the warm/ UV-B treatment (pairwise comparisons, $p<0.001)$. The interaction term was not significant $\left(F_{2,441}=\right.$ $0.053, p=0.949$ ). 


\subsection{DISCUSSION}

Embryos in egg masses exposed to simulated tide pool conditions had higher mortality than embryos in unstressed conditions. However, there was no difference in time till hatching, larval size or cilia length at hatching between the two treatments. Russell and Phillips (2009a) exposed Siphonaria australis egg masses to simulated tide pool conditions, however they used summertime natural light as the source of UVR. Full sun exposure resulted in extremely high embryonic mortality compared to UV-blocked or shaded treatments in tidal pool conditions. These results agree with the results found in this study, where embryonic mortality increased by $75 \%$ in tide pool conditions compared to control conditions.

Several other studies have emphasised the synergistic effects of intertidal stressors on the mortality during embryonic development (Rose, 1986; Roller \& Stickle, 1989; Pechenik et al. 2003; Li \& Brawley, 2004; Russell \& Phillips, 2009b; Deschaseaux et al. 2011). It appears that when UVR is blocked or is not a factor, temperature becomes the main factor driving embryonic mortality and development (Pechenik et al. 2003; Deschaseaux et al. 2011). Przeslawski et al. (2005) studied the synergistic effects of salinity, temperature and light exposure on the egg masses of intertidal gastropods and found that embryonic mortality increased in tide pool conditions and embryonic development was retarded. All combinations with full spectrum light elevated mortality by 8-12 times in comparison to blocked UV, in which mortality was overall low regardless of temperature and salinity. This study showed that intertidal species are very vulnerable of UVR, especially when other environmental stressors occur at the same time (Przeslawski et al. 2005).

For $S$. australis larvae in this study, the relative importance of egg mass and larval stress was mediated by the specific stressor. For survival, there was no effect of any treatment until 7 days after hatching. From that point on, the biggest effect on larval survival was larval exposure to UV-B. Regardless of what temperature larvae experienced, larval survival was extremely low when 
exposed to UV-B. UVR has been shown to reduce embryonic and/ or larval survivorship for a range of species, including echinoderms (Lesser \& Barry, 2003; Lamare et al. 2004; Nahon et al. 2009), ascidians (Bingham \& Reyns, 1999), fish (Huff et al. 2004; Ylönen et al. 2005; Olson et al. 2006; Sharma et al. 2007; Vehniaeinen et al. 2007), corals (Kuffner, 2001; Wellington \& Fitt, 2003), amphibians (Blaustein et al. 1994; Pahkala et al. 2003; Bancroft et al. 2008; Searle et al. 2009) and algae (Boelen et al. 2000; Bischof et al. 2006; Steinhoff et al. 2008).

Effects of conditions experienced in $S$. australis egg masses were most evident when larvae were shaded from UV-B. For these shaded treatments, larvae exposed to warm temperatures had higher mortality and were smaller when from egg masses that had also been stressed. The role of temperature during larval life stages has been widely recognized. Generally an increase in temperature is associated with a decrease in development time, and faster growth until a threshold temperature has been reached (Martens, 1985; McLaren \& Corkett, 1981; McLaren, et al. 1988; Larez et al. 2000).

There was little effect of brief exposures to elevated temperatures on larval growth, which is consistent with a study by Klinzing and Pechenik (2000); but again there was a strong effect of exposure to UV-B, where larvae periodically exposed to high UV-B were smaller, and increased little in size from hatching. Similar to the results for survival, effects of stress experienced in the egg mass were only evident for larvae shaded from UV-B, when by day 10 larvae from stressed egg masses were smaller than those from unstressed egg masses. Romansic et al. (2009) found that frog larvae were smaller under UVB exposure whereas a study by Pahkala et al. (2003) found that frog tadpole larvae of congeneric species grew larger under short-term exposure to UV-B radiation, suggesting that responses to UV-B are species-specific. Ylönen and Karjalainen (2004) investigated whitefish larvae under enhanced UV-B radiation and concluded that neither survival nor growth was affected by natural 
levels of UV-B radiation. All this suggests that the effects of UV-B on larval growth are complex.

The results for cilia length were complex and subtle; however by day 10 , reductions in cilia length only occurred for larvae that were exposed to UV-B as larvae. Cilia length may be important because it might impact feeding and swimming performance (Braubach et al. 2006; Chan et al. 2008; Richardson, 2002). Swimming performance is an important trait for escaping predators (Richardson, 2002; Strobbe et al. 2010) and possibly better avoidance of environmental stressors near the water surface. Cilia length may also impact on feeding performance with longer cilia resulting in higher feeding rates (Klinzing \& Pechenik, 2000; Kingsley-Smith et al. 2005; Strathmann \& Gruenbaum, 2006). UV-B radiation may thus be potentially having indirect effects on larval performance.

Overall, these results suggest that stress on embryos in the egg mass resulted in sub-lethal damage that increased vulnerability to one stressor (increased temperature) and increased the tolerance to another stressor (UV-B radiation) experienced in the larval stage. This does not support part of my initial hypothesis (UV-B remains supported) that larvae which survived stress in the egg mass would be fitter because weaker larvae may have been culled out by selective mortality.

Carry-over effects of UV-B radiation experienced during embryonic development have become evident in early amphibian life stages. Sublethal damage in the egg mass resulted in malformations, slower growth and development at the larval stage (Blaustein et al. 1994; Smith et al. 2000; Ankley et al. 2002; Belden \& Blaustein, 2002; Pahkala et al. 2002; Romansic et al. 2009). Pahkala et al. (2001) examined UV-B radiation on amphibian embryos and the effects on later larval stages and found that while UV-B had negative effects on embryos in egg masses, the effects did not become evident until later larval stages where development and metamorphosis were delayed and abnormalities in development were frequent. Reduced growth and delayed 
metamorphosis can reduce fitness of juveniles or adults in a variety of marine species and affect population dynamics (Pechenik et al. 2001; Phillips, 2002, 2004).

Sublethal effects often express themselves only in later stages of development (carry-over effects). Therefore, experiments measuring the effects of exposure only in early development after exposure may underestimate the actual impacts of UV-B radiation. It is important to measure possible carry-over effects of stressors on later life stages (particularly metamorphosis and settlement) over a sufficient length of time (Huebner et al. 2006; Croteau et al. 2008). This was not possible in my study due to high mortality of larvae in UV-B treatments after ten days.

\subsubsection{Summary}

In conclusion, UV-B radiation can cause high mortality in embryonic egg masses or have sublethal effects which are carried-over to the next life stage and can affect growth, development, induce malformations and abnormalities, delay metamorphosis, and cause behavioural changes (Smith et al. 2000; Hatch \& Blaustein, 2000; Kats et al. 2000; Belden \& Blaustein, 2002; Pahkala et al. 2003;Bancroft et al. 2008; Croteau et al. 2008; Caldwell et al. 2011). All these effects may impact on the individual, population or community level (Bothwell et al.1994; Mostajir et al. 1999 but see Wahl et al. 2004).

Whether early embryonic stress in the egg mass has carry-over effects or not on later life stages needs to be investigated further. Larval examination until settlement and metamorphosis may show further carry-over effects and impacts on trans-generational population dynamics, and should be examined in future studies. 


\section{CHAPTER 5}

\section{General Discussion}

\subsection{Summary of findings}

Embryos developing in encapsulated egg masses of coastal habitats face a variety of environmental stressors that can cause high mortality by acting separately and/ or simultaneously with each other.

In this study I examined the effects of several common physical stressors in the intertidal and shallow subtidal on the development of encapsulated gastropod embryos. The responses to the individual stressors salinity, temperature and UV-B radiation were species-specific and highly dependent on the level of each stressor and the duration of exposure. Low salinity, high temperature and high UV-B radiation caused elevated embryonic mortality in all intertidal and subtidal egg masses thus potentially affecting species' reproductive success and population dynamics; however the responses to the stressors tended to be greater for the subtidal species. This supports my hypothesis that intertidal species are more tolerant to environmental stressors than subtidal species. My hypothesis that UV-B radiation causes very high embryonic mortality for $S$. australis has also been supported but high temperature was equally damaging.

The effects of chronic exposure were generally higher than periodic exposure for all species, suggesting that embryos may be able to recover from short durations of stress, which commonly occur during low tide. While both intertidal and subtidal egg masses are more frequently exposed to periodic stress than chronic stress, it appears that high intertidal organisms have evolved adaptations to cope with large fluctuations in abiotic conditions (Pechenik, 1982; Podolsky \& Hofmann, 1998; Wraith et al. 2006; Chaparro et al. 2008). 
Previous research shows that while environmental stressors can cause embryonic mortality in species from the high intertidal, embryonic mortality is generally higher for species inhabiting the lower shore (Przeslawski, 2004; Deschaseaux et al. 2010). Species-specific tolerance levels of adults to different stressors have been shown to contribute to the vertical distribution of species on rocky shores (Connell 1961b; Paine \& Levin, 1981).

While impacts of stressors can be directly observed through an increase in embryonic mortality, the effects of elevated but sub-lethal stressors became apparent as the time for larvae to hatch generally increased for most species. Hatching times generally increased in stressful conditions, including UV-B radiation and low salinity, for all species. This is contrary to previous research suggesting that embryonic development time decreases as temperature increases (Spight, 1975; Watt \& Aiken, 2003). It also supports the theory that encapsulation time of embryos should reflect rates of mortality in embryonic stages (Pechenik, 1979; Chaparro et al. 2008).

S. australis was highly susceptible to UV-B radiation and had high embryonic mortality in response to both short-term and long-term exposure. UV-B radiation not only increased mortality in egg masses but also affected the hatching success of larvae. Although embryonic mortality increased in high UV$B$ radiation, a small proportion of embryos in egg masses of the intertidal species continued development and hatched as larvae. These results illustrate the embryonic resilience to stress for species in the high intertidal.

A lack of empirical research exists for determining the effects of stressors at different times of embryonic development. In this study, the response of embryos to low salinity at different times during early development was species-specific for subtidal species but had no effect on the intertidal species. High temperature and high UV-B both caused highest embryonic mortality during the very early stages of embryonic development for both intertidal and subtidal species, being particularly damaging during the first day 
after spawning. This solidifies the idea that early development in encapsulated gastropod egg masses is highly vulnerable to environmental stressors.

Previous research has suggested that later embryos of marine invertebrates exhibit higher tolerance to heat stress and UV-B radiation than early embryos, as they are capable of inducing heat shock proteins to cope with thermal stress and may have higher concentrations of mycosporine-like amino acids (MAAs) that act as screening compounds against UVR (Carefoot et al. 1998; Adams \& Shick, 2001; Wraith et al. 2006).

Simultaneous stressors caused higher embryonic mortality together than as single stressors. Low salinity caused higher embryonic mortality in subtidal species than intertidal species. When combined with high temperature, the response was magnified, suggesting that salinity and temperature stress act synergistically. This supports recent studies which suggest that by examining environmental stressors on their own, possible synergistic effects between multiple stressors can be underestimated (Sih et al. 2004; Przeslawski et al. 2005; Bancroft et al. 2008; Russell \& Phillips, 2009a). The relationship between multiple stressors experienced in early life stages and later life stages is complex; this study has tried to increase the understanding of how sublethal stress during embryonic development affects susceptibility to stress in larval stages. Effects of sublethal stress in the egg mass were delayed and not immediately detectable at hatching. While this study found little or no effects of stressors during early life stages on the larval size at hatching, hatching size and growth during early development has been shown to have important impacts on the susceptibility to predation or starvation during the larval stage (Moloney et al. 1994).

Carry-over effects became apparent through time but whether previously stressed embryos were more or less vulnerable to stress in larval stages was dependent on the stressor, as stress experienced during embryonic development increased vulnerability to one stressor while the tolerance of larvae to another stressor increased. This did not fully support my initial 
hypothesis that larvae surviving stressful conditions during embryonic development would be fitter than larvae which did not experience stress during embryonic development.

Carry-over effects of sublethal stressors in early life stages have been identified for a large range of species including invertebrates, amphibians, fish, birds and mammals (Pechenik et al. 1998; Qiu \& Qian, 1999; Pahkala et al. 2003; Norris, 2005; Norris \& Taylor, 2006; Harrison et al. 2011). I have demonstrated that links between early and later developmental stages in intertidal gastropods with encapsulated embryos do exist and interactions between simultaneous stressors are complex.

\subsection{Further directions}

This study has demonstrated that environmental stressors affect early embryonic development and larval stages and has determined that responses to single and multiple stressors are species-specific. The seasonality of egg mass deposition varied between species used in this research and made it difficult to compare the effects on intertidal and subtidal encapsulated embryos further due to time constraints; more intertidal and subtidal species need to be examined to establish whether there are general trends of differences between egg masses from different coastal habitats in response to specific environmental stressors.

Low salinity caused relatively high embryonic mortality for all species examined in this research, whereas high salinity has had little effect for the intertidal $S$. australis as a stressor on its own. During a preliminary study on the effects of Instant Ocean $₫$ sea salt, embryos in intertidal egg masses could withstand extremely high salinity over a short period time. It may therefore be of interest to further explore threshold levels for intertidal species which have proven to be generally more tolerant to periodic exposure to salinity and temperature extremes than subtidal species. 
I have shown that very early embryonic stages of development in egg masses are highly vulnerable to various stressors. While this study has suggested that day 1 after spawning is most vulnerable to environmental stress, this should be investigated further to determine why this stage is more vulnerable to stressors than other.

Although the larval life stage for $S$. australis was affected by temperature and UV-B radiation, whether larvae are most vulnerable to stress during a certain time has yet to be further explored. Larvae were only periodically exposed to temperature and UV-B radiation stress (4 hours daily) in this research whereas both stressors can naturally occur in coastal waters over longer periods of time on hot cloudless days and the effects of these factors may be underestimated here. During events of rain larvae can also be exposed to decreased salinity and the effects of multiple combinations of stressors should thus be explored. Previous research has shown that stress experienced during early larval stages may affect the ability to settle and metamorphose as well as adult performance (Qiu \& Qian, 1999; Diederich et al. 2011; Tauchman \& Pomorya, 2011), therefore further research should focus on carry-over effects until adulthood which was not possible in this study due to time constraints and high mortality rates of larvae in stressful conditions.

I have suggested that stress experienced in the egg mass will affect the susceptibility to one stressor during larval development but increased the tolerance to another. While this suggests a complex relationship between early life stages of intertidal gastropods, the effects of different stressors and their simultaneous effects through development to adult performance remain yet to be explored. 


\section{REFERENCES}

Adams, N. L., \& Shick, J. M. (2001). Mycosporine-like amino acids prevent UVB-induced abnormalities during early development of the green sea urchin Strongylocentrotus droebachiensis. Marine Biology, 138, 267280.

Allen, J. D. (2008). Size-Specific Predation on Marine Invertebrate Larvae. Biological Bulletin, 214(1), 42-49.

Allen, J. D., \& Pechenik, J. A. (2010). Understanding the Effects of Low Salinity on Fertilization Success and Early Development in the Sand Dollar Echinarachnius parma. Biological Bulletin, 218, 189-199.

Anger, K., \& Dawirs, R. (1981). Influence of starvation on the larval development of Hyas araneus (Decapcda, Majidae). Helgolaender Meeresuntersuchungen, 34, 287-311.

Anil, A. C., Chiba, K., Okamoto, K., \& Kurokura, H. (1995). Influence of temperature and salinity on larval development of Balanus amphitrite: implications in fouling ecology. Marine Ecological Progress Series, 118, 159-166.

Anil, A. C., Desai, D. V., \& Khandeparker, L. (2001). Larval development and metamorphosis in Balanus amphitrite Darwin (Cirripedia; Thoracica) : significance of food concentration, temperature and nucleic acids. Journal of Experimental Marine Biology and Ecology, 263, 125-141.

Ankley, G. T., Diamond, S. A., Tietge, J. E., Holcombe, G. W., Jensen, K. M., Defoe, D. L., et al. (2002). Assessment of the Risk of Solar Ultraviolet Radiation to Amphibians. I. Dose-Dependent Induction of Hindlimb Malformations in the Northern Leopard Frog (Rana pipiens). Environment, Science and Technology, 36, 2853-2858. 
Bancroft, B. A., Baker, N. J., \& Blaustein, A. R. (2008). A Meta-Analysis of the Effects of Ultraviolet B Radiation and Its Synergistic Interactions with $\mathrm{pH}$, Contaminants, and Disease on Amphibian Survival. Conservation Biology, 22(4), 987-996.

Barry, J. P., Baxter, C. H., Sagarin, R. D., \& Gilman, S. E. (2008). ClimateRelated, Long-Term Faunal Changes in a California Rocky Intertidal Community. Science.

Belden, L. K., \& Blaustein, A. R. (2002). Population Differences in Sensitivity to UV-B Radiation for Larval Long-Toed Salamanders. Ecology, 83(6), 1586-1590.

Belden, L. K., \& Blaustein, A. R. (2002). UV-B Induced Skin Darkening in Larval Salamanders Does Not Prevent Sublethal Effects of Exposure on Growth. Copeia, 2002(3), 748-754.

Bender, E. A., Case, T. J., \& Gilpin, M. E. (1984). Perturbation Experiments in Community Ecology: Theory and Practice. Ecology, 65(1), 1-13.

Benedettic-Cecchi, L. (2006). Understanding the consequences of changing biodiversity on rocky shores: How much have we learned from the past experiments? Journal of Experimental Marine Biology and Ecology, 338, 193-204.

Benkendorff, K., Davis, A., \& Bremner, J. B. (2001). Chemical Defense in the Egg Masses of Benthic Invertebrates: An Assessment of Antibacterial Activity in 39 Mollusks and 4 Polychaetes. Journal of Invertebrate Pathology, 78, 109-118. 
Beuchel, F., Gulliksen, B., \& Carroll, M. L. (2006). Long-term patterns of rocky bottom macrobenthic community structure in an Arctic fjord (Kongsfjorden, Svalbard) in relation to climate variability (1980-2003). Journal of Marine Systems, 63, 35-48.

Biermann, C. H., Schinner, G. O., \& Strathmann, R. R. (1992). Influence of solar radiation, microalgal fouling, and current on deposition site and survival of embryos of a dorid nudibranch gastropod. Marine Ecological Progress Series, 86, 205-215.

Bingham, B. L., \& Reyns, N. B. (1999). Ultraviolet Radiation and Distribution of the Solitary Ascidian Corella inflata (Huntsman). Biological Bulletin, 196, 94-104.

Bischof, K., Gomez, I., Molis, M., Hanelt, D., Karsten, U., Lueder, U., et al. (2006). Ultraviolet radiation shapes seaweed communities. Reviews in Environmental Science and Biotechnology, 5, 141-166.

Bischof, K., Hanelt, D., \& Wiencke, C. (1998). UV-radiation can affect depthzonation of Antarctic macroalgae. Marine Biology, 131, 597-605.

Blaustein, A. R., \& Belden, L. K. (2003). Amphibian defenses against ultraviolet-B radiation. Evolution \& Development, 5(1), 89-97.

Blaustein, A. R., Hoffman, P. D., Hokit, D. G., Kiesecker, J. M., Walls, S. C., \& Hays, J. B. (1994). UV Repair and Resistance to Solar UV-B in Amphibian Eggs: A Link to Population Declines? Proceedings of the Academy of Natural Sciences, 91(5), 1791-1795.

Blaustein, A. R., Kiesecker, J. M., Chivers, D. P., \& Anthony, R. G. (1997). Ambient UV-B Radiation Causes Deformities in Amphibian Embryos. Proceedings of the Academy of Natural Sciences, 94(25), 13735-13737. 
Blaustein, A. R., Kiesecker, J. M., Chivers, D. P., Hokit, D. G., Marco, A., Belden, L. K., et al. (1998). Effects of Ultraviolet Radiation on Amphibians: Field Experiments. American Zoologist, 38(6), 799-812.

Boelen, P., de Boer, K. M., Kraay, G. W., Veldhuis, M. J. W., \& Buma, A. G. J. (2000). UVBR-induced DNA damage in natural marine picoplankton assemblages in the tropical Atlantic Ocean. Marine Ecological Progress Series, 193, 1-9.

Bonaventura, R., Poma, V., Russo, R., Zito, F., \& Matranga, V. (2006). Effects of UV-B radiation on development and hsp70 expression in sea urchin cleavage embryos. Marine Biology, 149, 79-86.

Booth, C. R., Morrow, J. H., Coohill, T. P., Cullen, J. J., Frederick, J. E., Haeder, D.-P., et al. (1997). Impacts of Solar UVR on Aquatic Microorganisms. Photochemical and Photobiology, 65(2), 252-269.

Bothwell, M. L., Sherbot, D. M. J., \& Pollock, C. M. (1994). Ecosystem response to solar ultraviolet-B radiation: influence of trophic level interactions. Science, 265, 97-100.

Braubach, O. R., Dickinson, A. J. G., Evans, C. C. E., \& Croll, R. P. (2006). Neural control of the velum in larvae of the gastropod, Ilyanassa obsoleta. The Journal of Experimental Biology, 209, 4676-4689.

Brennand, H. S., Soars, N., Dworjanyn, S. A., Davis, A., \& Byrne, M. (2010). Impact of Ocean Warming and Ocean Acidification on Larval Development and Calcification in the Sea Urchin Tripneustes gratilla. PLOS ONE, 5(6), e11372.

Brierley, A. S., \& Kingsford, M. J. (2009). Impacts of Climate Change on Marine Organisms and Ecosystems. Current Biology, 19, R602-R614. 
Bryars, S. R., \& Havenhand, J. N. (2006). Effects of constant and varying temperatures on the development of blue swimmer crab (Portunus pelagicus) larvae: Laboratory observations and field predictions for temperate coastal waters. Journal of Experimental Marine Biology and Ecology, 329, 218-229.

Caldwell, G. S., Lewis, C., Pickavance, G., Taylor, R. L., \& Bentley, M. G. (2011). Exposure to copper and a cytotoxic polyunsaturated aldehyde induces reproductive failure in the marine polychaete Nereis virens (Sars). Aquatic Toxicology, 104, 126-134.

Cancino, J. M., Gallardo, J. A., \& Torres, F. A. (2003). Combined effects of dissolved oxygen concentration and water temperature on embryonic development and larval shell secretion in the marine snail Chorus giganteus (Gastropoda: Muricidae). Marine Biology, 142, 133-139.

Carefoot, T. H., Harris, M., Taylor, B. E., Donovan, D., \& Karentz, D. (1998). Mycosporine-like amino acids: possible UV protection in eggs of the sea hare Aplysia dactylomela. Marine Biology, 130, 389-396.

Castanaga, L. A., Asorey, C. M., Sandoval, M. T., Perez-Coll, C. S., Argibay, T. I., \& Herkovits, J. Stage-Dependent Teratogenic and Lethal Effects Exerted by Ultraviolet B Radiation on Rhinella (Bufo) arenarum Embryos. Environmental Toxicology and Chemistry, 28(2), 427-433.

Castanaga, L. A., Asorey, C. M., Sandoval, M. T., Perez-Coll, C. S., Argibay, T. I., \& Herkovits, J. (2009). Stage-Dependent Teratogenic and Lethal Effects Exerted by Ultraviolet B Radiation on Rhinella (Bufo) arenarum Embryos. Environmental Toxicology and Chemistry, 28(2), 427-433.

Caswell, H. (1981). The Evolution of "Mixed" Life Histories in Marine Invertebrates and Elsewhere. The American Naturalist, 117(4), 529-536. 
Chaffee, C., \& Strathmann, R. R. (1984). Constraints on Egg Masses. I. Retarded Development Within Thick Egg Masses. Journal of Experimental Marine Biology and Ecology, 84, 73-83.

Chambers, R. J., \& McQuaid, C. D. (1994a). African Species of the Intertidal Limpet Siphonaria (Gastropoda, Pulmonata). Journal of Molluscan Studies, 60, 263-275.

Chambers, R. J., \& McQuaid, C. D. (1994b). A Review of Larval Development in the Intertidal Limpet Genus Siphonaria (Gastropoda: Pulmonata). Journal of Molluscan Studies, 60, 415-423.

Chan, H. Y., Xu, W. Z., Shin, P. K., \& Cheung, S. G. (2008). Prolonged exposure to low dissolved oxygen affects early development and swimming behaviour in the gastropod Nassarius festivus (Nassariidae). Marine Biology, 153, 735-743.

Chaparro, O. R., Cubillos, V. M., Montiel, Y. A., Paschke, K. A., \& Pechenik, J. A. (2008). Embryonic encapsulation and maternal incubation: Requirements for survival of the early stages of the estuarine gastropod Crepipatella dilatata. Journal of Experimental Biology and Ecology, 365(1), 38-45.

Clemens-Seely, K., \& Phillips, N. E. (2011). Effects of Temperature on Hatching Time and Hatchling Proportions in a Poecilogonous Population of Haminoea zelandiae. Biological Bulletin, 221, 189-196.

Coglianese, M. P. (1982). The effects of salinity on copper and silver toxicity to embryos of the Pacific Oyster. Archives of Environmental Contamination and Toxicology, 11(3), 297-303. 
Coglianese, M. P., \& Martin, M. (1981). Individual and interactive effects of environmental stress on the embryonic development of the Pacific oyster, Crassostrea gigas. I. The toxicity of copper and silver. Marine Environmental Research, 5(1), 13-27.

Collin, R. (2003). Worldwide patterns of in mode of development in calyptraeid gastropods. Marine Ecological Progress Series, 247, 103-122.

Connell, J. H. (1961b). The Influence of Interspecific Competition and Other Factors on the Distribution of the Barnacle Chthamalus stellatus. Ecology, 42(4), 710-723.

Cook, S. d. C. (2010). New Zealand Coastal Marine Invertebrates (Vol. 1). Christchurch: Canterbury University Press.

Costlow, J. D., Bookhout, C. G., \& Monroe, R. (1960). The Effect of Salinity and Temperature on Larval Development of Sesarma cinereum (Bosc) Reared in the Laboratory. Biological Bulletin, 118(2), 183-202.

Creese, R. G. (1980). Reproductive Cycles and Fecundities of Two Species of Siphonaria (Mollusca: Pulmonata) in South-eastern Australia. Australian Journal of Marine and Freshwater Research, 31, 37-47.

Croteau, M. C., Davidson, M. A., Lean, D. R. S., \& Trudeau, V. L. (2008). Global Increases in Ultraviolet B Radiation: Potential Impacts on Amphibian Development and Metamorphosis. Physiological and Biochemical Zoology, 81(6), 743-761.

Dahlhoff, E., Stillman, J. H., \& Menge, B. A. (2002). Physiological Community Ecology: Variation in Metabolic Activity of Ecologically Important Rocky Intertidal Invertebrates Along Environmental Gradients. Integrative and Comparative Biology, 42, 862-871. 
Davis, M. (2000). The Combined Effects of Temperature and Salinity on Growth, Development, and Survival for Tropical Gastropod Veligers of Strombus gigas. Journal of Shellfish Research, 19(2), 883-889.

Dayton, P. K. (1971). Competition, Disturbance, and Community Organization: The Provision and Subsequent Utilization of Space in a Rocky Intertidal Community. Ecological Monographs, 41(4), 351-389.

Deschaseaux, E., Taylor, A., \& Maher, W. (2011). Measure of stress response induced by temperature and salinity changes on hatched larvae of three marine gastropod species. Journal of Experimental Marine Biology and Ecology, 397, 121-128.

Deschaseaux, E. S. M., Taylor, A. M., \& David, A. R. (2010). Cellular responses of encapsulated gastropod embryos to multiple stressors associated with climate change. Journal of Experimental Biology and Ecology, 383(2), 130-136.

Diederich, C. M., Jarrett, J. N., Chaparro, O. R., Segura, C. J., Arellano, S. M., \& Pechenik, J. A. (2011). Low salinity stress experienced by larvae does not affect post-metamorphic growth or survival in three calyptraeid gastropods. Journal of Experimental Marine Biology and Ecology, 397, 94-105.

Downes, A., \& Blunt, T. P. (1877). Researches on the effect of light upon bacteria and other organisms Proceedings of the Royal Society of London, 26, 488-500.

Eales, N. B. (1960). Revision of the world species of Aplysia (Gastropoda, Opisthobranchia) Bulletin of the British Museum (Natural History), 5(10), 267-404. 
Epel, D., Hemela, K., Shick, M., \& Patton, C. (1999). Development in the Floating World: Defenses of Eggs and Embryos against Damage from UV Radiation American Zoologist, 39(2), 271-278.

Etter, R. J. (1989). Life History Variation in the Intertidal Snail Nucella lapillus Across a Wave-Exposure Gradient. Ecology, 70(6), 1857-1876.

Finke, G., Navarrete, S. A., \& Bozinovic, F. (2007). Tidal regimes of temperate coasts and their influences on aerial exposure for inertidal organisms. Marine Ecology Progress Series, 343, 57-62.

Garton, D., \& Stickle, W. B. (1980). Effects of Salinity and Temperature on the Predation Rate of Thais haemastoma on Crassostrea virginica Spat. Biological Bulletin, 158(1), 49-57.

Gaudy, R., Guerin, J. P., \& Moraitou-Apostolopoulou, M. (1982). Effect of Temperature and Salinity on the Population Dynamics of Tisbe Holothuriae Humes (Copepoda: Harpacticoida) fed on two different Diets. Journal of Experimental Biology and Ecology, 57, 257-271.

Gibson, G. D. (2003). Larval Development and Metamorphosis in Pleurobranchaea maculata, With a Review of Development in the Notaspidea (Opisthobranchia). Biological Bulletin, 205, 121-132.

Godley, B. J., Broderick, A. C., Downie, J. R., Glen, F., Houghton, J. D., Kirkwood, I., et al. (2001). Thermal conditions in nests of loggerhead turtles: further evidence suggesting female skewed sex ratios of hatchling production in the Mediterranean. Journal of Experimental Marine Biology and Ecology, 263, 45-63. 
Gosselin, L. A., \& Chia, F.-S. (1995). Characterizing temperate rocky shores from the perspective of an early juvenile snail: the main threats to survival of newly hatched Nucella emarginata. Marine Biology, 122, 625635.

Green, B. S., \& Fisher, R. (2004). Temperature influences swimming speed, growth and larval duration in coral reef fish larvae. Journal of Experimental Biology and Ecology, 299, 115-132.

Grubert, M. A., \& Ritar, A. J. (2004a). The effect of temperature on the embryonic and larval development of blacklip (Haliotis rubra) and greenlip ( $H$. laevigata) abalone. Invertebrate Reproduction and Development, 45(3), 197-203.

Grubert, M. A., \& Ritar, A. J. (2004b). Temperature effects on the dynamics of gonad and oocyte development in captive wild-caught blacklip (Haliotis rubra) and greenlip (H. laevigata) abalone. Invertebrate Reproduction and Development, 45(3), 197-203.

Häder, D.-P. (2011). Does Enhanced Solar UV-B Radiation Affect Marine Primary Producers in Their Natural Habitats? Photochemistry and Photobiology, 87, 263-266.

Häder, D.-P., Helbling, E. W., Williamson, C. E., \& Worrest, R. C. (2011). Effects of UV radiation on aquatic ecosystems and interactions with climate change. Photochemistry and Photobiology Science, 10, 242-262.

Häder, D.-P., Kumar, H. D., Smith, R. C., \& Worrest, R. C. (1998). Effects on aquatic ecosystems. Journal of Photochemistry and Photobiology $B$ : Biology, 46, 53-68. 
Häder, D.-P., Kumar, H. D., Smith, R. C., \& Worrest, R. C. (2007). Effects of solar UV radiation on aquatic ecosystems and interactions with climate change. Photochemical and Photobiological Sciences, 6, 267-285.

Harrison, X. A., Blount, J. D., Inger, R., Norris, D. R., \& Bearhop, S. (2011). Carry-over effects as drivers of fitness differences in animals. Journal of Animal Ecology, 80, 4-18.

Hatch, A. C., \& Blaustein, A. R. (2000). Combined Effects of UV-B, Nitrate, and Low pH Reduce the Survival and Activity Level of Larval Cascades Frogs (Rana cascadae). Archives of Environmental Contamination and Toxicology, 39, 494-499.

Haug, T., Kjuul, A. K., Styrvold, O. B., Sandsdalen, E., Olsen, O. M., \& Stensvag, K. (2002). Antibacterial activity in Strongylocentrotus droebachiensis (Echinoidea), Cucumaria frondosa (Holothuroidea), and Asterias rubens (Asteroidea). Journal of Invertebrate Pathology, 81, 94102.

Hockberger, P. E. (2002). A History of Ultraviolet Photobiology for Humans, Animals and Microorganisms. Photochemistry and Photobiology, 76(6), 561-579.

Hoegh-Guldberg, O., \& Pearse, J. S. (1995). Temperature, Food Availability, and the Development of Marine Invertebrate Larvae. American Zoologist, 35(4), 415-425.

Hu, M., Li, Q., \& Li, L. (2010). Effect of salinity and temperature on salinity tolerance of the sea cucumber Apostichopus japonicus. Fisheries Science, 76, 267-273. 
Huang, X., Huang, L., Li, Y., Xu, Z., Fong, C. W., Huang, D., et al. (2006). Main seagrass beds and threats to their habitats in the coastal sea of South China. Chinese Science Bulletin, 51(2), 136-142.

Huebner, J. D., Young, D. L. W., Loadman, N. L., Lentz, V. J., \& Wiegand, M. D. (2006). Age-Dependent Survival, Reproduction and Photorepair Activity in Daphnia magna (Straus, 1820) After Exposure to Artificial Ultraviolet Radiation. Photochemistry and Photobiology, 82, 1656-1661.

Huff, D. D., Grad, G., \& Williamson, C. E. (2004). Environmental Constraints on Spawning Depth of Yellow Perch: The Roles of Low Temperature and Higher Solar Ultraviolet Radiation. Transactions of the American Fisheries Society, 133, 718-726.

Hutton, F. W. (1874). Description of two new species of Aplysia. Transactions of the Royal Society of New Zealand, 7, 279.

IPCC. (2007). Climate Change 2007: Synthesis Report. Geneva, Switzerland.

Karentz, D., \& Lutze, L. H. (1990). Evaluation of Biologically Harmful Ultraviolet Radiation in Antarctica with a Biological Dosimeter Designed for Aquatic Environments. Limnology and Oceanography, 35(3), 549-561.

Kats, L. B., Kiesecker, J. M., Chivers, D. P., \& Blaustein, A. R. (2000). Effects of UV-B Radiation on Anti-predator Behavior in Three Species of Amphibians. Ethology, 106, 921-931.

Kaurola, J., Taalas, P., Koskela, T., Borkowski, J., \& Josefsson, W. (2000). Long-term variation of UV-B doses at three stations in northern Europe. Journal of Geophysical Research, 105(D16), 20,813-820,820. 
Kazlauskiene, N., \& Stasiunaite, P. (1999). The Lethal and Sublethal Effect of Heavy Metal Mixture on Rainbow Trout (Oncorhynchus Mykiss) in its Early Stages of Development. Acta Zoologica Lituanica Hydrobiologica, 9(2), 47-55.

Kempf, S. C. (1981). Long- Lived Larvae of the Gastropod Aplysia juliana: Do They Disperse and Metamorphose or Just Slowly Fade Away? Marine Ecology Progress Series, 6, 61-65.

Kennedy, V. S., Roosenburg, W. H., Zion, H. H., \& Castagna, M. (1974). Temperature-Time Relationships for Survival of Embryos and Larvae of Mulinia lateralis (Mollusca: Bivalvia). Marine Biology, 24, 137-145.

Keough, M. J., \& Quinn, G. P. (1998). Effects of Periodic Disturbances from Trampling on Rocky Intertidal Algal Beds. Ecological Applications, 8, 141-161.

Kingsley-Smith, P. R., Richardson, C. A., \& Seed, R. (2005). Growth and development of the veliger larvae and juveniles of Polinices pulchellus (Gastropoda: Naticidae). Journal of the Marine Biological Association, 85, 171-174.

Klinzing, M. S., \& Pechenik, J. A. (2000). Evaluating whether velar lobe size indicates food limitation among larvae of the marine gastropod Crepidula fornicata Journal of Experimental Biology, 252, 255-279.

Kuffner, I. B. (2001). Effects of ultraviolet (UV) radiation on larval settlement of the reef coral Pocillopora damicornis. Marine Ecology Progress Series, 217, 251-261.

Lake, P. S. (2000). Disturbance, patchiness, and diversity in streams. Journal of the North American Benthological Society, 19(4), 573-592. 
Lamare, M. D., Barker, M. F., \& Lesser, M. P. (2007). In situ rates of DNA damage and abnormal development in Antarctica and non-Antarctic sea urchin embryos. Aquatic Biology, 1(1), 21-32.

Lamare, M. D., \& Hoffmann, J. (2004). Natural variation of carotenoids in the eggs and gonads of the echinoid genus, Strongylocentrotus: implications for their role in ultraviolet radiation photoprotection. Journal of Experimental Marine Biology and Ecology, 312, 215-233.

Lamare, M. D., Lesser, M. P., Barry, T. M., \& Schimanski, K. B. (2004). Variation in sunscreen compounds (mycosporine-like amino acids) for marine species along a gradient of ultraviolet radiation transmission within Doubtful Sound, New Zealand. New Zealand Journal of Marine and Freshwater Research, 38, 775-793.

Larez, M. B., Palazon-Fernandez, J. L., \& Bolanos, C. J. (2000). The effect of salinity and temperature on the larval development of Mithrax caribbaeus Rathbun, 1920 (Brachyura: Majidae) reared in the laboratory. Journal of Plankton Research, 22(10), 1855-1869.

Lee, H.-W., Ban, S., Ikeda, T., \& Matsuishi, T. (2003). Effect of temperature on development, growth and reproduction in the marine copepod Pseudocalanus newmani at satiating food condition. Journal of Plankton Research, 25(3), 261-271.

Lesser, M. P., \& Barry, T. M. (2003). Survivorship, development, and DNA damage in echinoderm embryos and larvae exposed to ultraviolet radiation (290-400nm). Journal of Experimental Marine Biology and Ecology, 292, 75-91. 
Lesser, M. P., Barry, T. M., Lamare, M. D., \& Barker, M. F. (2006). Biological weighting functions for DNA damage in sea urchin embryos exposed to ultraviolet radiation. Journal of Experimental Marine Biology and Ecology, 328, 10-21.

Lesser, M. P., Kruse, V. A., \& Barry, T. M. (2003). Exposure to ultraviolet radiation causes apoptosis in developing sea urchin embryos. The Journal of Experimental Biology, 206, 4097-4103.

Lesser, M. P., Lamare, M. D., \& Barker, M. F. (2004). Transmission of ultraviolet radiation through the Antarctic annual sea ice and its biological effects on sea urchin embryos. Limnology and Oceanography, 49(6), 1957-1963.

Levin, L. A. (1984). Life History and Dispersal Patterns in a Dense Infaunal Polychaete Assemblage: Community Structure and Response to Disturbance. Ecology, 65(4), 1185-1200.

Li, R., \& Brawley, S. H. (2004). Improved survival under heat stress in intertidal embryos (Fucus spp.) simultaneously exposed to hypersalinity and the effect of parental thermal history. Marine Biology, 144, 205-213.

Little, C., Pilkington, M. C., \& Pilkington, J. B. (1984). Development of Salinity Tolerance in the Marine Pulmonate Amphibola crenata (Gmelin). Journal of Experimental Biology and Ecology, 74, 169-177.

Liu, S., Zhang, Q. S., Wang, Y., Ju, Q., \& Tang, X. (2008). The response of the early developmental stages of Laminaria japonica to enhanced ultraviolet-B radiation. Science in China Series C: Life Sciences, 51(12), 1129-1136. 
Madronich, S., McKenzie, R., Bjorn, L. O., \& Caldwell, M. M. (1998). Changes in biologically active ultraviolet radiation reaching the Earth's surface. Journal of Photochemistry and Photobiology B: Biology, 46, 5-19.

Marshall, D. J., \& Keough, M. J. (2003a). Variation in the dispersal potential of non-feeding invertebrate larvae: the desperate larva hypothesis and larval size. Marine Ecological Progress Series, 255, 145-153.

Marshall, D. J., \& Keough, M. J. (2004). Variable effects of larval size on postmetamorphic performance in the field. Marine Ecology Progress Series, 279, 73-80.

Marshall, D. J., \& Keough, M. J. (2006). Complex life cycles and offspring provisioning in marine invertebrates. Integrative and Comparative Biology, 46(5), 643-651.

Marshall, D. J., Pechenik, J. A., \& Keough, M. J. (2003). Larval activity levels and delayed metamorphosis affect post-larval performance in the colonial ascidian Diplosoma listerianum. Marine Ecology Progress Series, 246, 153-162.

Marshall, N. A., \& Bailey, P. C. (2004). Impact of secondary salinastion on freshwater ecosystem: effects of contrasting, experimental, short-term releases of saline wastewater on macroinvertebrates in a lowland stream. Marine and Freshwater Research, 55, 509-523.

Martens, K. (1985). Effects of Temperature and Salinity on Postembryonic Growth in Mytilocypris henricae (Chapman) (Crustacea, Ostracoda). Journal of Crustacean Biology, 5(2), 258-272.

McDonald, B. G., \& Chapman, P. M. (2002). PAH phototoxicity- an ecologically irrelevant phenomenon? Marine Pollution Bulletin, 44, 1321-1326. 
McDonald, K. A., \& Gruenbaum, D. (2011). Swimming Performance in Early Development and the "Other" Consequences of Egg Size for Ciliated Planktonic Larvae. Integrative and Comparative Biology, 50(4), 589-605.

McKenzie, R., Bodeker, G., Scott, G., Slusser, J., \& Lantz, K. (2006).

Geographical differences in erythemally-weighted UV measured at midlatitude USDA sites. Photochemical and Photobiological Sciences, 5, 343-352.

McKenzie, R., Paulin, K. J., \& Kotkamp, M. (1997). Erythemal UV Irradiances at Lauder, New Zealand: Relationship between Horizontal and Normal Incidence. Photochemistry and Photobiology, 66(5), 683-689.

McLaren, I. A., \& Corkett, C. J. (1981). Temperature-dependent growth and the production by a marine copepod. Canadian Journal of Fisheries and Aquatic Science, 38, 78-83.

McLaren, I. A., Seviguy, J. M., \& Corkett, C. J. (1988). Body sizes, development rates, and genome sizes among Calanus species. Hydrobiologia, 167/168, 275-284.

McMahon, R. F. (2003). Acute hypo- and hypersaline activity responses relative to zonation of intertidal rocky shore and mangrove gastropods from the Burrup Peninsula, Western Australia. In F. E. Wells, D. I. Walker \& D. S. Jones (Eds.), The Marine Flora and Fauna of Dampier, Western Australia: Western Australian Museum, Perth.

Menge, B. A., Olson, A. M., \& Dahlhoff, E. (2002). Environmental Stress, Bottom-up Effects, and Community Dynamics: Integrating Molecular and Ecological Approaches. Integrative and Comparative Biology, 42, 892908. 
Metaxas, A., \& Scheibling, R. E. (1993). Community structure and organization of tidepools. Marine Ecology Progress Series, 98, 187-198.

Metaxas, A., \& Young, C. M. (1998). Behaviour of echinoid larvae around sharp haloclines: effects of the salinity gradient and dietary conditioning. Marine Biology, 131, 443-459.

Miliou, H., \& Moraitou-Apostolopoulou, M. (1991). Combined effects of temperature and salinity on the population dynamics of Tisbe holothuriae Humes (Copepoda: Harpacticoida). Arch. Hydrobiol., 121(4), 431-448.

Mita, M., Uehara, T., \& Nakamura, M. (2007). Effect of temperature on interactions between eggs and spermatozoa in four closely related species of sea urchins of the genus Echinometra. Invertebrate Reproduction and Development, 50(4), 181-185.

Moloney, C. L., Botsford, L. W., \& Largier, J. L. (1994). Development, survival and timing of metamorphosis of planktonic larvae in a variable environment: the Dungeness crab as an example. Marine Ecology Progress Series, 113, 61-79.

Moran, A. L., \& Emlet, R. B. (2001). Offspring Size and Performance in Variable Environments: Field Studies on a Marine Snail. Ecology, 82(6), 1597-1612.

Morgan, M. B., \& Cowlesb, D. L. (1997). The effects of temperature on the behaviour and physiology of Phataria unifascialis (Gray) (Echinodermata, Asteroidea) Implications for the species' distribution in the Gulf of California, Mexico. Journal of Experimental Marine Biology and Ecology, 208(1-2), 13-27.

Morley, M. S. (2004). A Photographic Guide to Seashells of New Zealand. Auckland, NZ: New Holland Publishers (NZ) Ltd. 
Mostajir B., Demers S., de Mora S., Belzile C., Chanut J.-P., Gosselin M., et al. (1999). Experimental test of the effect of ultraviolet-B radiation in a planktonic community. Limnology and Oceanography, 44, 586-596.

Nahon, S., Castro Porras, V. A., Pruski, A. M., \& Charles, F. (2009). Sensitivity to UV radiation in early life stages of the Mediterranean sea urchin Sphaerechinus granularis (Lamarck). Science of The Total Environment, 407(6), 1892-1900.

Nahon, S., Charles, F., Lantoine, F., Vetion, G., Escoubeyrou, K., Desmalades, M., et al. (2010). Ultraviolet radiation negatively affects growth and food quality of the pelagic diatom Skeletonema costatum. Journal of Experimental Marine Biology and Ecology, 383, 164-170.

NIWA. (2009). National Climate Summary.

Norris, D. R. (2005). Carry-over effects and habitat quality in migratory populations. Oikos, 109, 178-186.

Norris, D. R., \& Taylor, C. M. (2006). Predicting the consequences of carry-over effects for migratory populations. Biological Letters, 2, 148-151.

Olson, M. H., Colip, M. R., Gerlach, J. S., \& Mitchell, D. L. (2006). Quantifying Ultraviolet Radiation Mortality Risk in Bluegill Larvae: Effects of Nest Location. Ecological Applications, 16(1), 328-338.

Pahkala, M., Laurila, A., \& Merila, J. (2003). Effects of ultraviolet-B radiation on behaviour and growth of three species of amphibian larvae. Chemosphere, 51.

Pahkala, M., Laurila, A., \& Merilae, J. (2001). Carry-over effects of ultraviolet-B radiation on larval fitness in Rana temporaria. Proceedings of the Royal Society of London, 268, 1699-1706. 
Pahkala, M., Rasanen, K., Laurila, A., Johanson, U., Bjorn, L. O., \& Merila, J. (2002). Lethal and Sublethal Effects of UV-B/ pH Synergism on Common Frog Embryos. Conservation Biology, 16(4), 1-12.

Paine, R. T., \& Levin, S. A. (1981). Intertidal Landscapes: Disturbance and the Dynamics of Pattern Ecological Monographs, 51(2), 145-178.

Pechenik, J. A. (1979). Role of Encapsulation in Invertebrate Life Histories The American Naturalist, 114(6), 859-870.

Pechenik, J. A. (1982). Ability of some Gastropod Egg Capsules to Protect against Low-Salinity Stress. Journal of Experimental Biology and Ecology 63, 195-208.

Pechenik, J. A. (1983). Egg Capsules of Nucella Lapillus (L.) Protect against Low-Salinity Stress. Journal of Experimental Biology and Ecology, 71, 165-179.

Pechenik, J. A. (1999). On the advantages and disadvantages of larval stages in benthic marine invertebrate life cycles. Marine Ecology Progress Series, 177, 269-297.

Pechenik, J. A., Gleason, T., Daniels, D., \& Champlin, D. (2001). Influence of larval exposure to salinity and cadmium stress on juvenile performance of two marine invertebrates (Capitella sp. I and Crepidula fornicata). Journal of Experimental Marine Biology and Ecology, 264, 101-114.

Pechenik, J. A., \& Lima, G. M. (1984). Relationship between Growth, Differentiation, and Length of Larval Life for Individually Reared Larvae of the Marine Gastropod, Crepidula fornicata. Biological Bulletin, 166(3), 537-549. 
Pechenik, J. A., Marsden, I. D., \& Pechenik, O. (2003). Effects of temperature, salinity, and air exposure on development of the estuarine pulmonate gastropod Amphibola crenata. Journal of Experimental Biology, 292, 159-176.

Pechenik, J. A., Pearse, J. S., \& Qian, P.-Y. (2007). Effects of Salinity on Spawning and Early Development of the Tube-Building Polychaete Hydroides elegans in Hong Kong: Not Just the Sperm's Fault? Biological Bulletin, 212, 151-160.

Pechenik, J. A., Wendt, D. E., \& Jarrett, J. N. (1998). Metamorphosis is Not a New Beginning. Bioscience, 48(11), 901-910.

Peterson-Smith, J., \& Shea, K. (2010). Seedling emergence and early survival of Carduus spp. in three habitats with press and pulse disturbances. The Journal of the Torrey Botanical Society, 137(2), 287-296.

Phillips, N. E. (2002). Effects of Nutrition-Mediated Larval Condition on Juvenile Performance in a Marine Mussel. Ecology, 83(9), 2562-2574.

Phillips, N. E. (2004). Variable Timing of Larval Food Has Consequences for Early Juvenile Performance in a Marine Mussel. Ecology, 85(8), 23412346.

Podolsky, R. D. (2000). Intertidal embryos: temperature tradeoffs during early development. American Zoologist 40(6), 1174.

Podolsky, R. D. (2003). Integrating Development and Environment to Model Reproductive Performance in Natural Populations of an Intertidal Gastropod. Integrative and Comparative Biology, 43(3), 450-458. 
Podolsky, R. D., \& Hofmann, G. E. (1998). Embryo development during tiderelated thermal stress, evidence of a protective role for heat shock proteins American Naturalist, 38, 187.

Przeslawski, R. (2004). A review of the effects of environmental stress on embryonic development within intertidal gastropod egg masses Molluscan Research, 24, 43-63.

Przeslawski, R. (2005). Combined effects of solar radiation and desiccation on the mortality and development of encapsulated embryos of rocky shore gastropods. Marine Ecology Progress Series, 298, 169-177.

Przeslawski, R., \& Davis, A. R. (2007). Does spawning behavior minimize exposure to environmental stressors for encapsulated gastropod embryos on rocky shores? Marine Biology, 152, 991-1002.

Przeslawski, R., Davis, A. R., \& Benkendorff, K. (2004). Effects of ultraviolet radiation and visible light on the development of encapsulated molluscan embryos. Marine Ecology Progress Series, 268, 151-160.

Przeslawski, R., Davis, A. R., \& Benkendorff, K. (2005). Synergistic effects associated with climate change and the development of rocky shore molluscs. Global Change Biology, 11, 515-522.

Pyefinch, K. A. (1943). The Intertidal Ecology of Beardsley Island, North Wales, with Special Reference to the Recolonization of Rock Surfaces and the Rock-Pool Environment. The Journal of Animal Ecology, 12(2), 82-108.

Qiu, J.-W., \& Qian, P.-Y. (1999). Tolerance of the barnacle Balanus amphitrite amphitrite to salinity and temperature stress: effects of previous experience. Marine Ecological Progress Series, 188, 123-132. 
Quoy, J. R., \& Gaimard, J. P. (1832). Voyage de decouvertes de L'Astrolabe pendant les annees 1826-1827-1828-1829, sous le commandement de M.J. Dumont D'Urville. Zoologie, 2, 1-686.

Rawlings, T. A. (1990). Associations between Egg Capsule Morphology and Predation among Populations of the Marine Gastropod, Nucella emarginata. Biological Bulletin, 179(3), 312-325.

Rawlings, T. A. (1996). Shields against ultraviolet radiation: an additional protective role for the egg capsules of benthic marine gastropods. Marine Ecological Progress Series, 136, 81-95.

Richardson, J. M. L. (2002). Burst swim speed in tadpoles inhabiting ponds with different top predators. Evolutionary Ecology Research, 4, 627-642.

Richmond, C. E., \& Woodin, S. A. (1996). Short-term fluctuations in salinity: effects on planktonic invertebrate larvae. Marine Ecology Progress Series, 133, 167-177.

Rius, M., Turon, X., \& Marshall, D. J. (2009). Non-lethal effects of an invasive species in the marine environment: the importance of early life-history stages. Oecologia, 159, 873-882.

Roller, R. A., \& Stickle, W. B. (1989). Temperature and salinity effects on the intracapsular development, metabolic rates, and survival to hatching of Thais haemastoma canaliculata( Gray) (Prosobranchia : Muricidae) under laboratory conditions. Journal of Experimental Marine Biology and Ecology, 125, 235-251.

Romansic, J. M., Waggener, A. A., Bancroft, B. A., \& Blaustein, A. R. (2009). Influence of ultraviolet-B radiation on growth, prevalence of deformities, and susceptibility to predation in Cascades frog (Rana cascadae) larvae. Hydrobiologia, 624(1), 219-233. 
Rose, R. A. (1986). Direct development in Rostanga arbutus (Angas) (Mollusca: Nudibranchia) and the effects of temperature and salinity on embryos reared in the laboratory. Journal of the Malacological Society of Australia, 7, 141-154.

Roughgarden, J., Gaines, S., \& Possingham, H. (1988). Recruitment Dynamics in Complex Life Cycles. Science, 241(4872), 1460-1466.

Rumrill, S. S. (1990). Natural mortality of marine invertebrate larvae. Ophelia, 32(1-2), 163-198.

Russell, J. (2008). Effects of ultraviolet radiation (UVR) and other environmental stressors on the development of intertidal mollusc embryos. Victoria University of Wellington, Wellington.

Russell, J., \& Phillips, N. (2009b). Species-specific vulnerability of benthic marine embryos of congeneric snails (Haminoea spp.) to ultraviolet radiation and other intertidal stressors. The Biological Bulletin, 217(1), 65-68.

Russell, J., \& Phillips, N. E. (2009a). Synergistic effects of ultraviolet radiation and conditions at low tide on egg masses of limpets (Benhamina obliquata and Siphonaria australis) in New Zealand. Marine Biology, 156, 579-587.

Sanford, E. (2002). Water Temperature, Predation, and the Neglected Role of Physiological Rate Effects in Rocky Intertidal Communities. Integrative and Comparative Biology, 42, 881-889.

Sarver, D. J. (1978). The ecology and energetics of Aplysia juliana (Quoy and Quaimard, 1832). Unpublished Ph. D. dissertation, University of Hawaii, Honolulu. 
Scheltema, R. S. (1965). The relationship of salinity to larval survival and development of Nassarius obsoletus (Gastropoda). Biological Bulletin, 129, 340-354.

Scheltema, R. S. (1967). The Relationship of Temperature to the Larval Development of Nassarius obsoletus (Gastropoda). Biological Bulletin, 132(2), 253-265.

Schiel, D. R. (2006). Guide to common intertidal species of the South Island, New Zealand. Christchurch: University of Canterbury.

Schindler, D. W., Jefferson, C. P., Parker, B. R., \& Stainton, M. P. (1996). Consequences of climate warming and lake acidification for UV-B penetration in North American boreal lakes. Nature, 379(6567), 705-709.

Searle, C. L., Belden, L. K., Bancroft, B. A., Han, B. A., Biga, L. M., \& Blaustein, A. R. (2009). Experimental examination of the effects of ultraviolet-B radiation in combination with other stressors on frog larvae. Oecologia, 162, 237-245.

Seckmeyer, G., \& McKenzie, L. A. (1992). Increased Ultraviolet Radiation in New Zealand (45 degrees South) relative to Germany (48 degrees North). Nature, 359(6391), 135.

Shafer, D. J., Wyllie-Echeverria, S., \& Sherman, T. D. (2008). The potential role of climate in the distribution and zonation of the introduced seagrass Zostera japonica in North America. Aquatic Botany, 89, 297-302.

Sharma, J. G., Masuda, R., \& Tanaka, M. (2007). Orientation behaviour of Pagrus major larvae exposed to UV-B radiation in laboratory conditions. International Journal of Radiation Biology, 83(1), 49-52. 
Sih, A., Bell, A. M., \& Kerby, J. L. (2004). Two stressors are far deadlier than one. Trends in Ecology and Evolution, 19(6), 274-276.

Sinha, R. P., Singh, N., Kumar, A., Kumar, H. D., Hader, M., \& Hader, D.-P. (1996). Effects of UV irradiation on certain physiological and biochemical processes in cyanobacteria. Journal of Photochemistry and Photobiology, 32(1-2), 107-113.

Situm, M., Buljan, M., Bulat, V., Mihic, L. L., Bolanca, Z., \& Simic, D. (2008). The Role of UV Radiation in the Development of Basal Cell Carcinoma. Collegium antropologicum, 32, 167-170.

Smith, G. R., Waters, M. A., \& Rettig, J. E. (2000). Consequences of embryonic UV-B exposure for embryos and tadpoles of the plains leopard frog. Conservation Biology 14, 1903-1907.

Somero, G. N. (2002). Thermal Physiology and Vertical Zonation of Intertidal Animals: Optima, Limits, and Costs of Living. Integrative and Comparative Biology, 42, 780-789.

Sousa, W. P. (1979). Disturbance in Marine Intertidal Boulder Fields: The Nonequilibrium Maintenance of Species Diversity Ecology 60(6), 12251239.

Spight, T. M. (1975). Factors Extending Gastropod Embryonic Development and Their Selective Cost. Oecologia, 21, 1-16.

Sponaugle, S., \& Grorud-Colvert. (2006). Environmental variability, early lifehistory traits, and survival of new coral reef fish recruits. Paper presented at the Integrating Function over Marine Life Cycles. 
Steinhoff, F. S., Wiencke, C., Mueller, R., \& Bischof, K. (2008). Effects of ultraviolet radiation and temperature on the ultrastructure of zoospores of the brown macroalga Laminaria hyperborea. Plant Biology, 10, 388397.

Strathmann, M. F. (1987). Reproduction and Development of Marine Invertebrates of the Northern Pacific Coast: University of Washington Press, United States of America.

Strathmann, R. R. (1985). Feeding and Nonfeeding Larval Development and Life-History Evolution in Marine Invertebrates. Annual Review of Ecology and Systematics, 16, 339-361.

Strathmann, R. R., \& Gruenbaum, D. (2006). Good eaters, poor swimmers: compromises in larval form. Integrative and Comparative Biology, 46(3), 312-322.

Strathmann, R. R., \& Hess, H. C. (1999). Two Designs of Marine Egg Masses and Their Divergent Consequences for Oxygen Supply and Desiccation in Air. American Zoologist, 39(2), 253-260.

Strobbe, F., McPeek, M. A., De Block, M., \& Stoks, R. (2010). Survival selection imposed by predation on a physiological trait underlying escape speed. Functional Ecology, doi:10.1111/j.13652435.2010.01752.x.

Struhsaker, J. W., \& Costlow, J. J. D. (1969). Some Environmental Effects on the Larval Development of Littorina picta (Mesagastropoda), reared in the Laboratory. Malacologia, 9(2), 403-419.

Switzer-Dunlap, M., \& Hadfield, M. G. (1977). Observations on Development, Larval Growth and Metamorphosis of Four Species of Aplysiidae (Gastropoda: Opisthobranchia) in Laboratory Culture. Journal of experimental marine Biology and Ecology, 29, 245-261. 
Tala, F., Veliz, K., Gomez, I., \& Edding, M. (2007). Early life stages of the South Pacific kelps Lessonia nigrescens and Lessonia trabeculata (Laminariales, Phaeophyceae) show recovery capacity following exposure to UV radiation. Phycologia, 46(4), 467-470.

Talbot, T., \& Lawrence, J. M. (2002). The effect of salinity on respiration, excretion, regeneration and production in Ophiophragmus filograneus (Echinodermata: Ophiuroidea). Journal of Experimental Marine Biology and Ecology, 275, 1-14.

Tauchman, E. C., \& Pomorya, C. M. (2011). Effect of ultraviolet radiation on growth and percent settlement of larval Lytechinus variegatus (Echinodermata: Echinoidea). Invertebrate Reproduction and Development, 55(3), 152-161.

Thiyagarajan, V., Harder, T., \& Qian, P.-Y. (2003). Combined effects of temperature and salinity on larval development and attachment of the subtidal barnacle Balanus trigonus Darwin. Journal of Experimental Marine Biology and Ecology, 287, 223-236.

Thomas, D. L., \& McClintock, J. B. (1990). Embryogenesis and the effects of temperature on embryonic development, juvenile growth rates, and the onset of oviposition in the fresh-water pulmonate gastropod Physella cubensis. Invertebrate Reproduction and Development, 17(1), 65-71.

Thorson, G. (1950). Reproductive and Larval Ecology of Marine Bottom Invertebrates. Biological Review, 25, 1-45.

Tomanek, L., \& Helmuth, B. S. T. (2002). Physiological Ecology of Rocky Intertidal Organisms: A Synergy of Concepts. Integrative and Comparative Biology, 42(4), 771-775. 
Trowbridge, C. D. (1994). Life at the edge: Population dynamics and salinity tolerance of a high intertidal, pool-dwelling ascoglossan opisthobranch on New Zealand rocky shores. Journal of Experimental Marine Biology and Ecology, 182, 65-84.

Veale, L. O., Hill, A. S., \& Brand, A. R. (2000b). An in situ study of predator aggregations on scallop (Pecten maximus (L.)) dredge discards using a static time-lapse camera system. Journal of Experimental Marine Biology and Ecology, 255, 111-129.

Vehniaeinen, E.-R., Haekkinen, J. M., \& Oikari, A. O. J. (2007). Fluence Rate or Cumulative Dose? Vulnerability of Larval Northern Pike (Esox lucius) to Ultraviolet Radiation. Photochemistry and Photobiology, 83, 444-449.

Wahl, M., Molis, M., Davis, A., Dobretsov, S., Du, S. T., Johansson, J. N., et al. (2004). UV effects that come and go: a global comparison of marine benthic community level impacts. Global Change Biology, 10(12), 19621972.

Wang, Y. L., Binkowski, F. P., \& Doroshov, S. I. (1985). Effect of temperature on early development of white and lake sturgeon, Acipenser transmontanus and A. fulvescens. Environmental Biology of Fishes, 14(1), 43-50.

Watt, J. L., \& Aiken, R. B. (2003). Effect of Temperature on Development Time in Egg Masses of the Intertidal Nudibranch, Denodronotus frondosus (Ascanius 1774) (Ophistobranchia, Denodrontacea). Northeastern Naturalist, 10(1), 17-24.

Wellington, G. M., \& Fitt, W. K. (2003). Influence of UV radiation on the survival of larvae from broadcast-spawning reef corals. Marine Biology, 143, 1185-1192. 
Wendt, D. E. (1996). Effect of larval swimming duration on success of metamorphosis and size of the ancestrular lophophore in Bugula neritina (Bryozoa). Biological Bulletin, 191, 224-233.

Willis, T. J., \& Babcock, R. C. (2000). A baited underwater video system for the determination of relative density of carnivorous reef fish. Marine and Freshwater Research, 51, 755-763.

Witman, J. D., \& Grange, K. R. (1998). Links between Rain, Salinity, and Predation in a Rocky Subtidal Community. Ecology, 79(7), 2429-2447.

Wollmuth, L. P., \& Crawshaw, L. I. (1988). The Effect of Development and Season on Temperature Selection in Bullfrog Tadpoles. Physiological Zoology, 61(5), 461-469.

Woods, H. A., \& DeSilets, J. R. L. (1997). Egg-Mass Gel of Melanochlamys diomedea (Bergh) Protects Embryos from Low Salinity. Biological Bulletin, 193(3), 341-349.

Wraith, J., Przeslawski, R., \& Davis, A. R. (2006). UV-Induced Mortality in Encapsulated Intertidal Embryos: Are Mycosporine-Like Amino Acids an Effective Sunscreen? Journal of Chemical Ecology, 32, 993-1004.

Ylönen, O., Huuskonen, H., \& Karjalainen, J. (2005). Effects of UV radiation on the vertical distribution of vendace [Coregonus alba (L.)] larvae in Finnish lakes. Ecology of Freshwater Fish, 14, 161-167.

Ylönen, O., \& Karjalainen, J. (2004). Growth and survival of European whitefish larvae under enhanced UV-B irradience. Journal of Fish Biology, 65, 869-875.

Yoshida, T., Toda, T., Hirano, Y., Matsuda, T., \& Kawaguchi, S. (2004). Effect of temperature on embryo development time and hatching success of 
the Antarctic krill Euphausia superba Dana in the laboratory. Marine and Freshwater Behaviour and Physiology, 37(2), 137-145. 